Final Report on Feasibility of Real-Time

Geochemical Analysis at Yucca Mountain, Nevada, Using LIBS Technology

J. D. Blacic

D. R. Pettit

D. A. Cremers

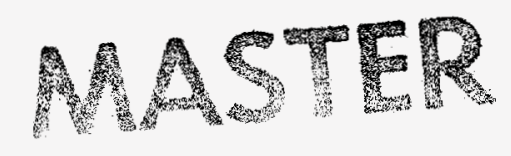

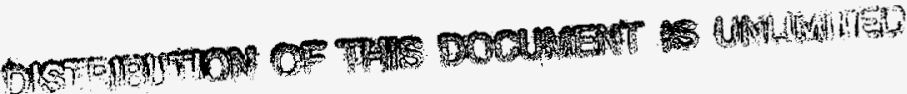




\section{DISCLAIMER}

Portions of this document may be illegible in electronic image products. Images are produced from the best available original document. 


\section{DISCLAIMER}

This report was prepared as an account of work sponsored by an agency of the United States Government. Neither the United States Government nor any agency thereof, nor any of their employees, make any warranty, express or implied, or assumes any legal liability or responsibility for the accuracy, completeness, or usefulness of any information, apparatus, product, or process disclosed, or represents that its use would not infringe privately owned rights. Reference herein to any specific commercial product, process, or service by trade name, trademark, manufacturer, or otherwise does not necessarily constitute or imply its endorsement, recommendation, or favoring by the United States Government or any agency thereof. The views and opinions of authors expressed herein do not necessarily state or reflect those of the United States Government or any agency thereof. 
TABLE OF CONTENTS

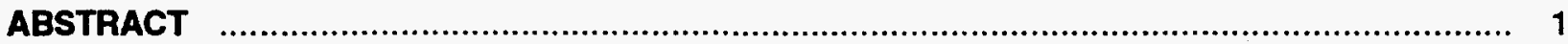

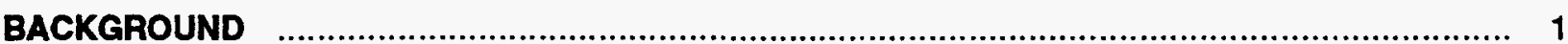

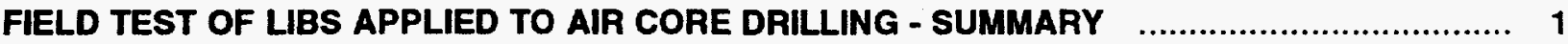

LABORATORY ANALYSIS OF MANGANESE OXIDE FRACTURE-FILLING

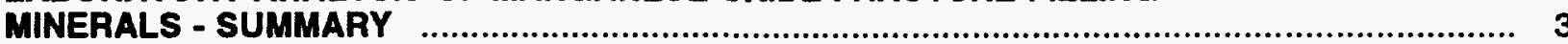

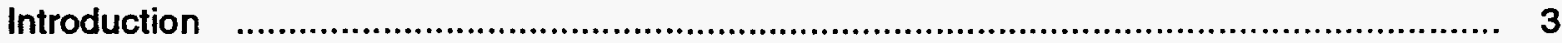

Summary of Laboratory Studies of Manganese Oxide

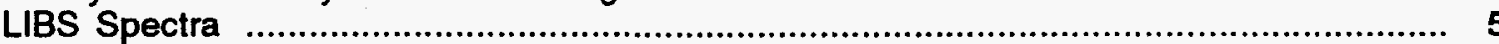

FRACTURE-FILLING MINERAL COMPOSITION ANALYSIS - FIELD

TEST RESULTS

Prototype LIBS Instrument Development .............................................................. 7

Field Test at the Exploratory Studies Facility .................................................................. 9

Analysis of Field Test Results ................................................................................. 9

FEASIBILITY OF USING LIBS FOR REAL-TIME ERIONITE DETECTION $\ldots \ldots \ldots \ldots \ldots \ldots \ldots \ldots \ldots \ldots . \ldots \ldots$

CONCLUSIONS

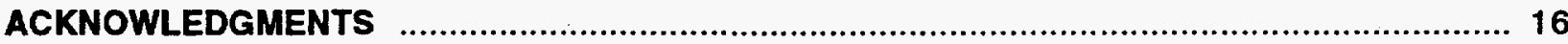

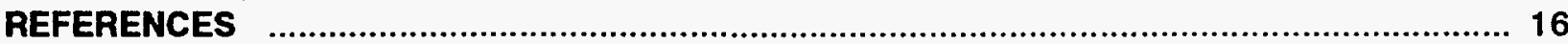

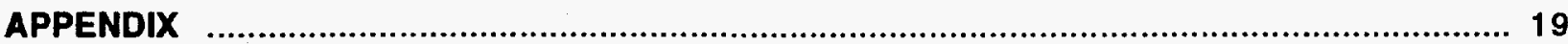




\title{
FINAL REPORT ON FEASIBILITY OF REAL-TIME GEOCHEMICAL ANALYSIS AT YUCCA MOUNTAIN, NEVADA, USING LIBS TECHNOLOGY
}

\author{
by
}

\author{
J. D. Blacic, D. R. Pettit, and D. A. Cremers
}

\begin{abstract}
Laser-induced breakdown spectroscopy (LIBS) is an analytic method whereby an intense laser pulse is used to vaporize and excite a small volume of material into atomic emission. Calibrated spectral analysis of the laser spark light provides detection and quantification of the elemental composition of the target material. We performed laboratory and field tests to assess the feasibility of developing field-portable LIBS-based instruments for real-time analyses of Yucca Mountain rocks in conjunction with Yucca Mountain Project drilling, coring, sampling, and characterization tasks. We developed one prototype instrument designed to analyze air core drilling dust and another prototype instrument designed to analyze rock and fracture surfaces. In realistic field tests at the Exploratory Studies Facility at Yucca Mountain, Nevada, we demonstrated that the LIBS prototypes are capable of measuring major, minor, and some trace elements in real time.

Laboratory LIBS analyses show that we can identify characteristic element ratios in a range of manganese oxide minerals present at Yucca Mountain as fracture surface coatings and matrix grains. Preliminary LIBS analyses also indicate that the $\mathrm{Li} / \mathrm{Na}$ ratio may distinguish tuffs containing the hazardous zeolite mineral erionite from non-erionite bearing tuffs, and that a LIBS-based instrument may be useful to detect in real time the probable presence of erionite encountered in core drilling and other operations at Yucca Mountain.
\end{abstract}

\section{BACKGROUND}

Laser-induced breakdown spectroscopy (LIBS) is a form of atomic emission analysis in which a pulsed laser is focused to a small spot to produce an energy density high enough to vaporize a small amount (micrograms) of material into its atomic constituents and electronically excite the atoms to emit light at wave lengths characteristic of the elements. LIBS is similar to standard, laboratory-based analytical methods such as flame or inductively coupled plasma atomic emission except that we use the very high energy density in a laser pulse to both vaporize and excite the test material. Small solidstate lasers and charge-coupled device (CCD) detectors are now commercially available and make it possible to construct a field-portable instrument of this type that could have a number of geochemistry applications in the Yucca Mountain Project (YMP). In order to test the feasibility of applying LIBS technology to YMP problems, we designed and constructed two different prototype field-portable instruments and assessed their functionality at the Exploratory Studies Facility (ESF).

\section{FIELD TEST OF LIBS APPLIED TO AIR CORE DRILLING - SUMMARY}

The main objective of this first field test was to demonstrate, under realistic field conditions, the feasibility of real-time elemental analysis of rock encountered in air core drilling using the technique of laser-induced breakdown spectroscopy (LIBS). The hydrochemistry horizontal core drilling in Test 

Alcove \#1 of the ESF offered a target of opportunity to test a prototype LIBS instrument aimed at analyzing the cuttings dust associated with the drilling operations. Broader objectives of the test included familiarization with the chemistry of the rock units and size distribution of the cuttings dust, familiarization with the operational aspects of coring and mining at the ESF, test of a dust sampling approach, and initial examination of LIBS field packaging and power issues.

Over the period March 2-9, 1994, hundreds of LIBS spectra were collected in real time reflecting the elemental composition of dust produced at the drill head of the second horizontal core hole in Test Alcove \#1 (Figure 1). The particle-laden, drill-coring effluent air stream served as the means to obtain a representative rock sample immediately surrounding the drill bit. A miniature cyclone separator, powered by a small vacuum cleaner, processed a portion of the drill-coring effluent air stream. Input to the LIBS cyclone was from a tap into the dust line just before it entered a bag filter. A pulsed NdYAG laser was used as the excitation source by focusing the $3 \mathrm{~mm}$-diameter exit beam into a spot less than a millimeter in diameter. The depth over which the beam remained tightly focused was about a centimeter. The focal point was centered inside a chamber $5 \mathrm{~cm}$ in diameter where the dust from the cyclone fell through the laser focal point region and into a collection jar. Laser power was insufficient to form an air plasma when no dust particles were present. When sufficient particles were present, a plasma formed, enveloping the dust and the surrounding air, thus providing a means to thermally excite atomic emission signals. An optical fiber bundle directed light from the plasma emissions to a spectrograph with a spectral range of $105 \mathrm{~nm}$ and a resolution of $0.4 \mathrm{~nm}$. Spectra were taken with the spectral range centered at $250,330,410$, and $500 \mathrm{~nm}$ so that representative, over-lapping spectral coverage from 200 to $550 \mathrm{~nm}$ was obtained for the dust. We found the spectra centered at $410 \mathrm{~nm}$ to be particularly useful; hence that is where most of the data were taken. All the sensitive equipment was built into two water/dust-proof shipping containers with filtered muffin fans providing the necessary ventilation (Figure 1).

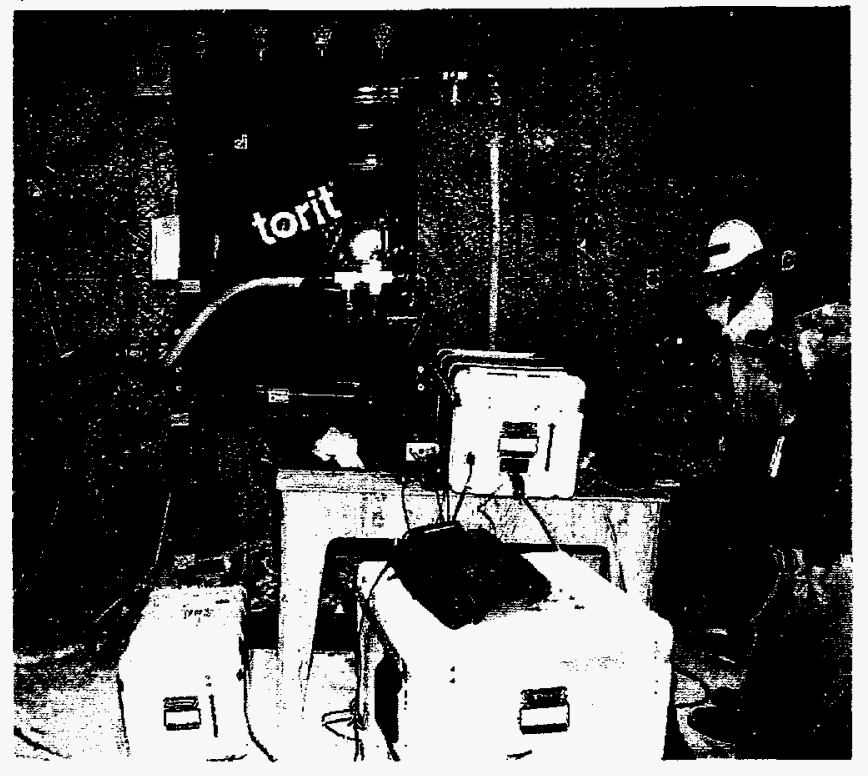

Fig. 1. Photograph of LIBS dust analyzer prototype in operation at the ESF. Dust-laden air from the core drill (to the left, out of view) is extracted before entering the Torit bag filter. A small cyclone separator (black apparatus on the wooden table) constrains the dust sample to the focal region of the laser (black, horizontal cylinder). The white box on the table contains the spectrograph and CCD camera; the larger white box next to the table contains the computer, power supply, and other electronics.
The field test was a complete success. We observed spectral lines for the major elements $\mathrm{Si}$, $\mathrm{Al}, \mathrm{K}, \mathrm{Na}$, and $\mathrm{Fe}$ and the minor elements $\mathrm{Ca}, \mathrm{Mg}$, $\mathrm{Ti}$, and $\mathrm{Mn}$. We identified the optimum spectral bands and the required level of resolution needed to improve the analysis for future work. The dust sampling system worked nominally, but the fineness of the cuttings and the associated dust clogging in our system were a surprise, resulting in some problems, as did the extensive and unanticipated loss of circulation into the formation over which we had no control. Some simple engineering improvements to the cyclone separator were identified if this approach to dust analysis is pursued in the future.

A detailed description of the equipment and results of the field test are given in Blacic, et al., (1995a).

\section{LABORATORY ANALYSIS OF MANGANESE OXIDE FRACTURE-FILLING MINERALS - SUM- MARY}

\section{Introduction}

An important aspect of the licensing and performance of a potential repository at Yucca 
Mountain will be the characterization, quantification, and documentation of the radionuclide sorptive capacity of the host rock. A key element of this process will be the characterization of the fracture mineral fillings. The manganese oxide minerals that occur heterogeneously throughout the Yucca Mountain block are especially important because of their potential to control or affect ground water redox reactions (Bish and Post, 1989) and to retard actinide mobility (Means, et al., 1978; Triay, 1991; Triay, et al., 1991); localization along fractures as coatings and fillings increases their importance because these fractures are likely to be the fast pathways of chemical transport by way of ground water. Evaluation of the actinide retardation capacity of $\mathrm{Mn}$-oxides is currently underway with mineralspecific and autoradiography experiments in progress (Vaniman, personal communication, 1995).

Up to this time, characterization of manganese minerals in the Yucca Mountain block has been done by time-consuming optical and scanning electron microscopy of a small number of samples returned to the laboratory, supported by laboratory analytical chemistry and $x$-ray diffraction analysis (Carlos, 1989; Carlos et al., 1990; Carlos et al., 1993). Complete fracture filling characterization at Yucca Mountain could be done with such methods, but manpower limits and access within the limited exposure time of the tunnel walls makes such an approach costly and difficult. Potentially thousands of analyses may be needed to fully characterize the distribution of sorbing minerals in the rock mass and along fracture surfaces in the vicinity of the repository. Extensive sampling or in situ measurements will have to be performed along the walls of much of the tunnel produced before wire and shotcrete support is put in place; fractures exposed in experiment alcoves need to be characterized; and core samples taken from below the repository horizon will have to be extensively characterized. It will be especially important to characterize the fractures below the potential repository horizon (e.g., in the Calico Hills tuffs) if excavations or core drilling are performed there since any lateral transport path will likely first pass downward through this region. We believe use of a LIBS instrument may be an optimum, perhaps unique, solution to this problem because of its capability for fine spatial resolution (point analysis) and rapid, near real-time analysis capability in the field (Blacic, et al., 1995a).

In order to assess its potential usefulness, we designed a portable LIBS unit with an analysis head that contains a laser source, optical fiber to convey the spark signal, and optical aiming magnifier and reticule to fix the analysis point; the prototype is described in detail in a section below. The instrument head is placed on the surface of a tunnel wall or core sample with a soft, conforming seal to safely enclose the laser beam. Such a device might be used as part of the tunnel wall characterization activities planned to be used at the gantry access of the tunnel boring machine (TBM). Point analyses along lines on the tunnel wall, obtained as the TBM advances, would, along with similar analyses of available core samples, allow construction of a fracture-filling data base. From such a data base a statistical estimate of, for example, the amount of sorptive manganese mineral fracture fillings within the repository block could be constructed. The in situ LIBS measurements would also be a useful guide to sample selection for more extensive laboratory characterization.

To prepare for a field test of the surface-analysis LIBS instrument prototype, we performed an initial laboratory LIBS study of selected Yucca Mountain core samples containing manganese oxide fracture coatings that were previously analyzed by the laboratory geochemical methods described above, along with LIBS analysis of a suite of standard manganese oxide minerals for comparison.

\section{Summary of Laboratory Studies of Manganese Oxide LIBS Spectra}

A laboratory-based LIBS system was set up and used to analyze YMP samples for manganese minerals occurring as vein fillings and fracture coatings; a suite of manganese oxide mineral standards were also analyzed for comparison. Spectra were taken centered at 272, 350, 400, and $655 \mathrm{~nm}$ which allowed for identification of the major and minor elements of interest.

Examples of the spectra with labeled emission peaks are shown in Figure 2a-d for tuff sample GU3 797. Given the large amount of manganese in all of the samples, ranging from $\sim 50$ to $\sim 90$ at. $\%$ $\mathrm{MnO}_{2}$, it is not surprising that the spectra are dominated by the many neutral and singly ionized lines for manganese. However, in only one case did we find an interference between an important element and a manganese line for which we could not substitute another line in a clear part of the spectrum, and that was for potassium. The best line for potassium in the bands we used is the neutral doublet at 

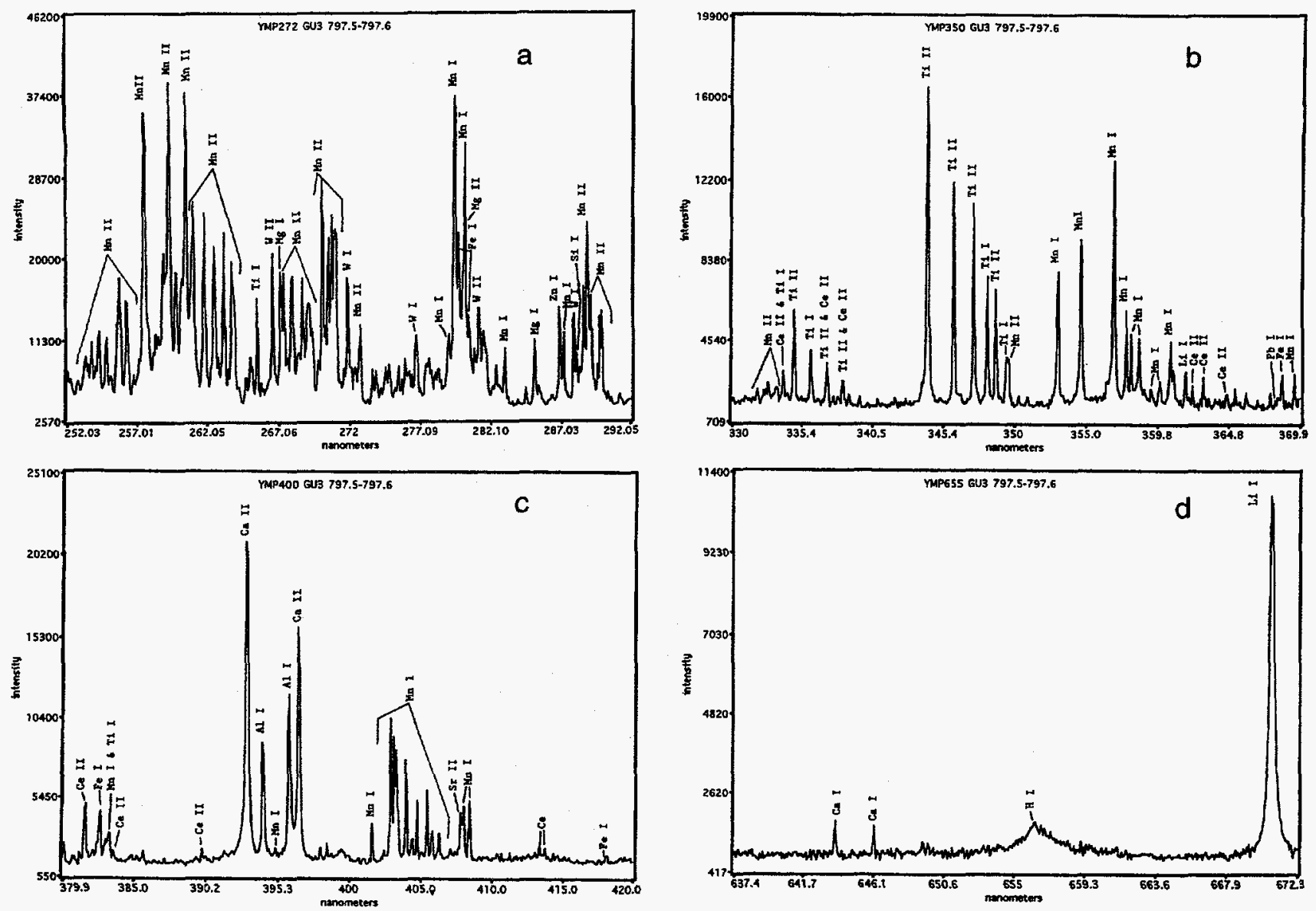

Fig. 2a-d. LIBS spectra of manganese-rich coating of fracture surface in sample GU3 797 (nearby samples are reported to contain the manganese minerals Rancieite and Lithiophorite, Carlos, et al., 1993). Element emission lines labeled with "I" are neutral species and those labeled with "II" are singly ionized species: (a) spectrum centered at $272 \mathrm{~nm}$; (b) spectrum centered at $350 \mathrm{~nm}$; (c) spectrum centered at $400 \mathrm{~nm}$; and (d) spectrum centered at $655 \mathrm{~nm}$.

404.4 and $404.7 \mathrm{~nm}$ but these are masked by strong neutral manganese lines at 404.5 and $404.9 \mathrm{~nm}$, respectively. For all of the other major element constituents of manganese oxide minerals, we were able to identify one or more isolated lines. These elements include $\mathrm{Al}, \mathrm{Ca}, \mathrm{Si}, \mathrm{Fe}, \mathrm{Mg}, \mathrm{Ba}, \mathrm{Sr}, \mathrm{Li}$, and $\mathrm{Pb}$. In addition, there are a number of minor or trace-level elements exhibiting LIBS emission lines which appear to vary systematically among the manganese oxide minerals and which may prove useful for correlation purposes. These include $\mathrm{Ti}, \mathrm{Zn}, \mathrm{W}, \mathrm{Cu}, \mathrm{Ni}$, and the rare earth element $\mathrm{Ce}$. We found that there are distinct differences in major, minor and trace element ratios among the manganese oxide standards, allowing them to be distinguished from one another, and there are significant variations in the same element ratios among the Yucca Mountain samples we analyzed.

During the LIBS data collection, multiple laser pulses were found not to ablate through the thin coating of manganese oxide minerals. This is essential for spectral consistency since four separate laser pulses are needed at each analysis spot, one at each setting of the grating. Multiple spot analyses on the manganese oxide mineral coatings were found to show no significant elemental variation over a particular sample. Differentiation between manganese mineralization, host rock, and other vein/coating mineralization was readily apparent, as seen in the spectra and in the element ratios, particularly those involving $\mathrm{Si}, \mathrm{Ca}$, and $\mathrm{Al}$. Absolute quantification of elemental concentrations from peak heights or areas is hardware-specific, and has not been performed for these preliminary LIBS analyses. However, relative comparisons and qualitative estimates of element variations can be obtained from the spectra by normalizing specific element peaks to a common element. For this purpose, element ratios for manganese oxide mineral standards and tuff samples were calculated for 
$\mathrm{Mg} / \mathrm{Mn}, \mathrm{Si} / \mathrm{Mn}, \mathrm{Pb} / \mathrm{Mn}, \mathrm{Al} / \mathrm{Mn}, \mathrm{Ca} / \mathrm{Mn}, \mathrm{Ce} / \mathrm{Mn}, \mathrm{Li} / \mathrm{Mn}$, and $\mathrm{Ba} / \mathrm{Mn}$, and are presented by the ratio of spectral line heights taken at $285.21 \mathrm{~nm}$ for $\mathrm{Mg}, 288.16 \mathrm{~nm}$ for Si, $368.35 \mathrm{~nm}$ for $\mathrm{Pb}, 396.15 \mathrm{~nm}$ for Al, $393.37 \mathrm{~nm}$ for $\mathrm{Ca}, 388.99 \mathrm{~nm}$ for $\mathrm{Ce}, 670.78 \mathrm{~nm}$ for $\mathrm{Li}, 669.38 \mathrm{~nm}$ for $\mathrm{Ba}$, and $356.95 \mathrm{~nm}$ for $\mathrm{Mn}$. These lines were chosen in part by signal strength and absence of interference with lines from other elements. A composite bar chart displays these ratios for the YMP samples in Figure 3; individual sample bar charts for all analyzed YMP samples and mineral standards are presented in Blacic, et al., 1995b.

In summary, our laboratory studies have demonstrated that the laser-induced breakdown spectroscopy (LIBS) surface analysis technique is capable of producing high resolution atomic emission spectra of manganese oxide mineral samples and fracture surface coatings from Yucca Mountain core samples indicating that qualitative measurement of all constituent elements except $\mathrm{K}$ and $\mathrm{Na}$ (in the presence of large amounts of $\mathrm{Mn}$ ) is possible with LIBS. We have identified four spectral bands which will cover all of the key elements for the manganese oxide minerals. Further work including detailed calibration of final hardware will be needed to make the system quantitative. The LIBS analyses should allow at least approximate estimates to be made of the relative proportions of specific manganese oxide minerals based on their distinctive element ratios and concentrations.

A detailed description of the laboratory methods used in the study and all of the data are given in Blacic, et al., 1995b.

\section{FRACTURE-FILLING MINERAL COMPOSITION ANALYSIS - FIELD TEST RESULTS}

\section{Prototype LIBS Instrument Development}

The surface-analysis LIBS prototype instrument was designed for rapid elemental analysis of user-selected small veins, irregular fracture coatings, and phenocrysts exposed on the tunnel walls at the ESF in the wake of the TBM as shown in Figure 4. The hardware consists of a Laser Photonics 20 $\mathrm{mJ}$ pulsed Nd-YAG laser built into an eye-safe, hand-held probe which is pressed against the surface to be analyzed. A compliant rubber boot prevents light leakage from around the probe-wall contact. A $20 \mathrm{X}$ inspection microscope is built into the probe with a crosshair reticule aligned with the spark location. An absorption filter for the YAG laser line $(1.06 \mu \mathrm{m})$ is attached to the microscope objective

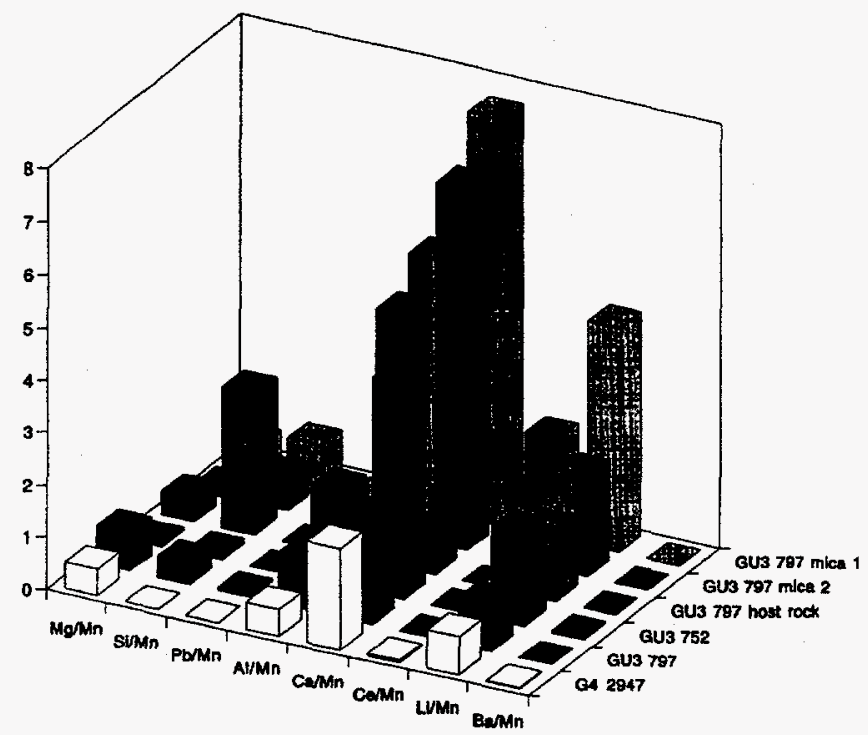

Fig. 3. Normalized LIBS element emission intensities for selected Yucca Mountain samples. Qualitative relative proportions of manganese oxide minerals can be deduced from the element emission intensity patterns (Blacic, et al., 1995b). so that the hand-held probe can be operated without the need for personnel to wear laser safety goggles. Two pressure sensitive interlocks, one located within the rubber boot and one on the outside of the probe ("laser enable") allow the laser to fire only when in firm contact with a solid surface and when the operator has manually pressed the enable button. The enabled laser can only be fired from the computer keyboard; thus, a Class I laser rating is achieved for the system. A 3-meter-long, round-to-line cross section, ultraviolet grade fiber-optic bundle collects the spark light from within the hand-held unit and directs it into a sealed instrument case enclosing a $1 / 4 \mathrm{~m}$ Chromex IS 250 spectrograph with a Santa Barbara ST6-UV CCD detector placed at the focal plane. An f-number matching optic is used between the end of the fiber and the entrance to the spectrograph. A Macintosh 180c notebook computer operates the CCD detector, the spectrograph, and the laser so that complete instrument control is achieved from 



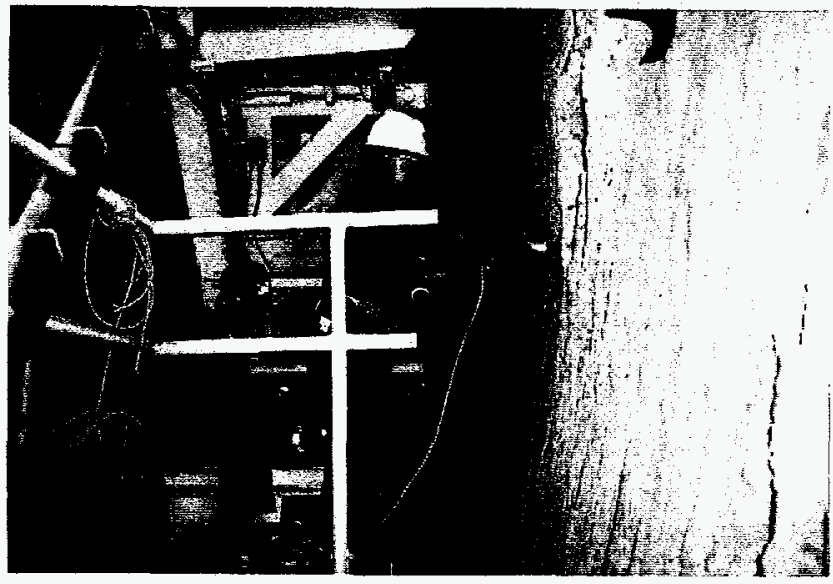

Fig. 4. Deployment of the prototype LIBS surface analyzer in the ESF. The instrument head is placed in contact with the surface to be analyzed. The head is connected by fiber-optic and power cables to the water/dust-proof box (white) containing the spectrograph, CCD camera, power conditioning, and other electronics. The system is controlled from a notebook computer. the keyboard. This markedly increases the speed of the spectra acquisition since the computer can shift the grating and recalibrate the wavelength automatically for each region of the spectrum. The spectra are archived both on floppy disk and hard drive storage media.

\section{Field Test at the Exploratory Studies Facility}

The prototype system was fielded for several days during late July, 1995 at the Exploratory Studies Facility at Yucca Mountain. Surface elemental analyses were performed on veins, fracture surfaces, phenocrysts and groundmass exposed in the tunnel wall from the observation gantry of the TBM. Spectra were collected at the then current TBM gantry position of 1033 to $1097 \mathrm{~m}$ from the portal. This was approximately $200 \mathrm{~m}$ from the advancing tunnel face. Electrical power was supplied from the TBM. TBM operators would move the observation gantry to user-requested points of interest providing convenient access to

the tunnel wall. The wall rock unit exposed at this location was crystal poor, lower non-lithophysal portions of the Tiva Canyon member of the Paintbrush tuff. This zone contained sporatic veins and fissures filled with dark mineralization. There was one area within the zone that appeared to be hydrothermally altered. Spectra were collected near locations where hand specimens had previously been collected and logged. The sample number placards were used as identifiers for our spectra so that direct correlation to laboratory analysis of the hand specimens can be made. Spectra were taken from placards labeled SPC00509155 to SPC00510512 and are noted on each spectrum as presented in the section on results. There was one zone of dark vein-filling mineralization at tunnel location 633 $\mathrm{m}$ at placard SPC00509034. Due to absence of electrical outlets in this vicinity, we took generously sized hand specimens from this location and analyzed them at the TBM gantry.

The 3-meter-long fiber-optic cable linking the hand probe to the instrument box proved adequate for reaching points of interest while the instrument box and notebook computer remained on the mobile platform. This system was designed to require two operators, one with the hand probe and one at the computer. A target was selected by the hand probe operator and then aligned with the reticule crosshairs. Downward pressure on the rubber seal while depressing the enable button were required to satisfy the interlocks. A verbal signal was then given from the hand probe operator to the computer operator to fire the laser. This two person system facilitated operational safety to prevent unintentional laser firing. The computer would scan the grating, recalibrate the spectrograph, and take several spectra over about a 30 second period. The system is shown in operation in Figures 5 and 6.

\section{Analysis of Field Test Results}

The prototype instrument operated as expected with no problems over the two days we spent collecting data in the ESF. As shown in Figures 4-6, one operator would select features to be analyzed and position the analysis head in the required position while the second operator would fire the laser from the computer keyboard and archive the spectra produced. We collected spectra in $20 \mathrm{~nm}$-wide bands centered at $285,315,330,395,405,590,665$, and $765 \mathrm{~nm}$. Within these bands we identified emission peaks for $\mathrm{Si}, \mathrm{Al}, \mathrm{Mg}, \mathrm{Ca}, \mathrm{Na}, \mathrm{K}, \mathrm{Li}, \mathrm{Mn}, \mathrm{Fe}, \mathrm{Ti}$, and $\mathrm{H}$ with good spectral resolution and 


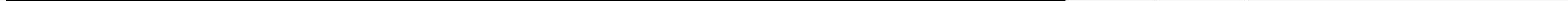




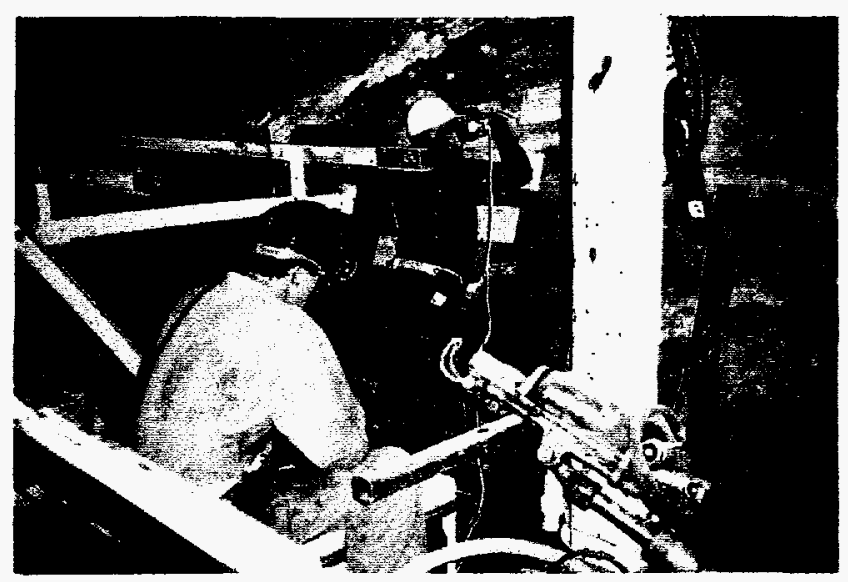

Fig. 5. Operation of the prototype LIBS surface analyzer. One operator positions the instrument head and enables the laser, and the second operator, sitting on the electronics box, fires the laser and collects the spectra using a notebook computer.

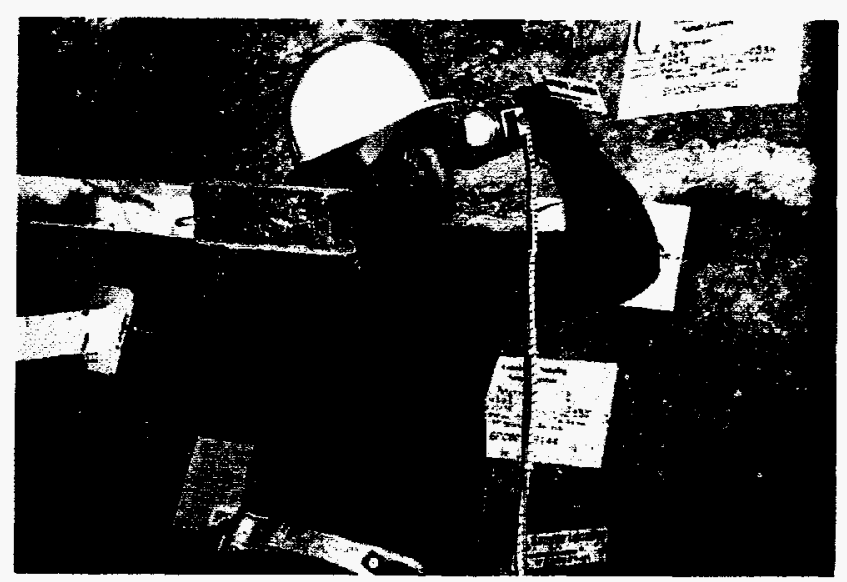

Fig. 6. Close-up of the analysis head in use. Precise positioning of the analysis point is performed with the aid of an integral inspection microscope. The white band of rock referred to in the text as an alteration rind is visible above the operator's elbow.

sensitivity. In selecting analysis locations, we paid particular attention to mineral-filled fractures that were visually apparent and we were able to detect $\mathrm{Mn}$ and Fe variations in these. We spent the most time analyzing what appeared to be a hydrothermal alteration zone exposed in the tunnel walls at $1033 \mathrm{~m}$.

This altered zone near sample location SPC00509155 appears as a geometrically complex area several meters in extent characterized by red to brown discoloration surrounded by a thin white to cream-colored zone within the light gray, crystal poor, non-lithophysal portion of the Tiva Canyon tuff. The zone has been heavily sampled by LANL and USGS personnel and detailed laboratory analysis is underway. Nevertheless, the potential utility of real-time analysis with the aid of our LIBS prototype is illustrated in Figures 7a-d and 7e-h where we compare the unaltered Tiva Canyon host rock with the thin, light-colored "rind" around the altered zone. Individual element emission peaks are identified in each spectral band that was collected, and plotted on the same intensity scales for comparison. Qualitatively, it can be seen that the host rock has apparently been leached and several elements removed or depleted in the altered rind material. By comparing peak heights and areas it can be seen (Figures $7 \mathrm{c}$ and $7 \mathrm{e}$ ) that within the altered rind $\mathrm{Fe}, \mathrm{Ti}$, and $\mathrm{Mn}$ appear to have decreased to levels below our detection limit (10's to 100's ppm;); there has also been significant reduction in $\mathrm{K}$ with smaller reductions in $\mathrm{Na}$ and $\mathrm{Li} ; \mathrm{Ca}, \mathrm{Al}$, and $\mathrm{Mg}$ appear to have decreased only slightly, and only $\mathrm{Si}$ appears to have increased in the altered rind zone relative to the nearby unaltered tuff. In the interior red-brown colored region of the altered zone, we noted increases of $\mathrm{Mn}$ and Fe with little depletion of the other elements; $\mathrm{Na}$ and Li may have increased. All of the spectra from this region and others are presented in the Appendix.

Overall, the prototype instrument worked satisfactorily, although the need for some operational improvements became apparent during the experiment. The contact area of the analysis head, $\sim 8.5$ $\mathrm{cm}$, was occasionally too large to easily bring the analysis point into optical focus, particularly on rough rock surfaces. In addition, the non-coaxial arrangement of the viewing optics made it difficult to maintain the laser spark centered on the crosshair except at a single fixed-focus position. These problems could be mitigated in an improved design by reducing the probe contact area to about $1 \mathrm{~cm}$ and by incorporating variable-focus, coaxial viewing optics. Once a final hardware design is achieved, quantitative calibration and software development to provide convenient presentation of real-time data to the operator would result in a more user-friendly system. 

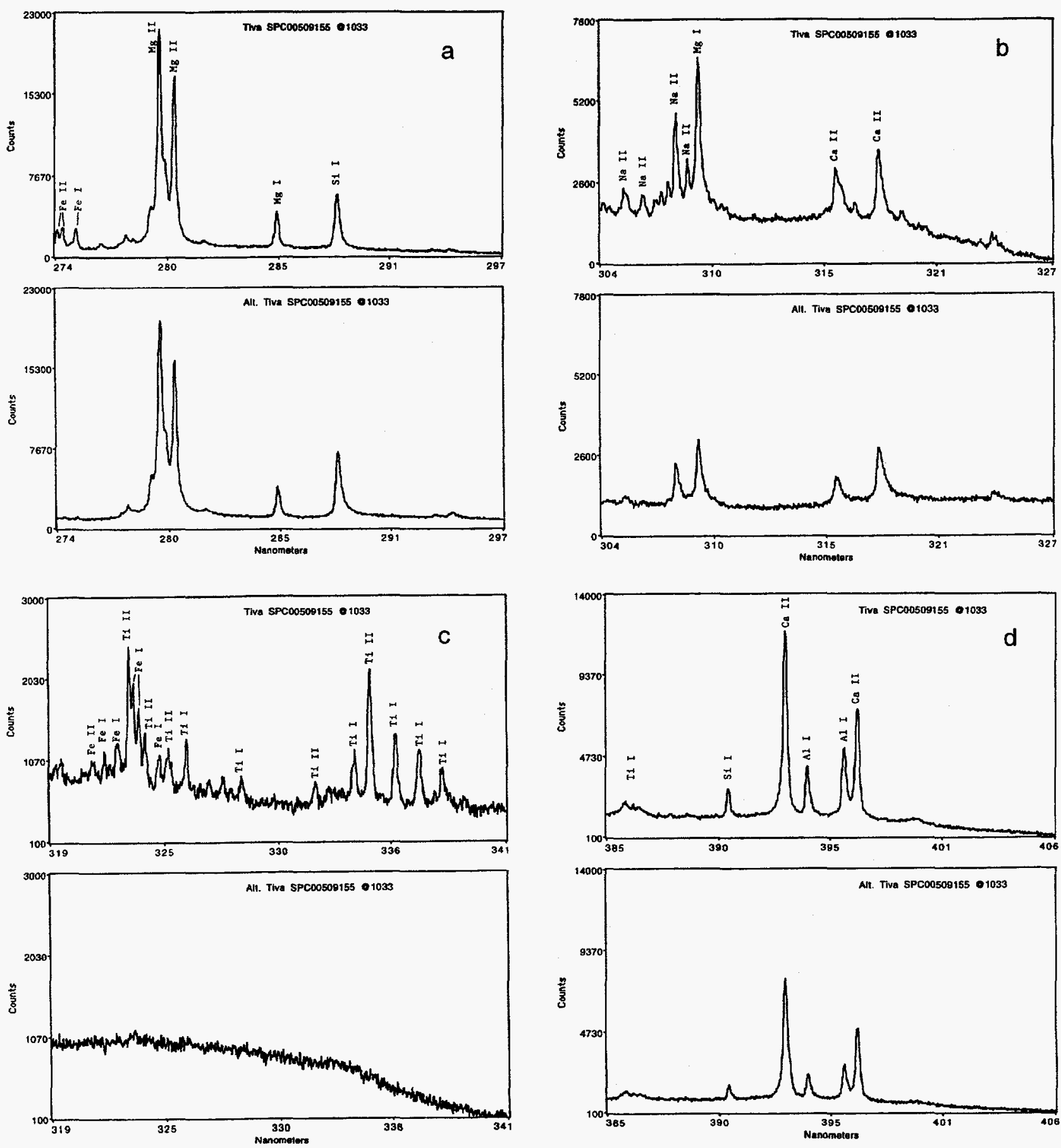

Fig. 7a-d. LIBS spectra of unaltered (top) and altered (bottom) Tiva Canyon tuffs near sample \#SPC00509155, approximately $1033 \mathrm{~m}$ from the portal of the ESF: (a) spectra centered at $285 \mathrm{~nm}$; (b) spectra centered at $315 \mathrm{~nm}$; (c) spectra centered at $330 \mathrm{~nm}$; and (d) spectra centered at $395 \mathrm{~nm}$. Element emission lines are labeled as in Figure 2a-d.

\section{FEASIBILITY OF USING LIBS FOR REAL-TIME ERIONITE DETECTION}

The zeolite mineral erionite, $\left(\mathrm{Na}_{2}, \mathrm{~K}_{2}, \mathrm{Ca}, \mathrm{Mg}\right)_{4.5}\left[\mathrm{AlgSi} 27 \mathrm{O}_{72}\right] \cdot 27 \mathrm{H}_{2} \mathrm{O}$, is reported to occur sporadically within certain portions of the Yucca Mountain block (Guthrie, et al., 1995). This mineral is a potential health hazard to personnel since it has been reported to be more carcinogenic than fibrous asbestos minerals (Guthrie, 1992). Drillers and miners exposed to high levels of rock dust are particularly at hazard if erionite should be encountered during their operations. The definitive method of 

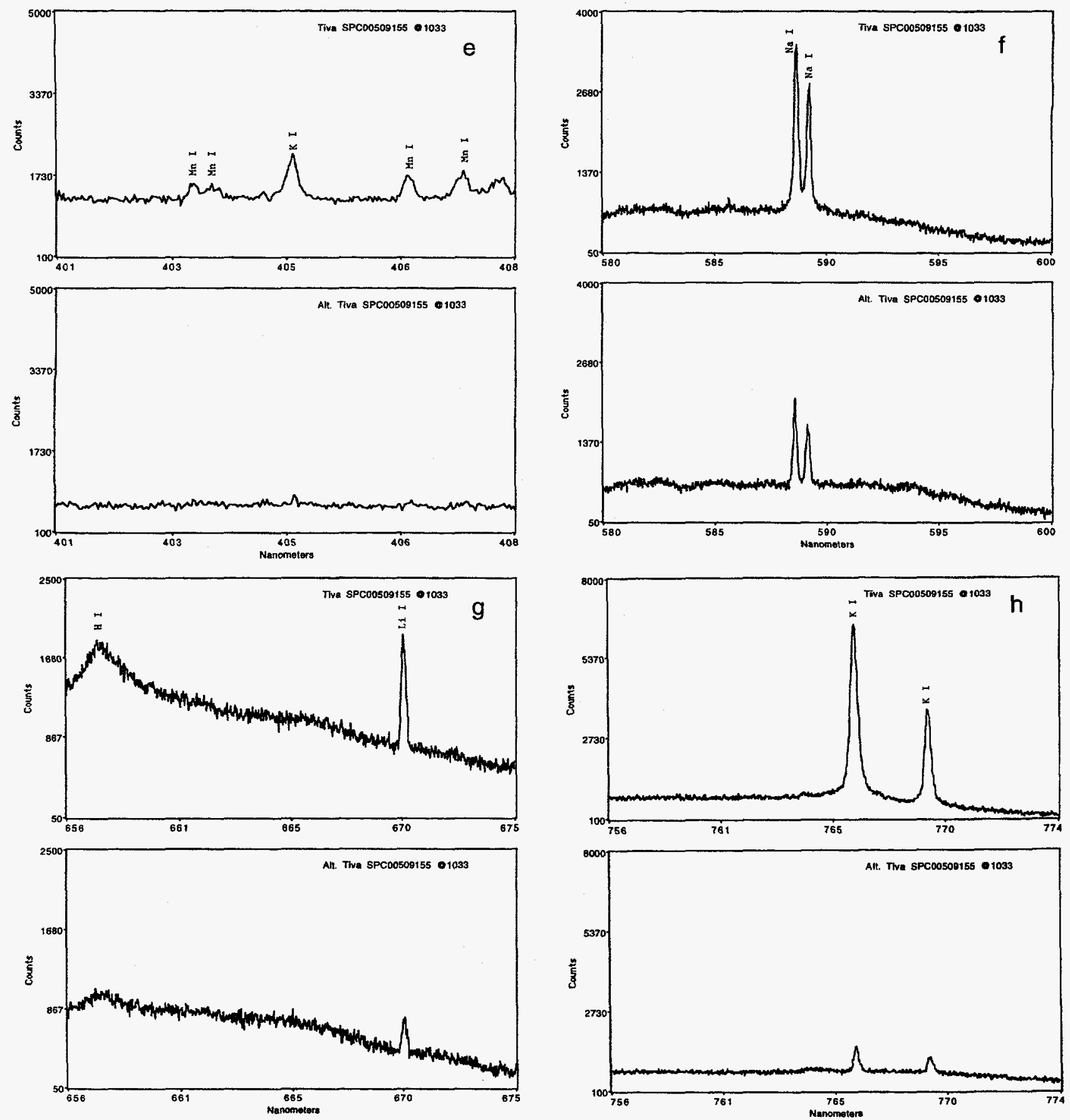

Fig. 7e-h. LIBS spectra of unaltered (top) and altered (bottom) Tiva Canyon tuffs near sample \#SPC00509155, approximately $1033 \mathrm{~m}$ from the portal of the ESF: (e) spectra centered at $405 \mathrm{~nm}$; (f) spectra centered at $590 \mathrm{~nm}$; (g) spectra centered at $665 \mathrm{~nm}$; and (h) spectra centered at 765 . Element emission lines are labeled as in Figure $2 a-d$.

detecting the presence of erionite is $\mathbf{x}$-ray diffraction by which its unique crystalline structure can be determined. However, the time and expense required to continuously monitor drilling and mining operations using $x$-ray diffraction induced us to investigate whether real-time LIBS analysis such as the drilling dust analyzer we have developed could be useful in detecting the presence of erionite.

In order for LIBS or any other real-time chemical analysis method to be useful in this respect, erionite must exhibit some chemical signature that will distinguish it from other mineral constituents at Yucca Mountain. We investigated this possibility in the laboratory by analyzing with the LIBS method 
samples previously determined by $\mathrm{x}$-ray analysis to contain erionite or chemically similar non-hazardous zeolite minerals such as clinoptilolite. Samples from above, within, and below the vitrophyre subzone of the Topopah Spring tuff, one of which was known to contain a high proportion of erionite (Guthrie, et al., 1995), were analyzed by LIBS. In examining the LIBS emission peaks, we noticed significant differences in $\mathrm{Na}$ and Li content of the samples (Figures 8 and 9 ). In order to quantify these apparent chemical differences, we plot the ratio of the areas under the $\mathrm{Li}$ and $\mathrm{Na}$ peaks in Figure 10. The sample containing erionite exhibits a significantly higher Li/Na ratio than nearby, non-erionitebearing samples, suggesting this chemical signature as a possible erionite detector. However, caution should be used in generalizing this result since only a few samples from one drill core have been analyzed and lateral chemical variation could result in false signals; $x$-ray diffraction remains the only sure way of detecting the presence of erionite. Nevertheless, if additional testing confirms the $\mathrm{Li} / \mathrm{Na}$ signature as reliably indicative of the presence of erionite at Yucca Mountain, real-time LIBS dust analysis could prove useful as an early warning of the possible presence of erionite requiring increased hazard reduction measures in operations and more detailed $\mathrm{x}$-ray analysis.

\section{CONCLUSIONS}

We performed laboratory analyses and developed and field-tested two new prototype instruments based on the laser-induced breakdown spectroscopy method to assess the feasibility of using this method in characterization tasks within the Yucca Mountain Project. One prototype allowed realtime analysis of cuttings dust produced by air core drilling operations, and the second prototype was

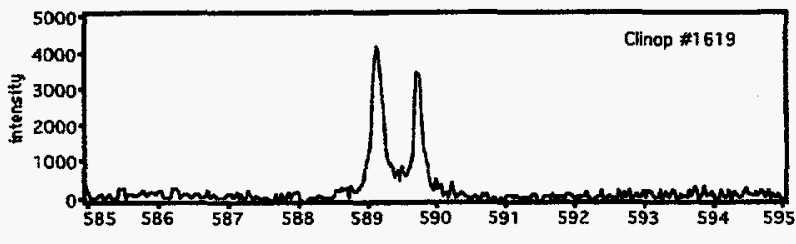
designed for real-time elemental analysis of rock surfaces in the field. In both cases, we demonstrated that the LIBS method was capable of measuring all major and minor and some trace ele-
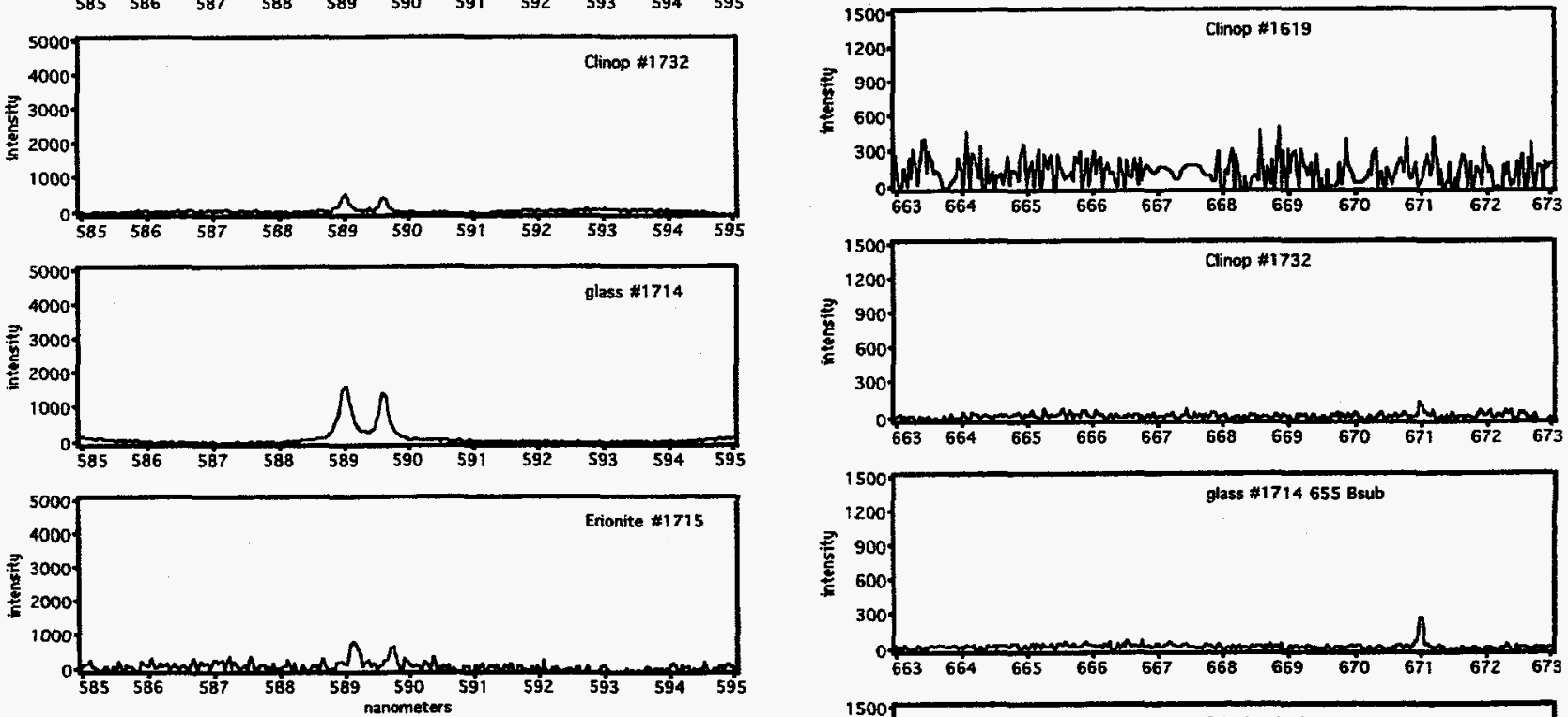

Fig. 8. LIBS spectra of rock powder samples from the lower Topopah Spring tuff encountered in drill hole UZ-14. The doublet peak near $589 \mathrm{~nm}$ is due to singly ionized sodium, and the peak heights are proportional to the relative concentrations of $\mathrm{Na}$ in the respective samples. The top and bottom spectra are the averages of five laser sparks, the center two spectra are the averages of ten laser sparks.

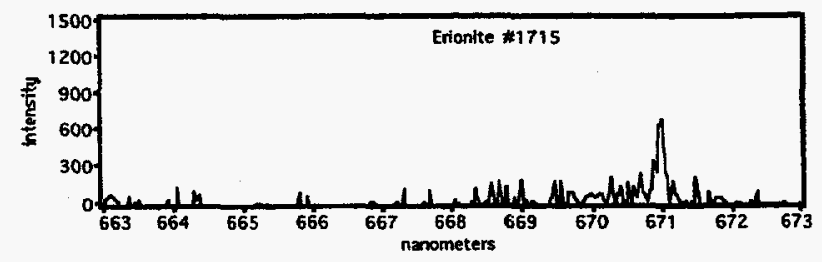

Fig. 9. LIBS spectra of the same rock powders shown in Figure 8. The peak near $671 \mathrm{~nm}$ is due to singly ionized lithium. Analysis conditions the same as for Figure 8. 
LIBS analysis of YMP drill core

USW UZ-14

Topopah Spring Tuff

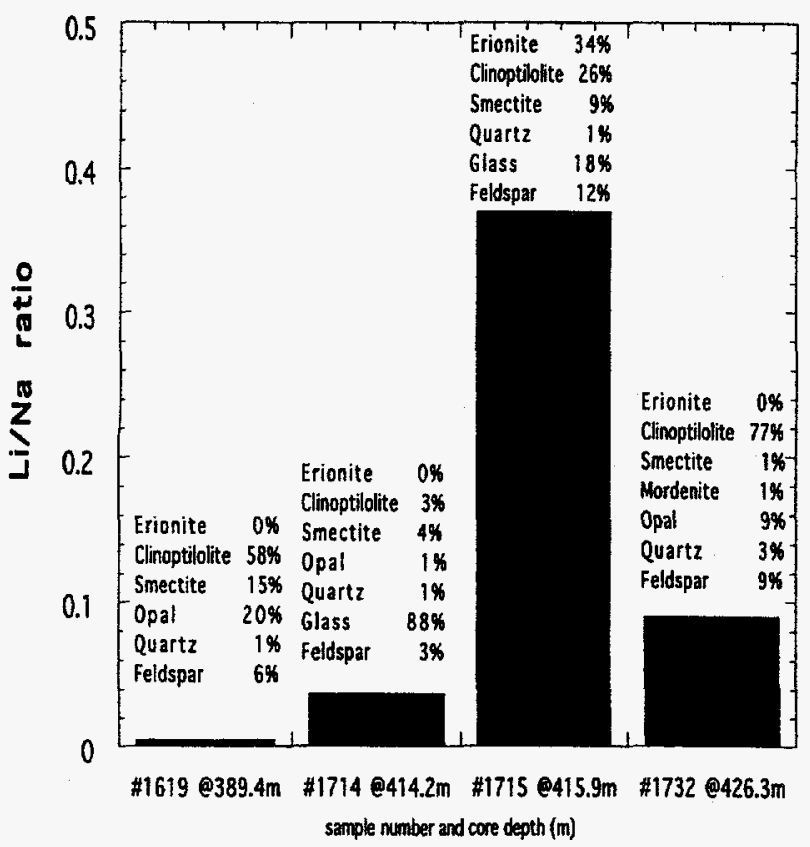

Fig. 10. Histogram of the ratios of emission peak

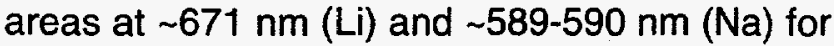
the UZ-14 samples, spectra from Figures 8 and 9. Sample numbers and depth locations in the UZ14 core hole are given at the base for each sample, and the approximate proportions of specific minerals (based on quantitative $x$-ray diffraction analysis, Bish, et al., 1995) are listed at the top. ment constituents of Yucca Mountain rocks in real time and in realistic field conditions at the ESF. We identified engineering improvements to the prototype designs, and we are confident that suitable calibration of second generation instruments would provide a semi-quantitative, real time field elemental analysis capability with a number of potential applications in drilling, coring, sampling, and characterization tasks at Yucca Mountain.

In laboratory analyses of manganese oxide fracture coatings on selected Yucca Mountain samples and comparison to mineral standards, we demonstrated that the LIBS method could produce quantitative element ratio signatures characteristic of specific manganese oxide minerals. We also identified the $\mathrm{Li} / \mathrm{Na}$ element ratio as a possible LIBS-method indicator of the presence of the hazardous mineral erionite in Yucca Mountain rocks. Real-time monitoring of air-coring dust for probable erionite using a LIBS instrument similar to our dust analyzer prototype appears to be feasible.

\section{ACKNOWLEDGMENTS}

During both field tests we received outstanding operational support from Alan Mitchell, Joel Spoeneman and Mike Taylor. The miners and drillers were very tolerant of our activities and sensitive to our needs. We would like to express our thanks to all of the people at the Alcove \#1 drill

site and the TBM; their help made our job easier and significantly contributed to the success of our operations.

At Los Alamos, Monty Ferris contributed many helpful suggestions during the design of the LIBS equipment and performed the initial construction of the surface analyzer head. Steve Chipera analyzed the grain size distribution of the core drill cuttings, supplied the manganese oxide mineral standards and collected what analytical data were available for them. Dale Counce performed the ICP analysis and Emily Kluk performed the XRF analysis. Ines Triay provided useful discussions of the potential sorptive capacity of manganese oxides and their importance at Yucca Mountain. Dave Vaniman and Barbara Carlos selected the relevant Yucca Mountain samples for us and provided many useful comments and suggestions throughout the study.

Finally, we would like to thank Ron Oliver for his strong support and encouragement throughout the project; the work could not have been done without Ron's help.

This work was supported by the Yucca Mountain Site Characterization Office as part of the Civilian Radioactive Waste Management Program. This project is managed by the U.S. Department of Energy, Yucca Mountain Site Characterization Project.

\section{REFERENCES}

Bish, D. L. and J. E. Post, "Thermal behavior of complex, tunnel-structure manganese oxides," Amer. Mineral., 74, 177-186 (1989). 
Bish, D. L., S. J. Chipera, D. Guthrie, and D. T. Vaniman, "Letter report: The occurrence and distribution of erionite in drill holes at Yucca Mountain, Nevada," Los Alamos National Laboratory Milestone report LA4058, in preparation, 1995.

Blacic, J., D. Pettit, and D. Cremers, "Field deployment test of LIBS technology at the Yucca Mountain Exploratory Studies Facility, test alcove \#1, March 2-9, 1994," Los Alamos National Laboratory Milestone report LA4047 (1995a).

Blacic, J., D. Pettit, and D. Cremers, "Preliminary LIBS analysis of Yucca Mountain manganese oxide minerals," Los Alamos National Laboratory report LA-13066-MS (1995b).

Carlos, B., "Fracture-coating minerals in the Topopah Spring Member and Upper Tuff of Calico Hills from Drill Hole J-13," Los Alamos National Laboratory report LA-11504-MS (1989).

Carlos, B. A., D. L. Bish, and S. J. Chipera, "Manganese-oxide minerals in fractures of the Crater Flat tuff in drill Core USW G-4, Yucca Mountain, Nevada," Los Alamos National Laboratory report LA11787-MS (1990).

Carlos, B. A., S. J. Chipera, D. L. Bish, and S. J. Craven, "Fracture-lining manganese oxide minerals in silicic tuff, Yucca Mountain, Nevada, U.S.A.," Chem. Geol., 107, 47-69 (1993).

Guthrie, G. D. Jr., "Biological effects of inhaled minerals," Amer. Min., 77, 225-242 (1992).

Guthrie, G. D.. Jr., D. L. Bish, S. J. Chipera, and R. Raymond, Jr., "Distribution of potentially hazardous phases in the subsurface at Yucca Mountain, Nevada," Los Alamos National Laboratory report LA-12573-MS (1995).

Means, J. L., D. A. Crerar, M. P. Borcsik, and J. O. Duguid, "Adsorption of Co and selected actinides by Mn and Fe oxides in soils and sediments," Geochim. Cosmochim. Acta, 42, 1763-1273 (1978).

Triay, I. R., "Radionuclide migration as a function of mineralogy," Oral presentation at 2nd annual High-Level Radioactive Waste Management Conf., Las Vegas, Nevada, Los Alamos National Laboratory, unpublished data (1991).

Triay, I. R., A. J. Mitchell, and M. A. Ott, "Radionuclide migration as a function of mineralogy," Proceedings of 2nd annual High-Level radioactive waste Management Conference, Las Vegas, Nevada, 494498 (1991).

Vaniman, D., personal communication (June1995). 


\section{APPENDIX}

\begin{tabular}{lcl}
$\begin{array}{l}\text { Description of Locations Where Data Were Taken } \\
\text { Data collection dates: } 7 / 25-26 / 95 \\
\text { Location: Yucca Mountain Project, Exploratory Studies Facility tunnel }\end{array}$ \\
\begin{tabular}{lcc} 
Location Number & Distance from Portal (m) & \multicolumn{1}{c}{ Description } \\
SPC00509034 & 626 & $\begin{array}{l}\text { Mineral-filled fracture in Tiva Canyon, } 1 \mathrm{~mm} \\
\text { wide, dark mineralization }\end{array}$ \\
SPC00509155 & 1033 & $\begin{array}{l}\text { Tiva Canyon, crystal poor, non-lithophysal } \\
\text { unit, pristine condition, light gray }\end{array}$ \\
SPC00509155 & 1033 & $\begin{array}{l}\text { Tiva Canyon, altered zone, outer white-colored } \\
\text { band }\end{array}$ \\
SPC00509153 & 1033 & $\begin{array}{l}\text { Grain in Tiva Canyon, inner altered zone, } 2 \\
\text { mm diameter, black }\end{array}$ \\
SPC00509153 & 1033 & $\begin{array}{l}\text { Grain in Tiva Canyon, inner altered zone, } 1 \\
\text { mm diameter, red }\end{array}$ \\
SPC00509143 & 1034 & $\begin{array}{l}\text { Grain in Tiva Canyon, inner altered zone, } 1 \\
\text { mm diameter, red }\end{array}$ \\
SPC00509145 & 1034 & $\begin{array}{l}\text { Grain in Tiva Canyon, inner altered zone, } 1 \\
\text { mm diameter, black }\end{array}$ \\
SPC00510507 & 1066 & $\begin{array}{l}\text { Grain in Tiva Canyon, } 1 \text { mm diameter, } \\
\text { brown }\end{array}$ \\
SPC00510512 & 1075 & $\begin{array}{l}\text { Mineral-filled fracture, } 2 \text { mm wide } \\
\text { translucent white }\end{array}$ \\
no number & amygdaloidal pocket, 25 mm diameter, \\
powdery white
\end{tabular} \\
\hline
\end{tabular}

Individual Spectra for Each Data Location 
Counts

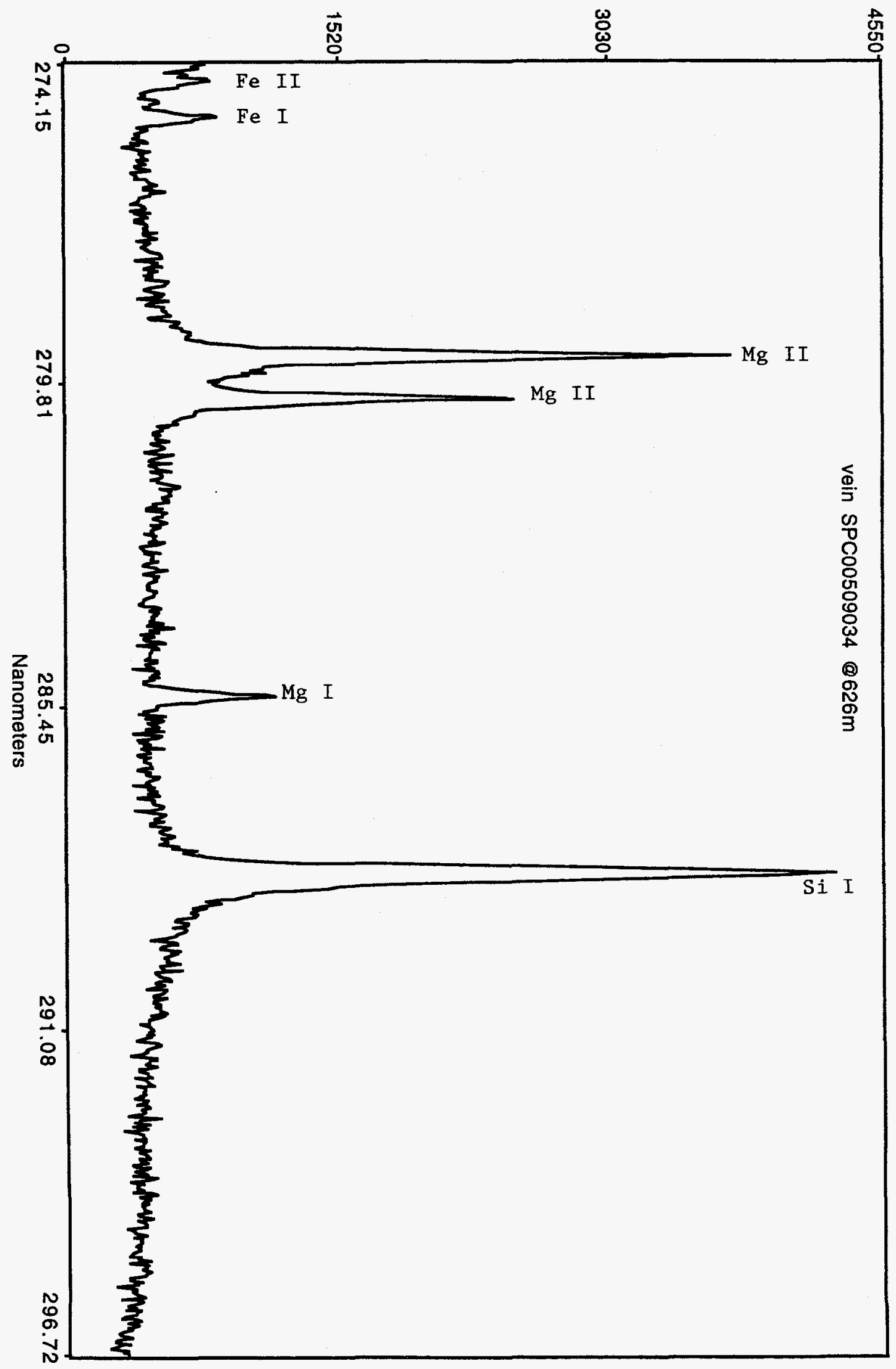




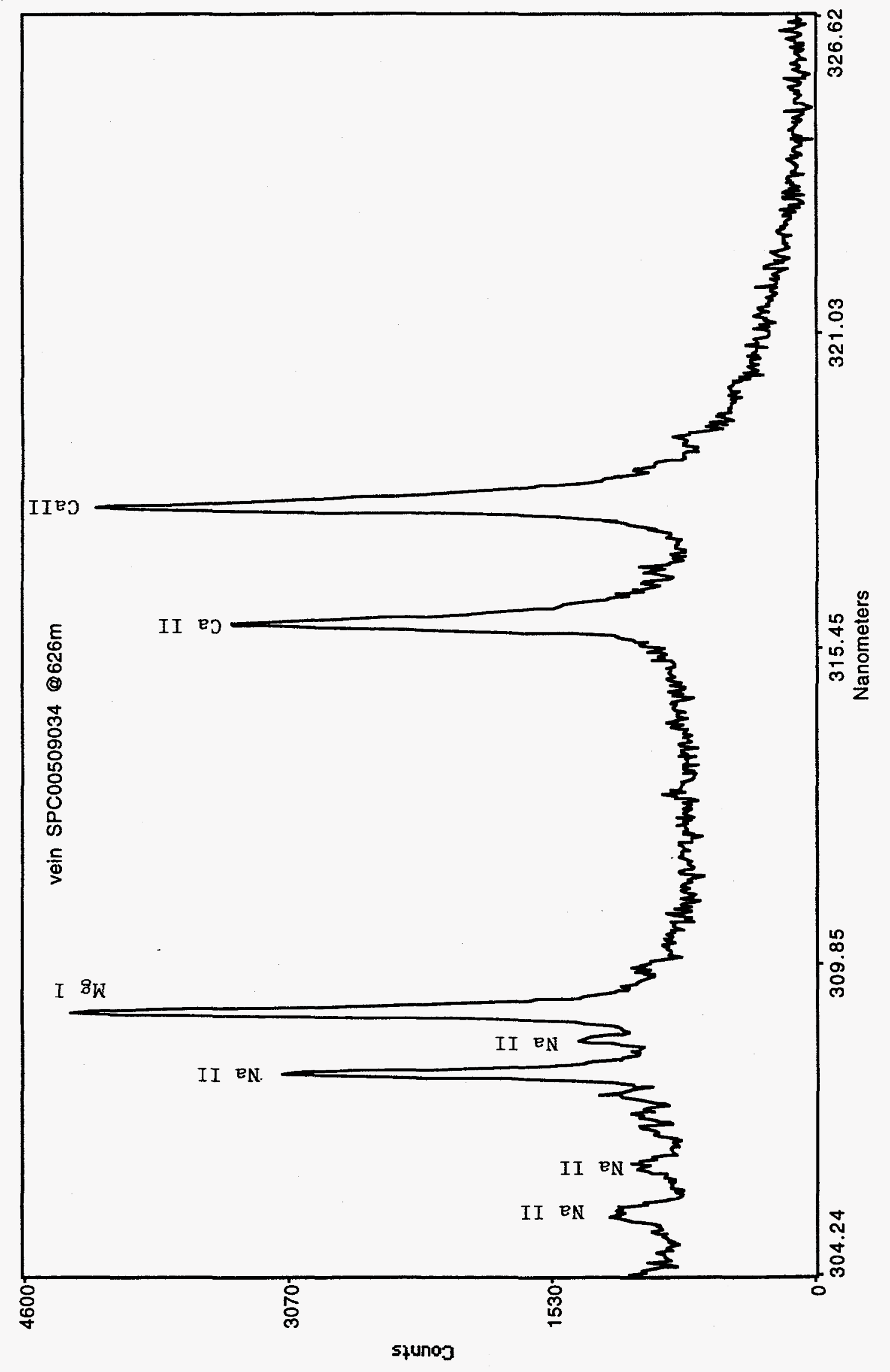




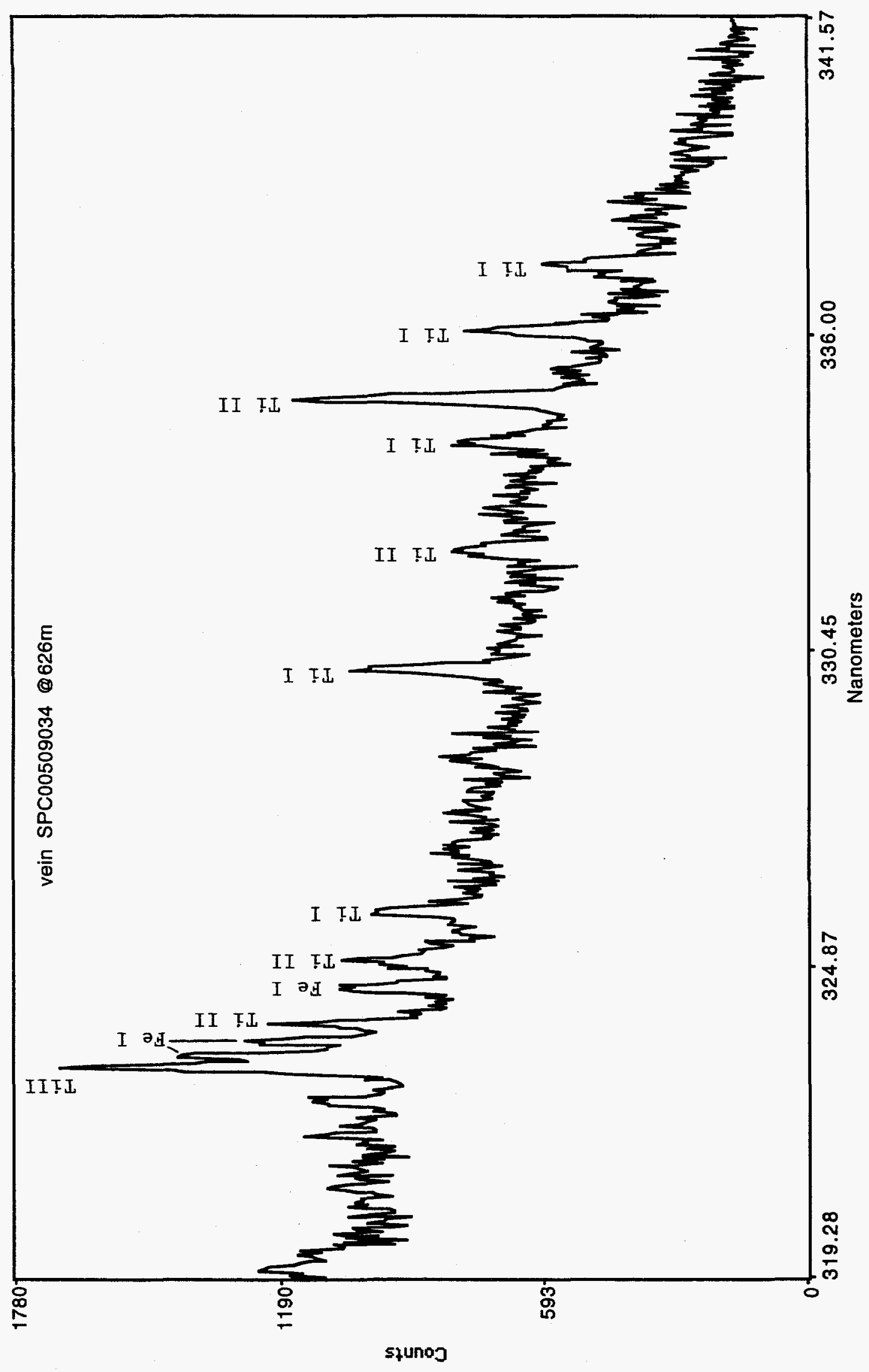




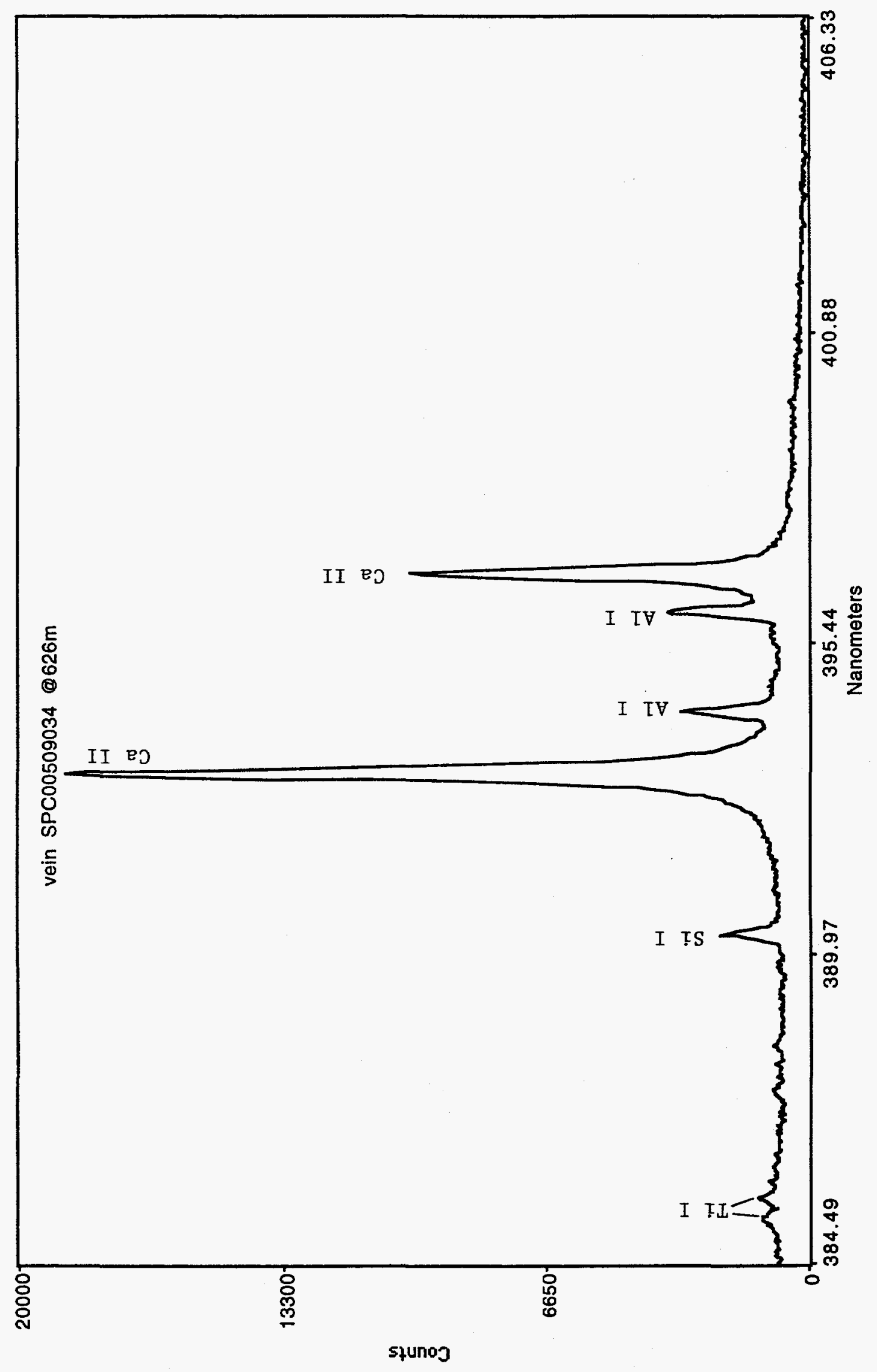




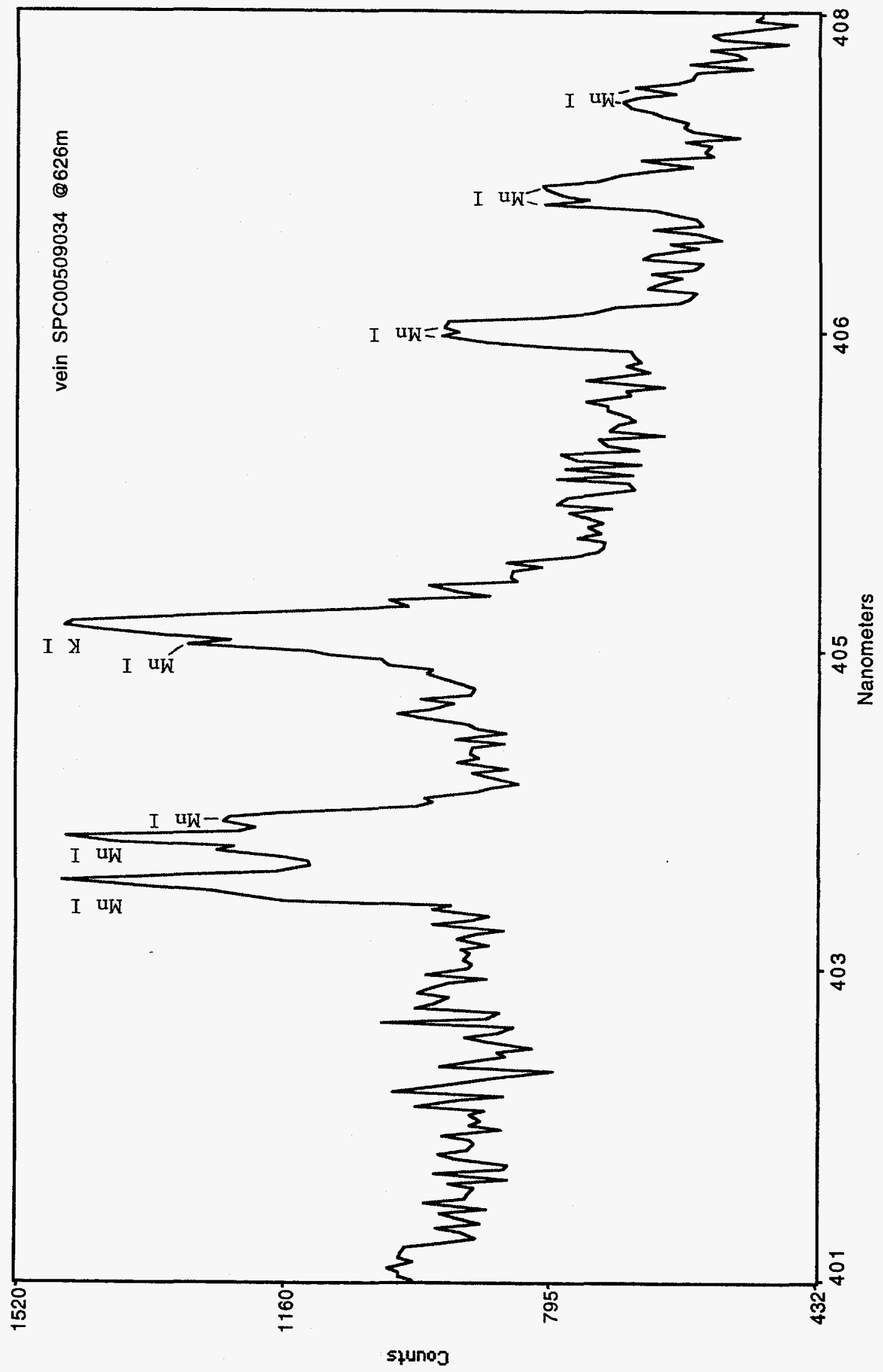




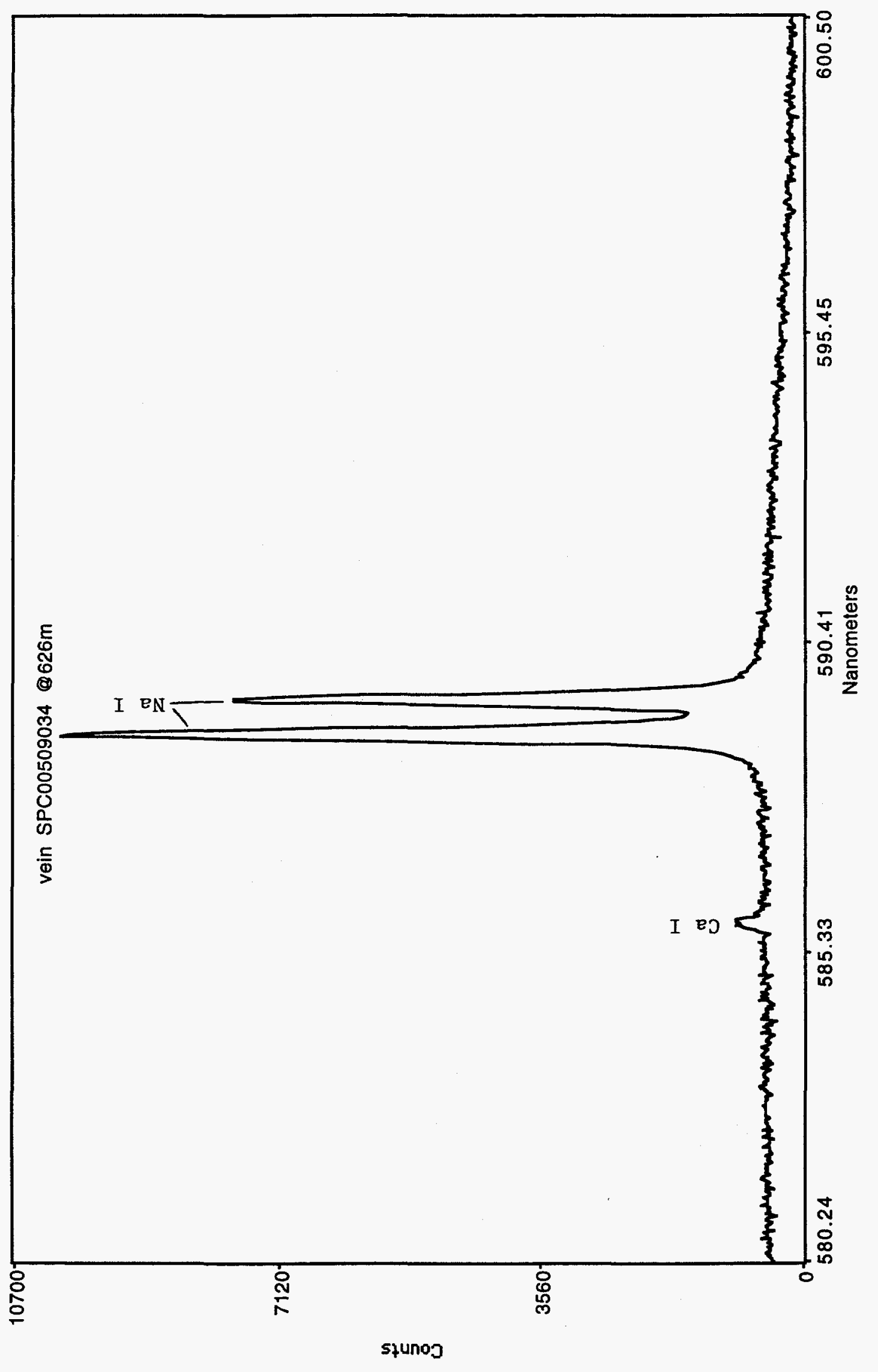




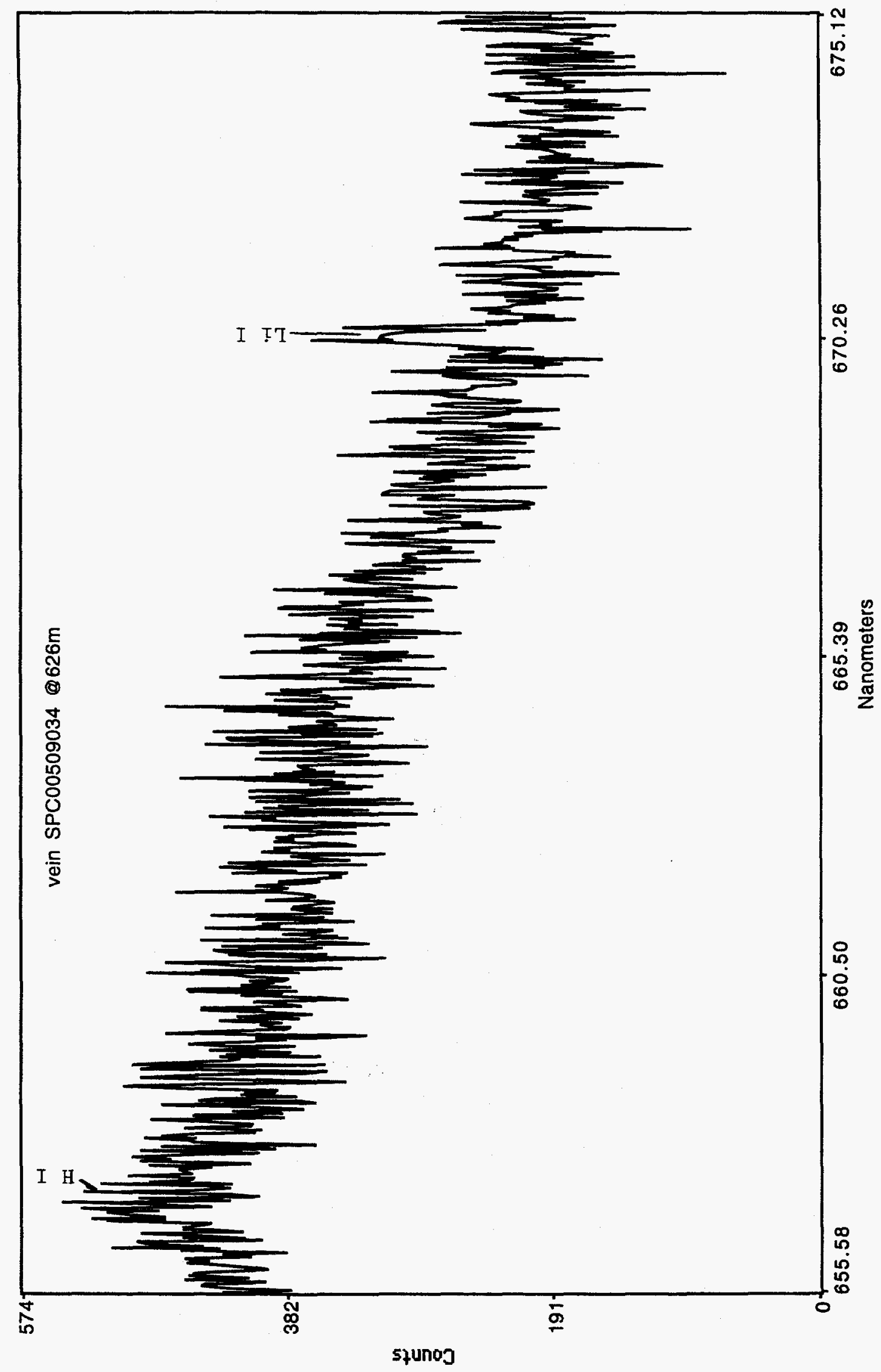




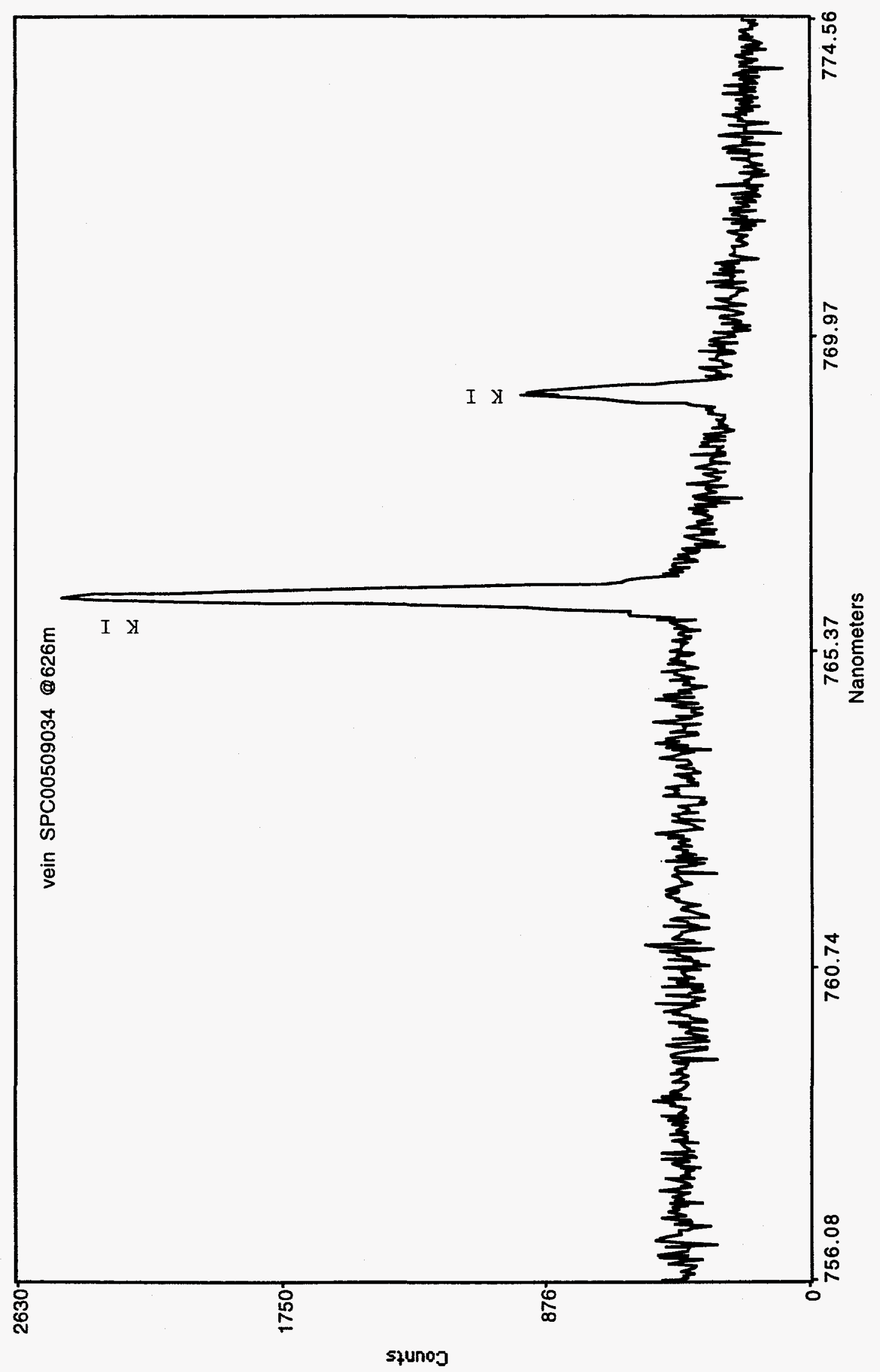




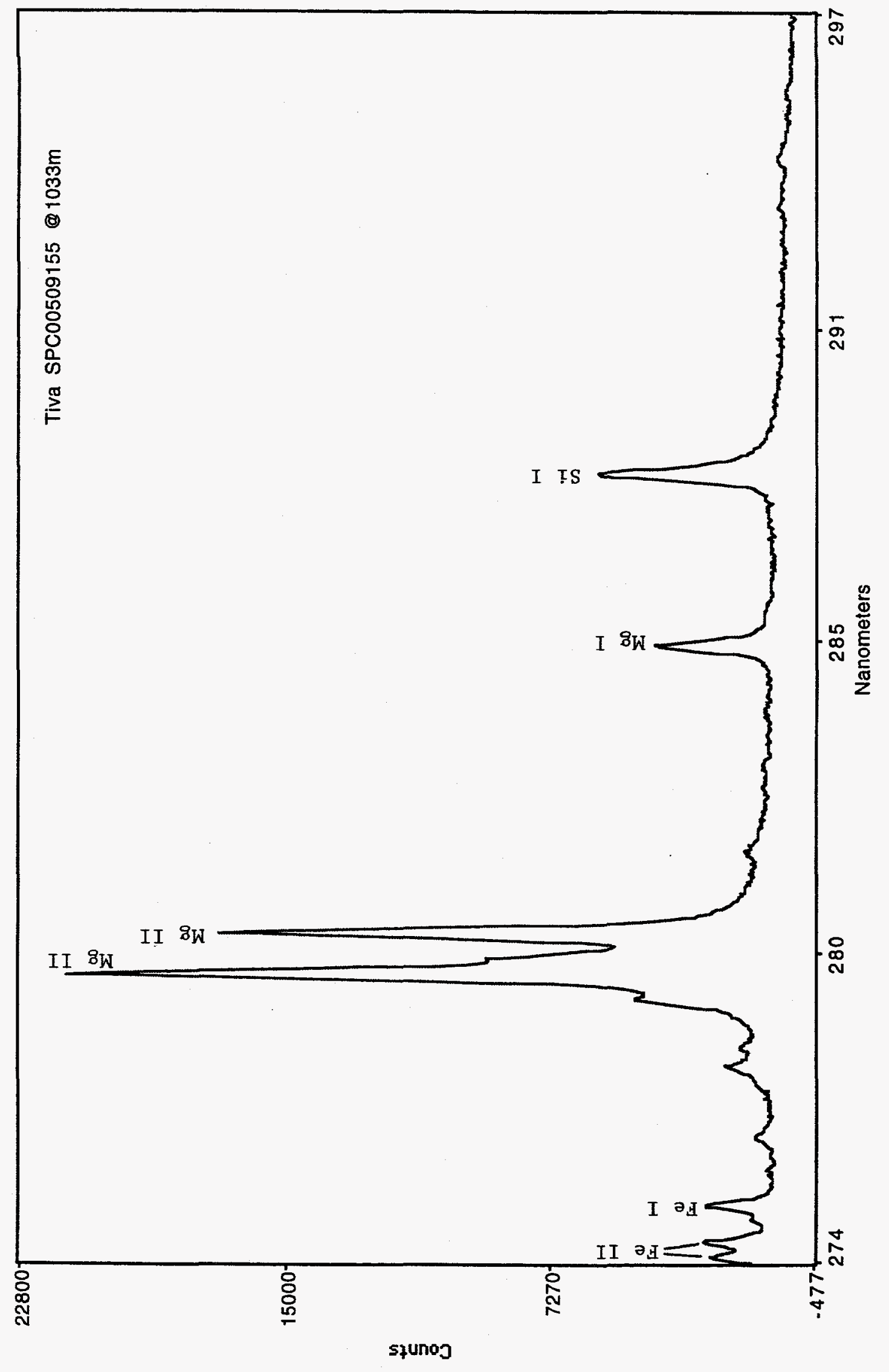




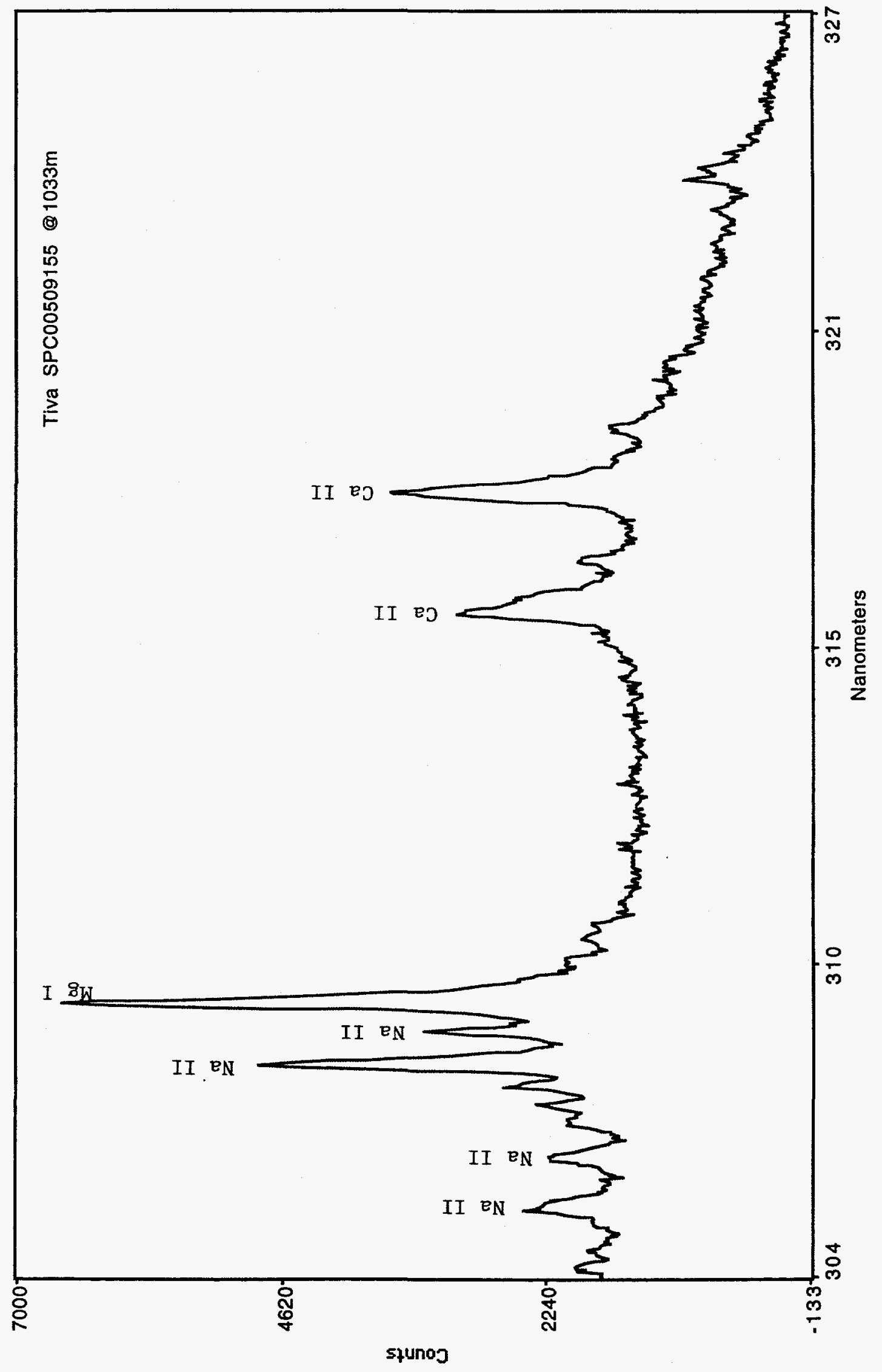




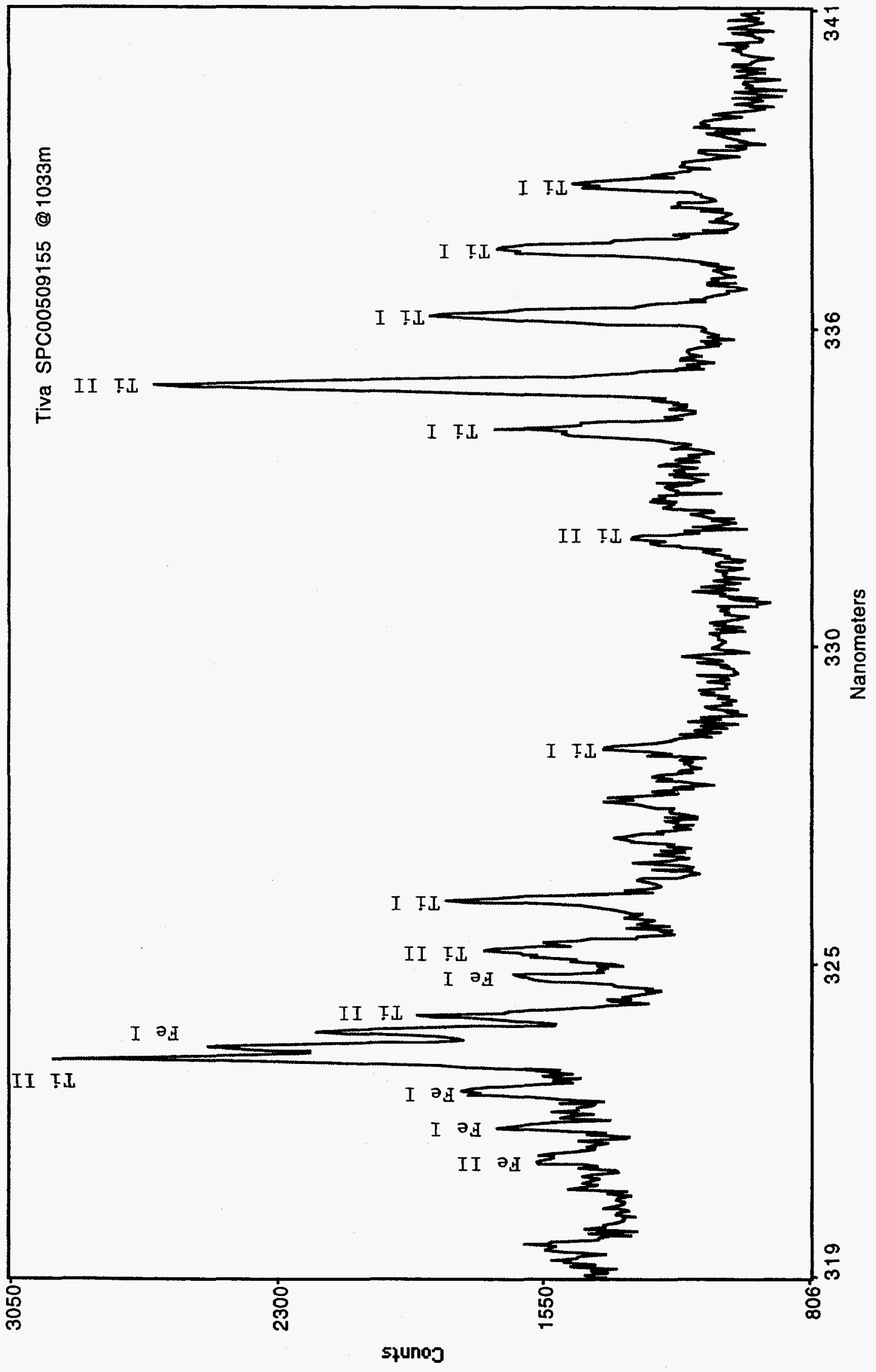




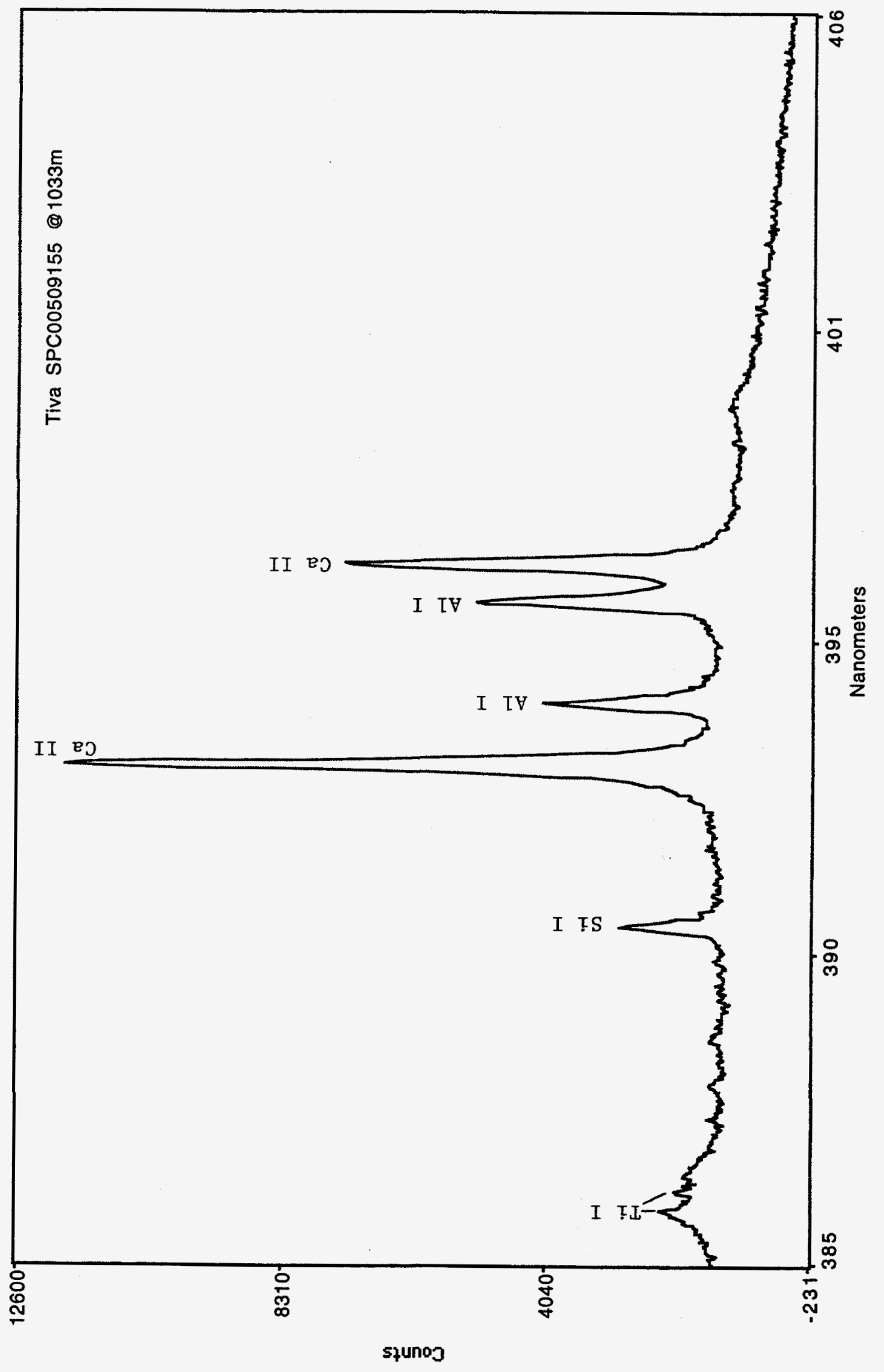




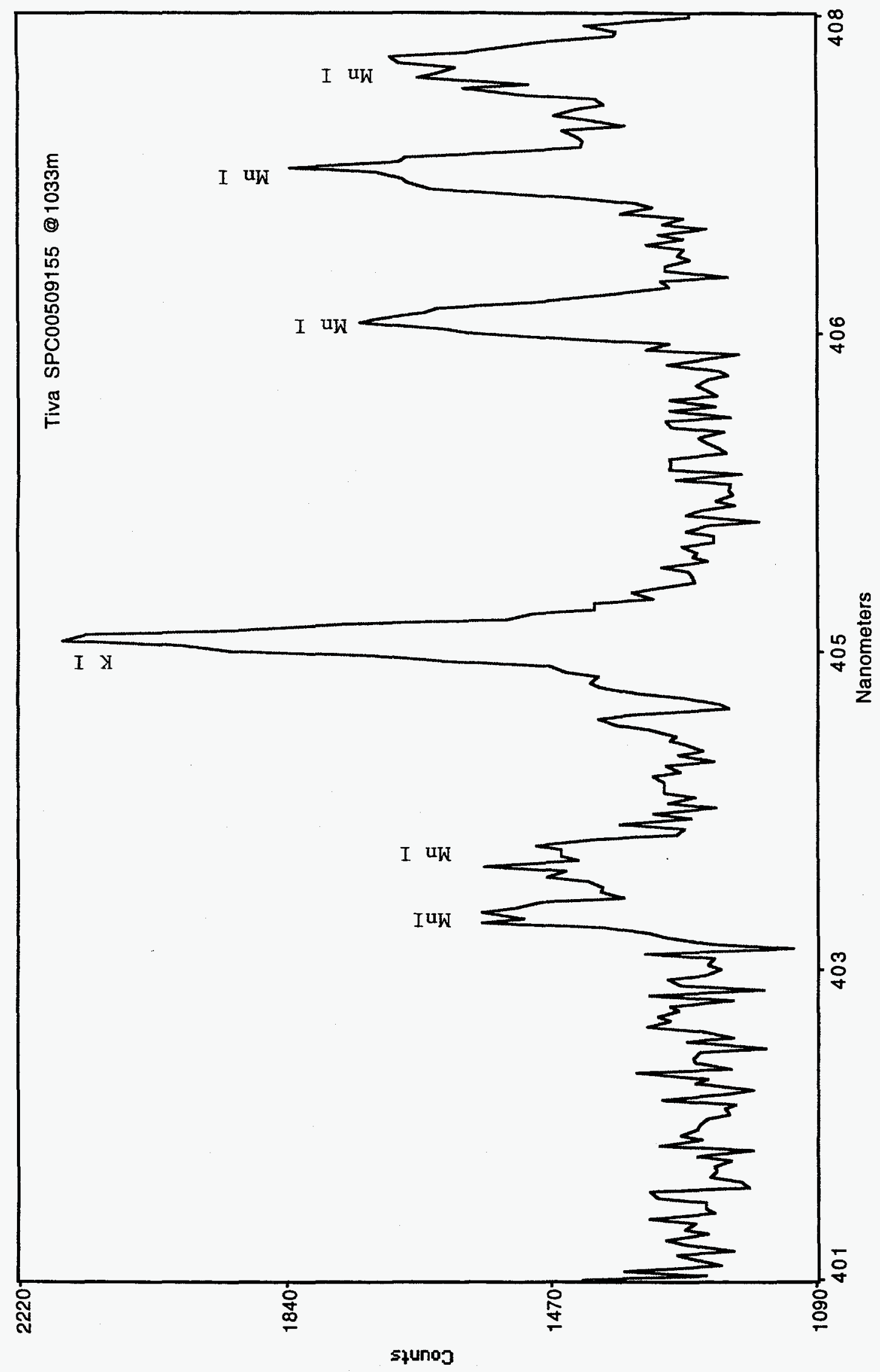




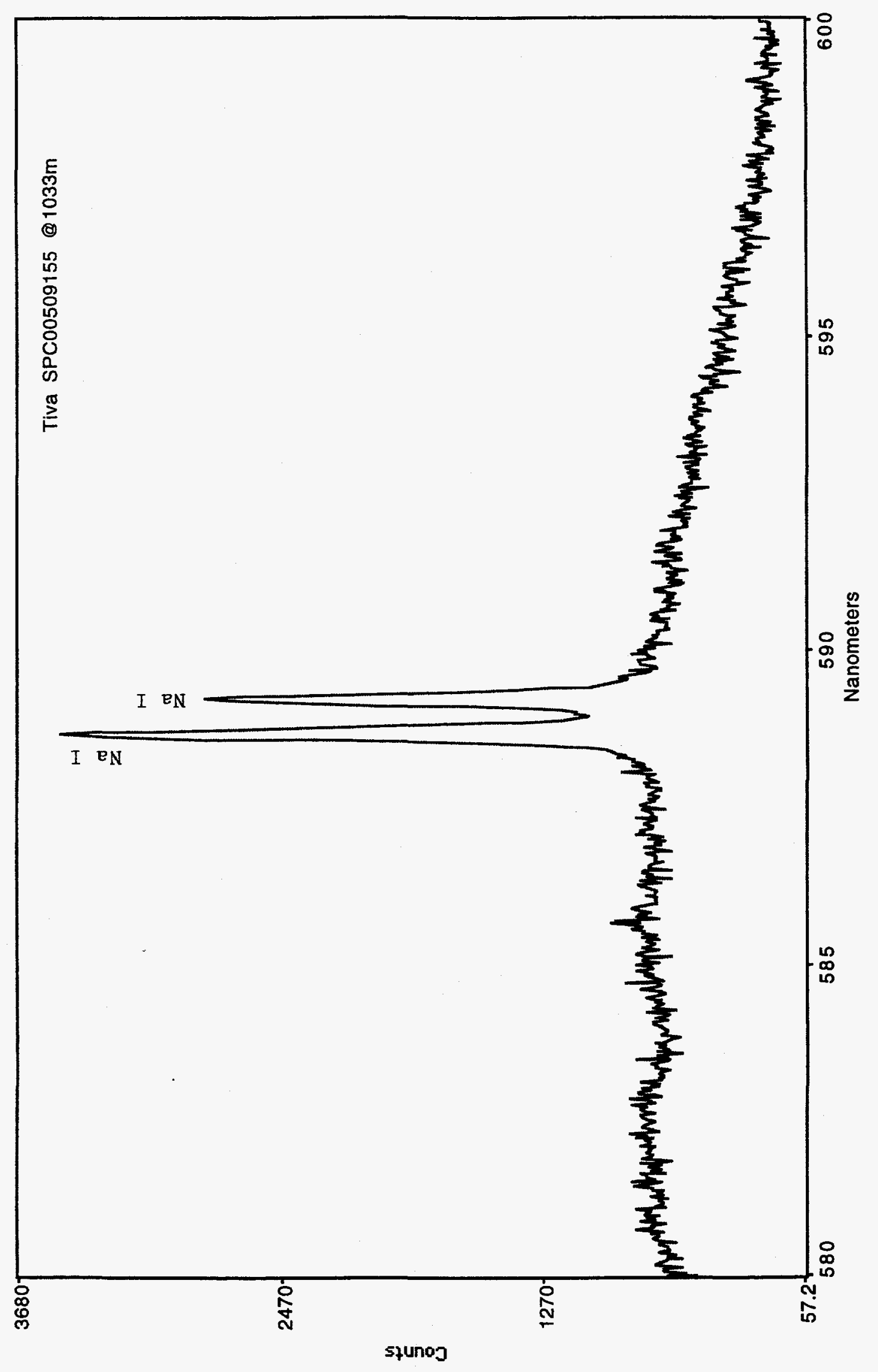




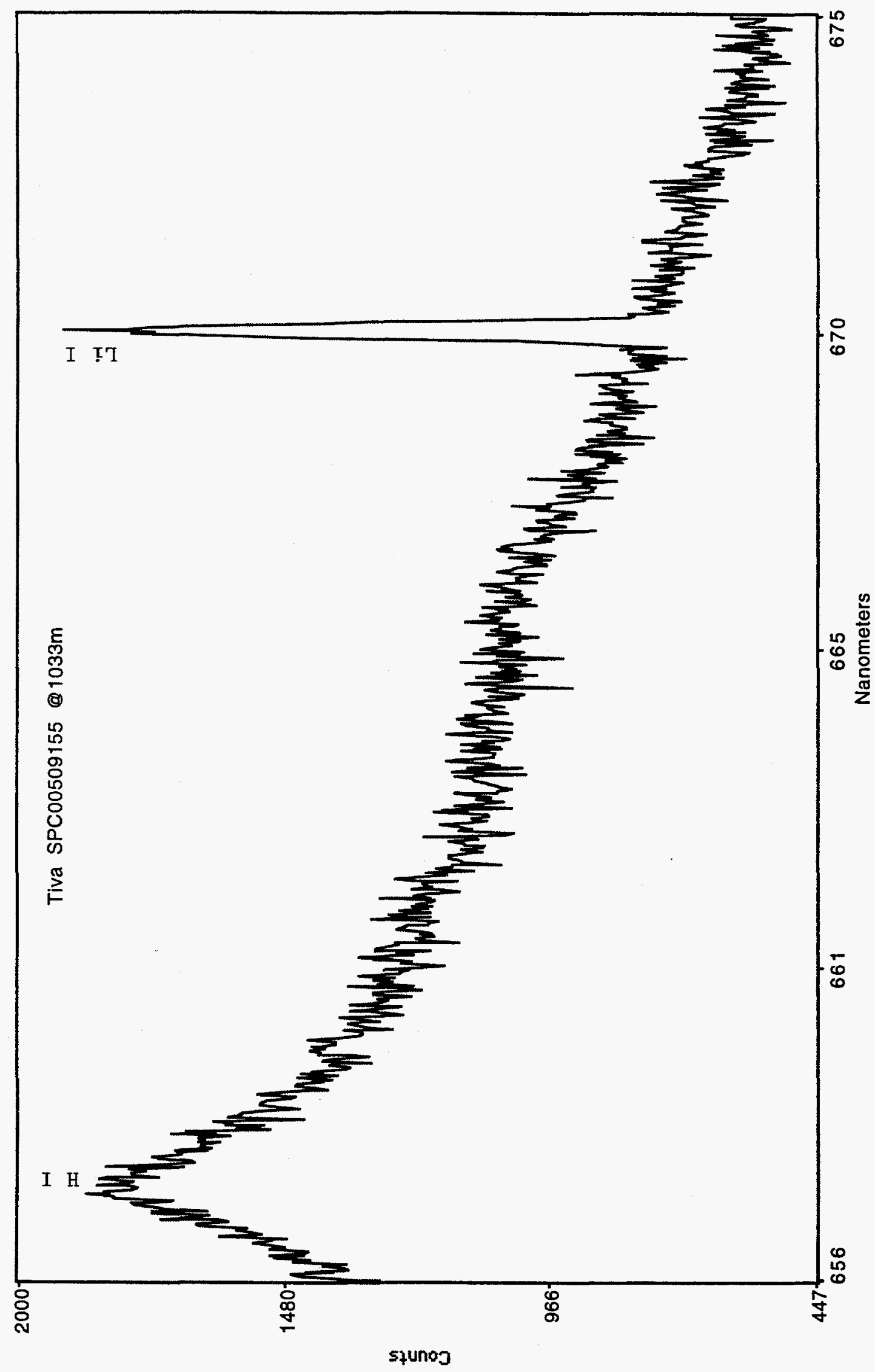




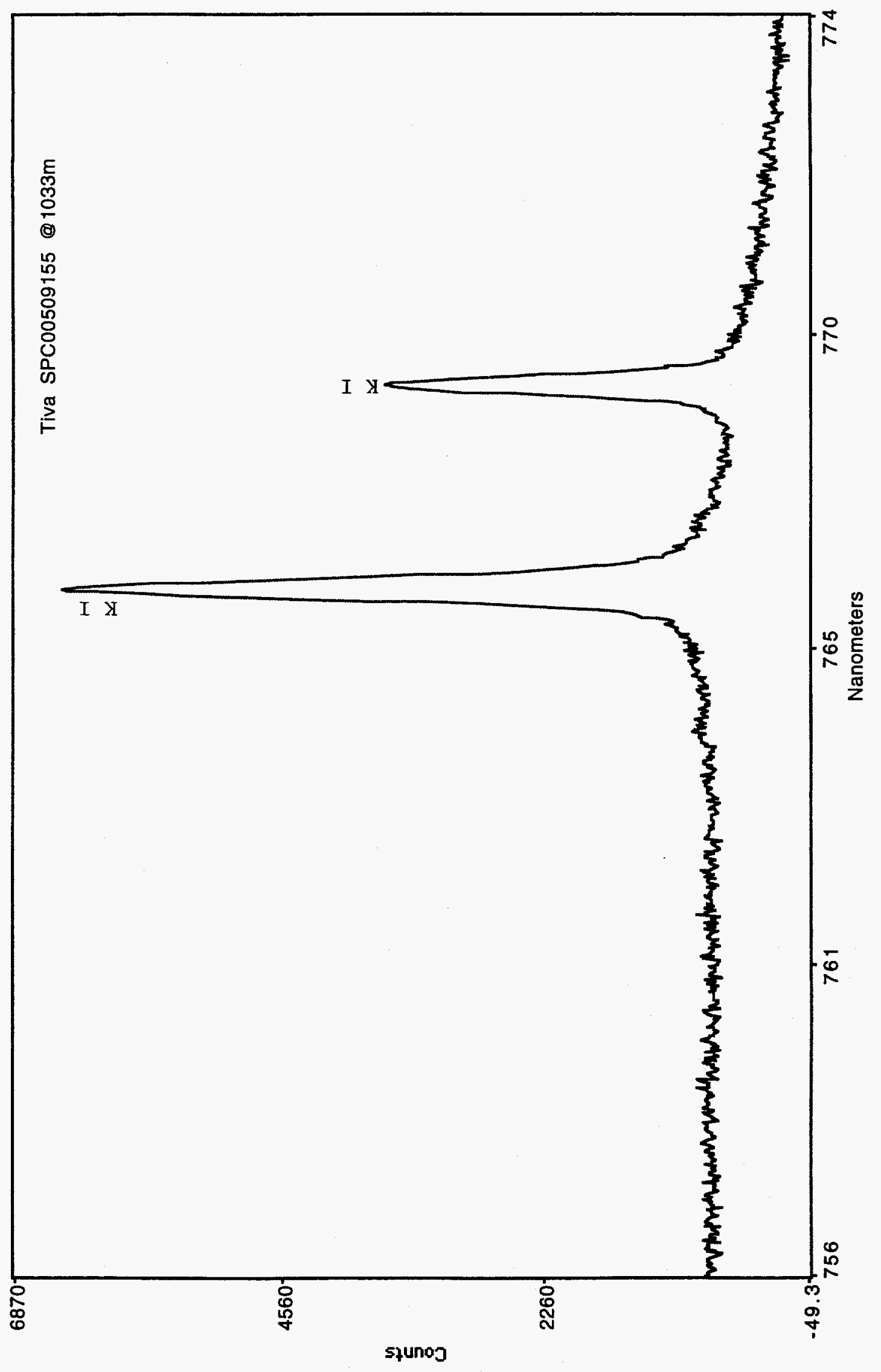




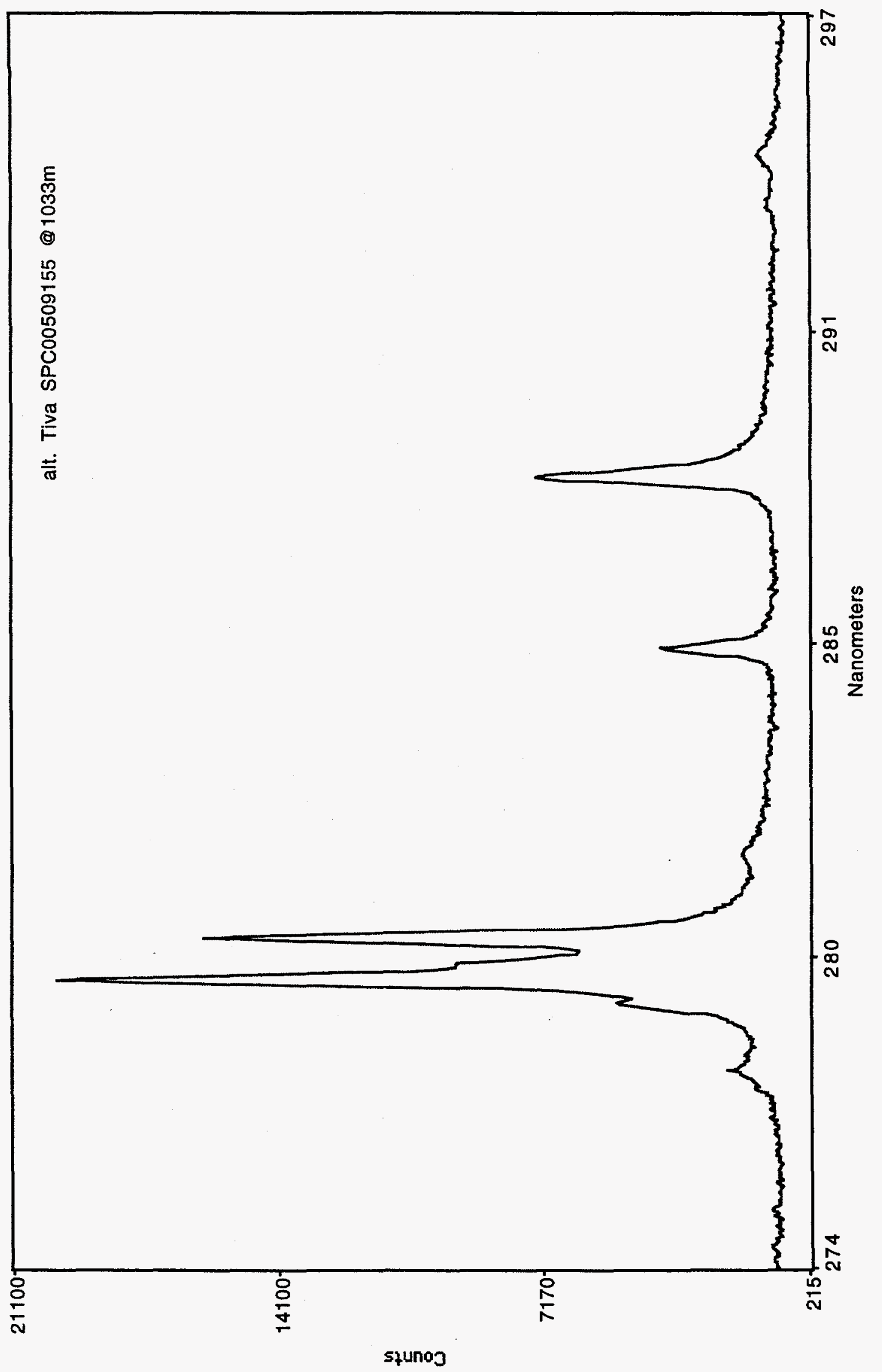




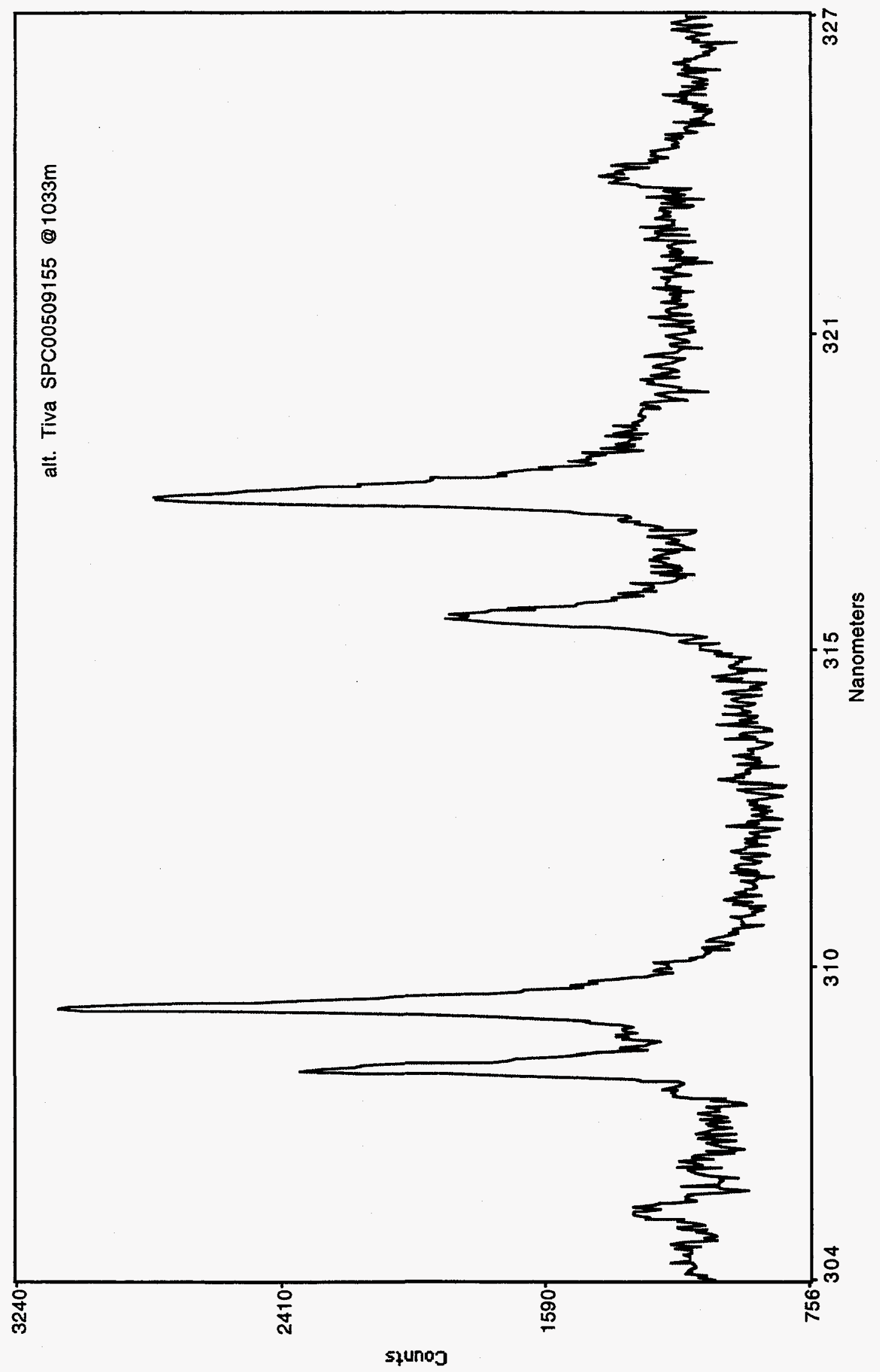




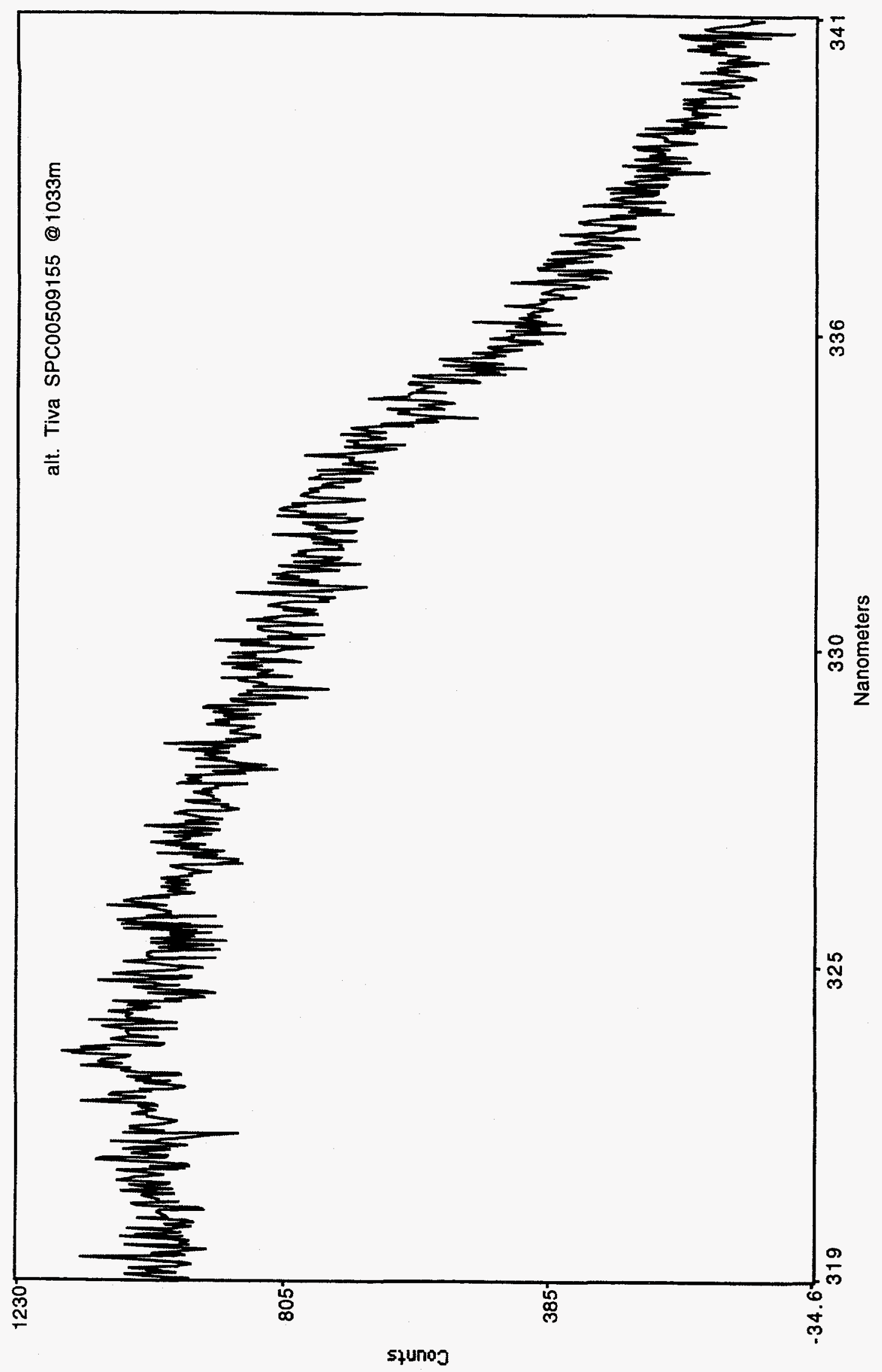




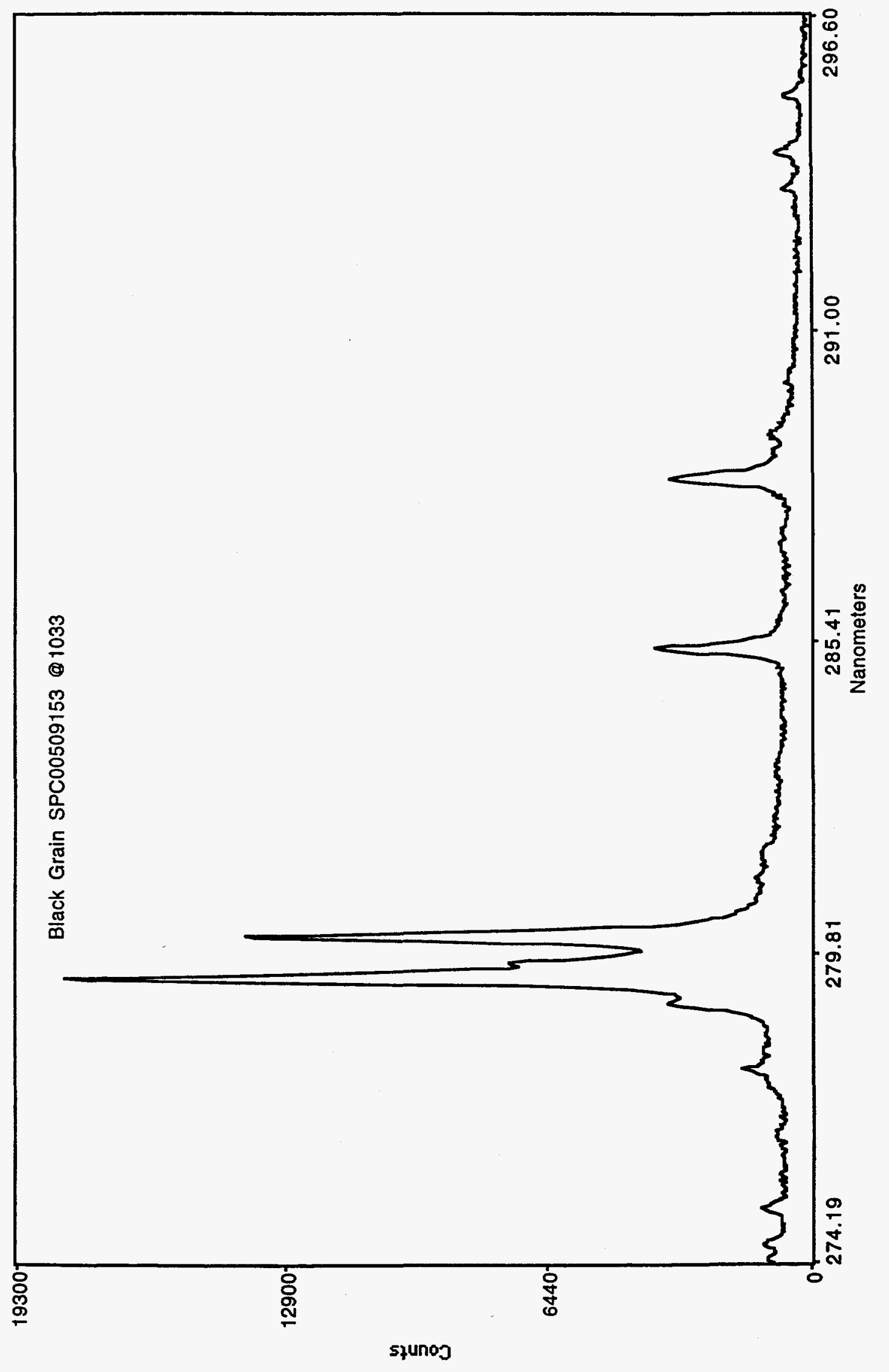




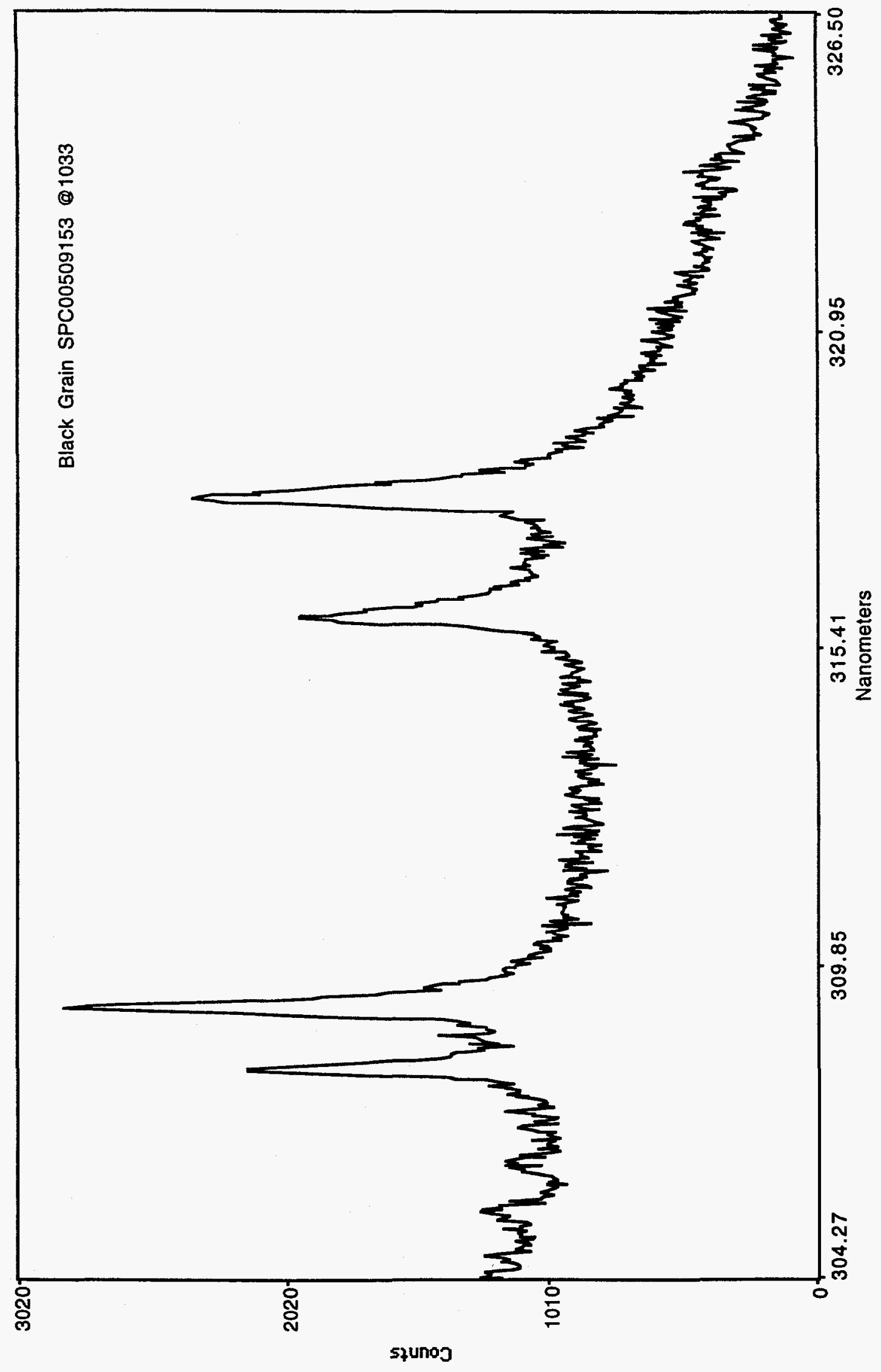




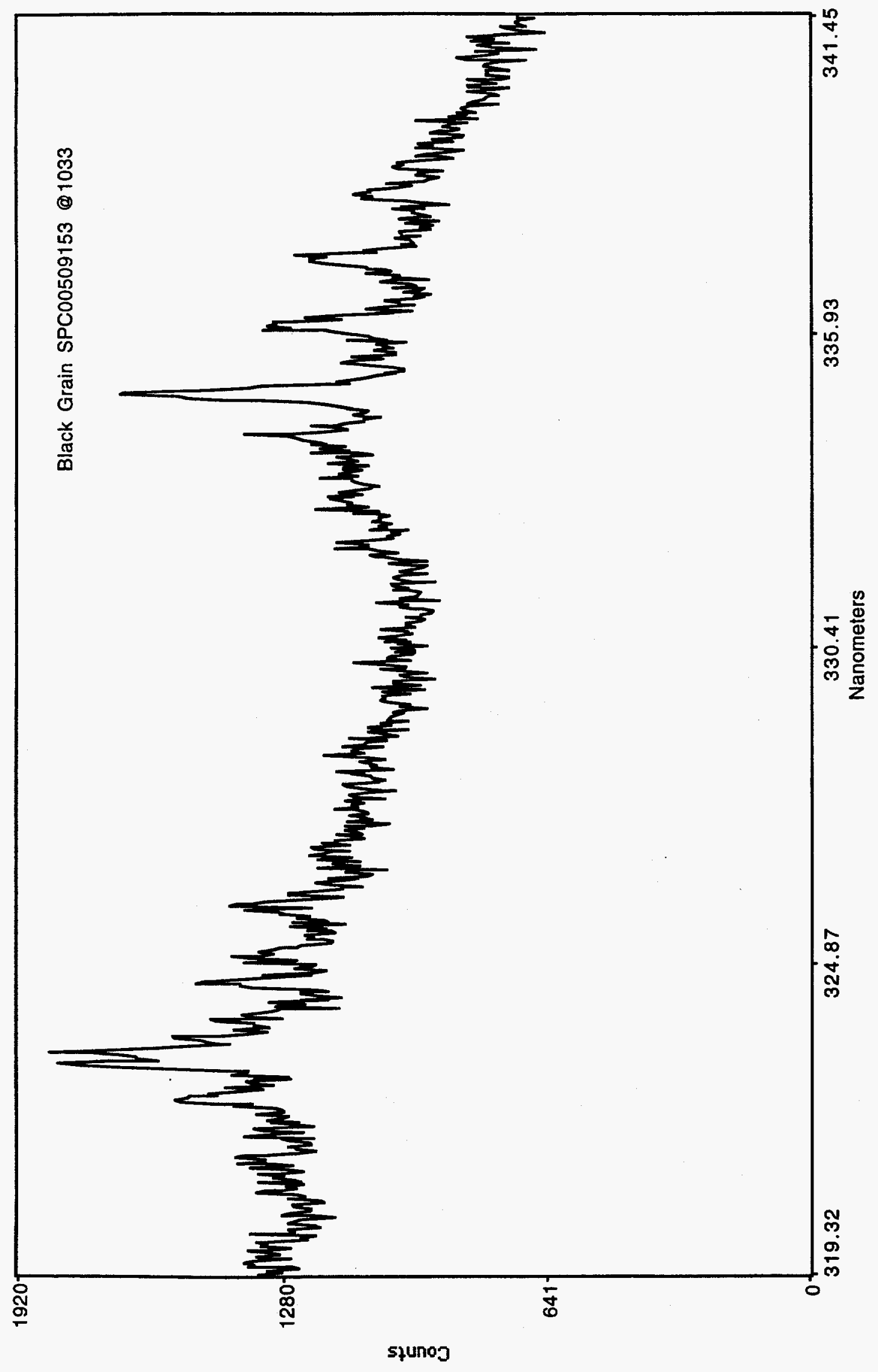




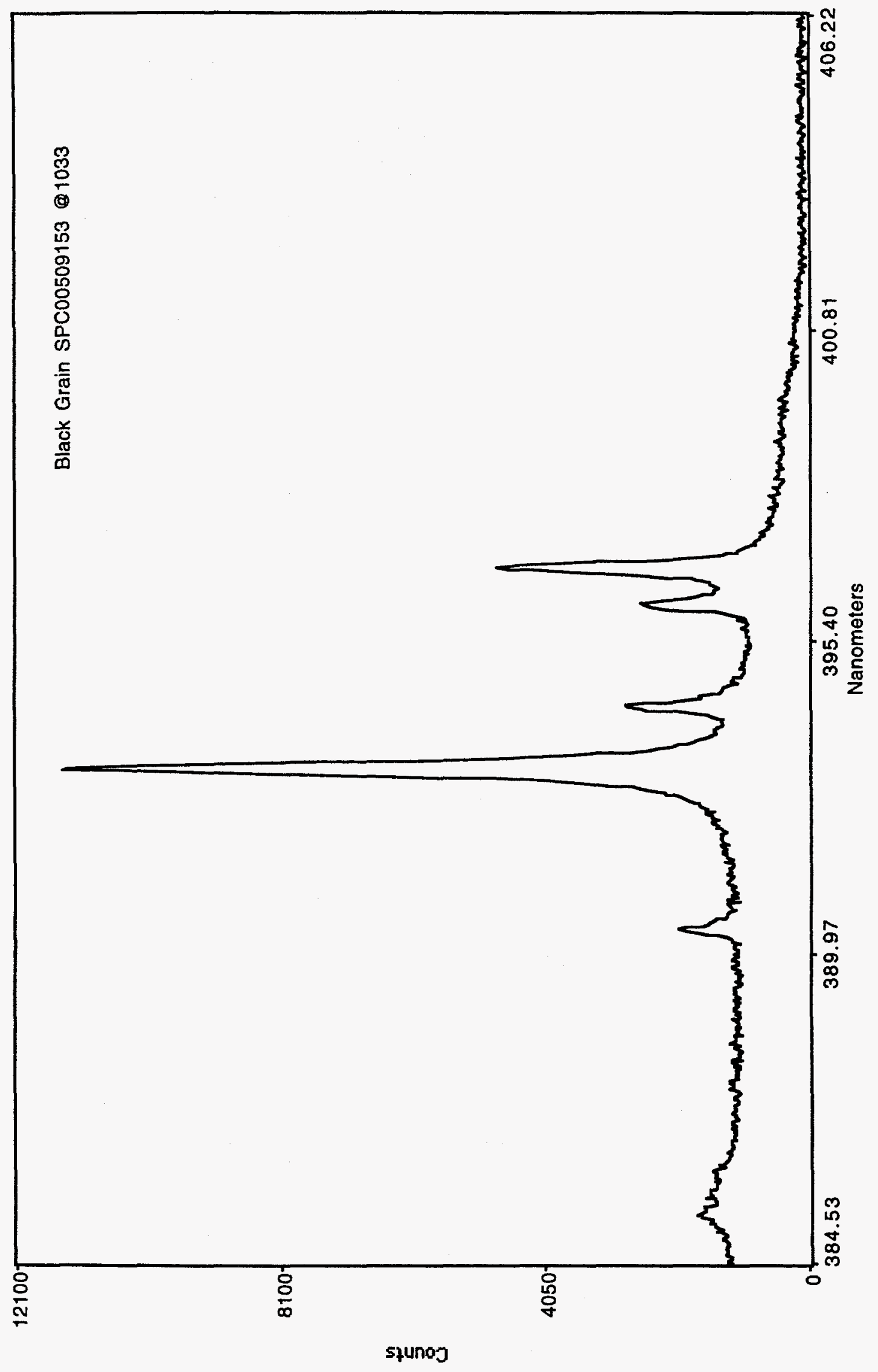




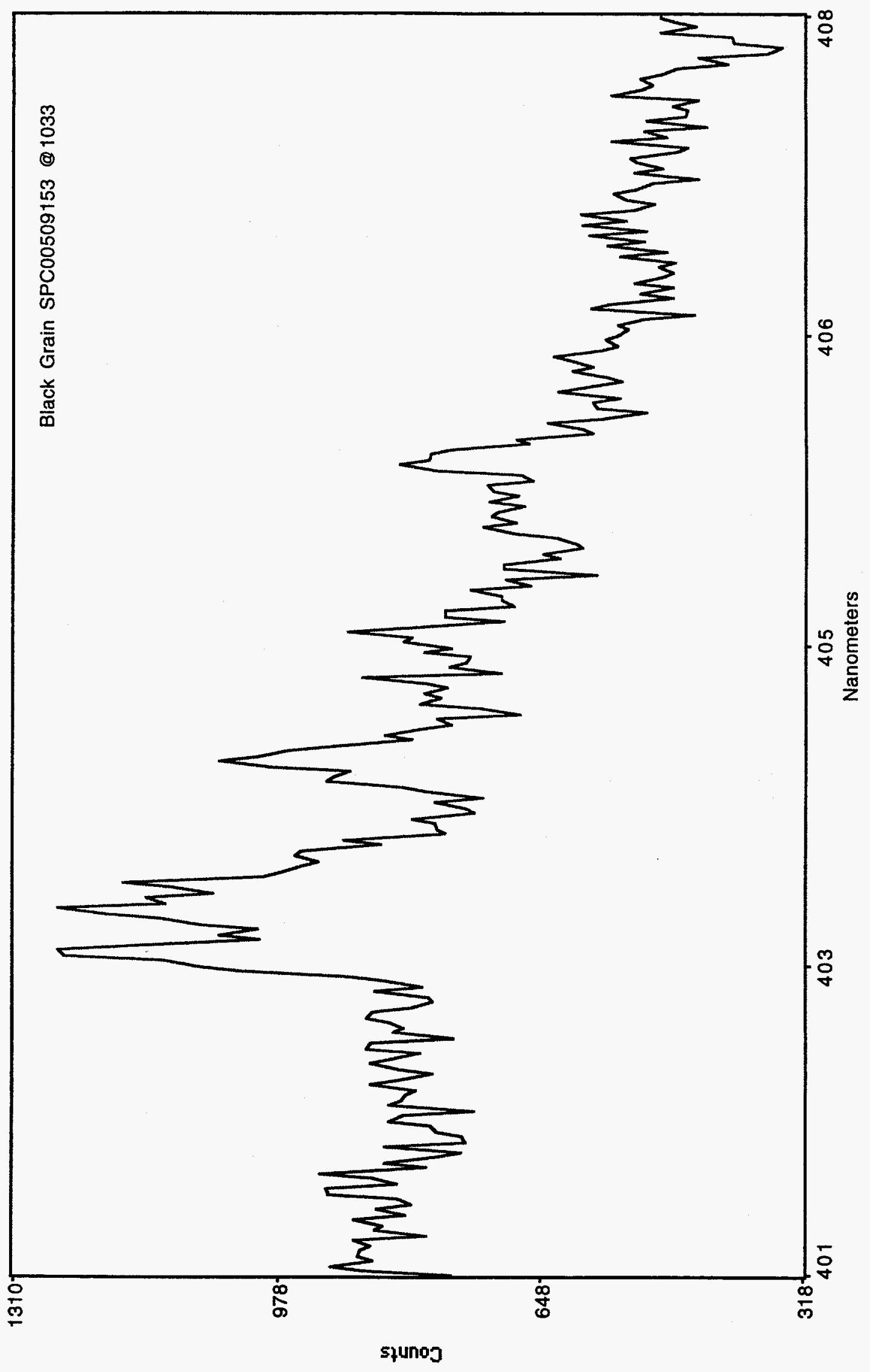




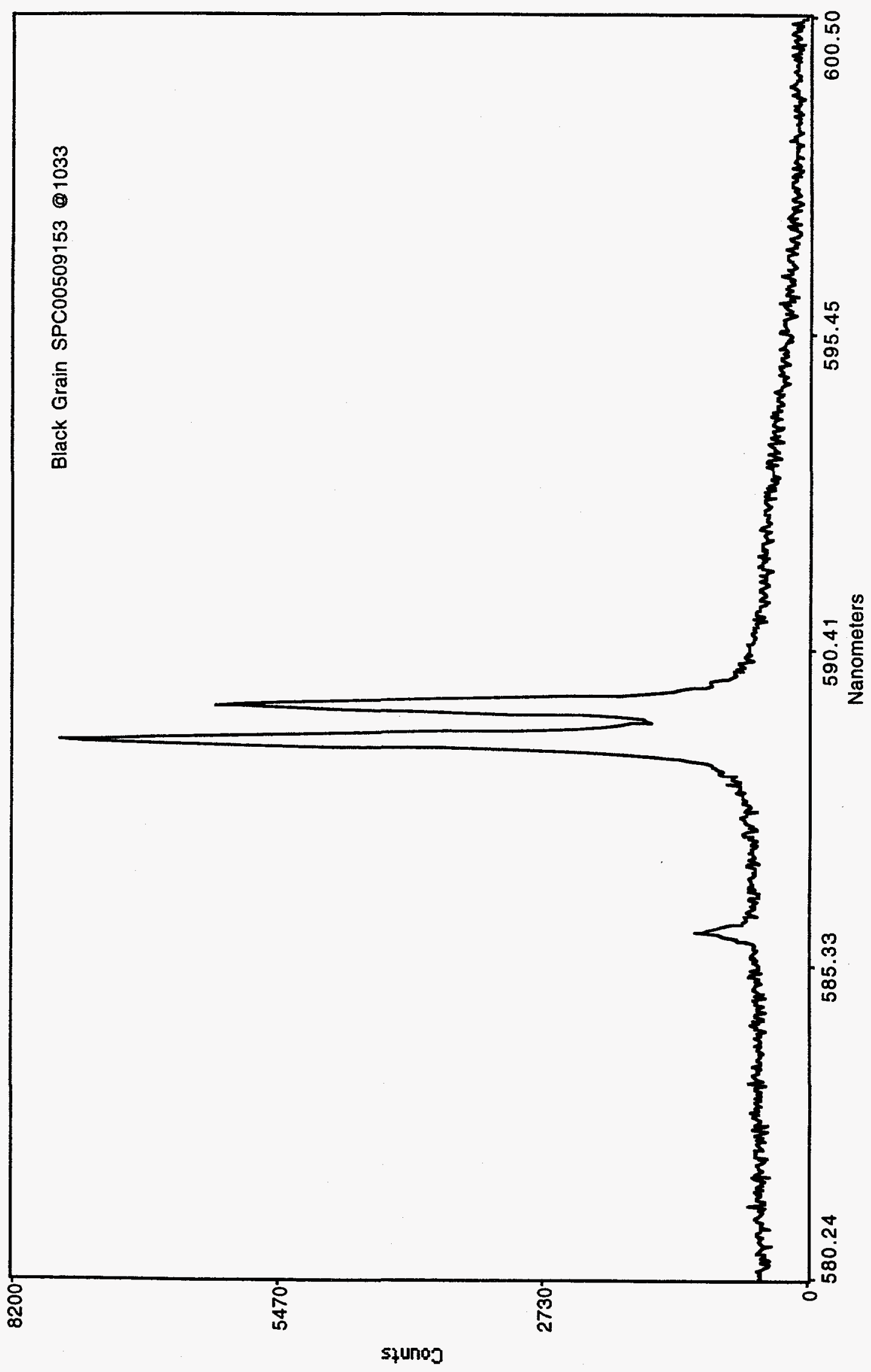




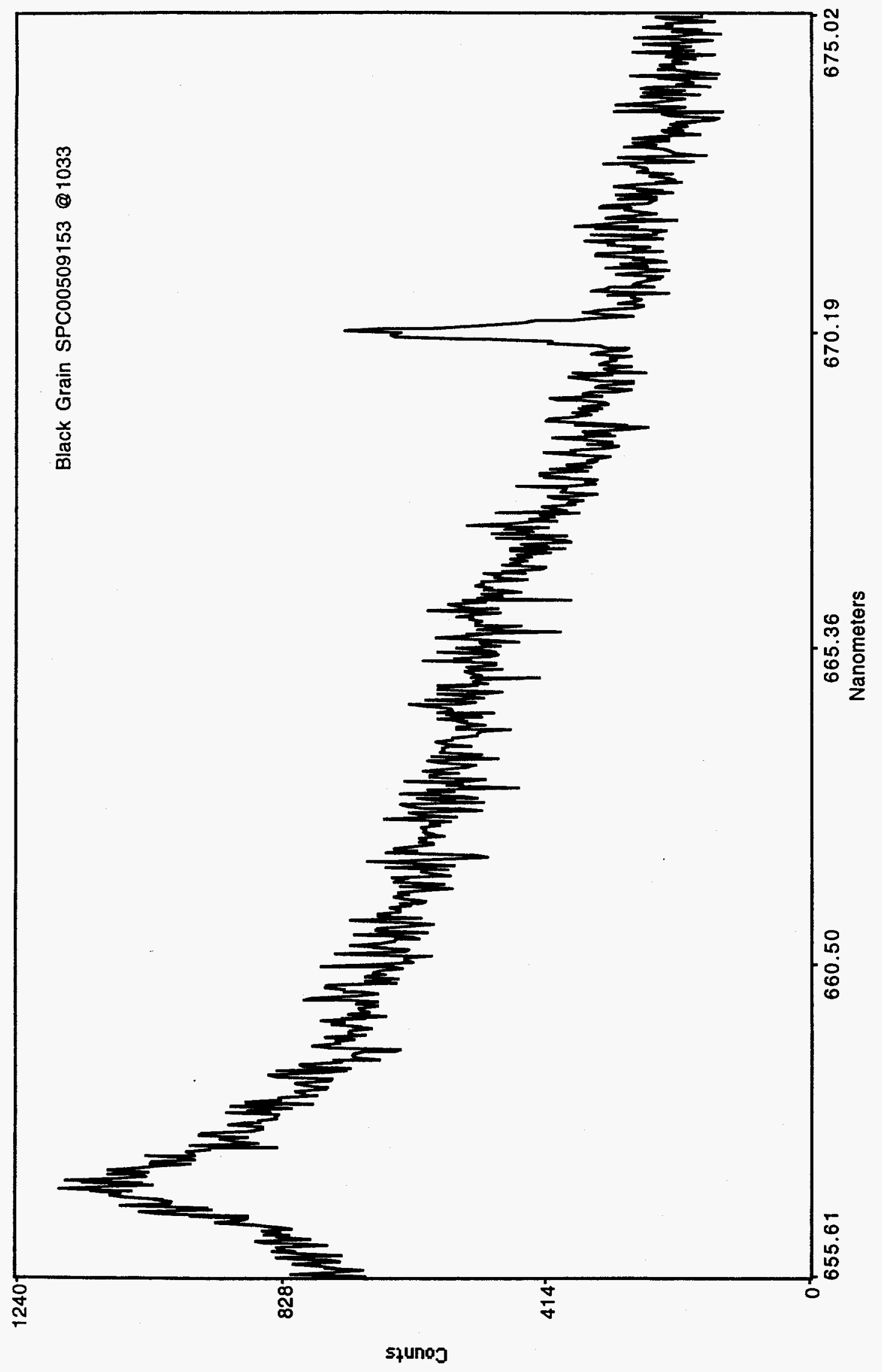




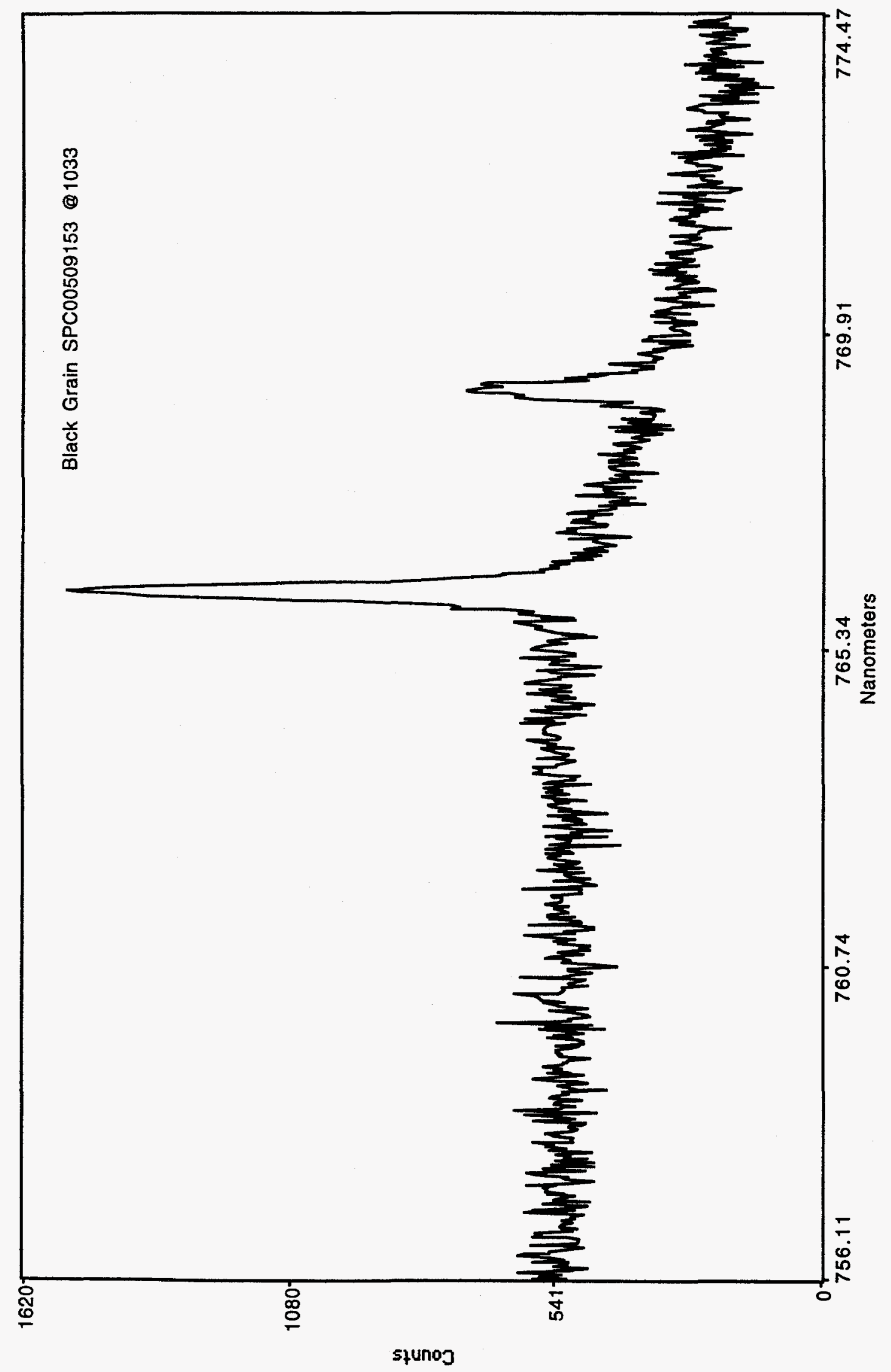




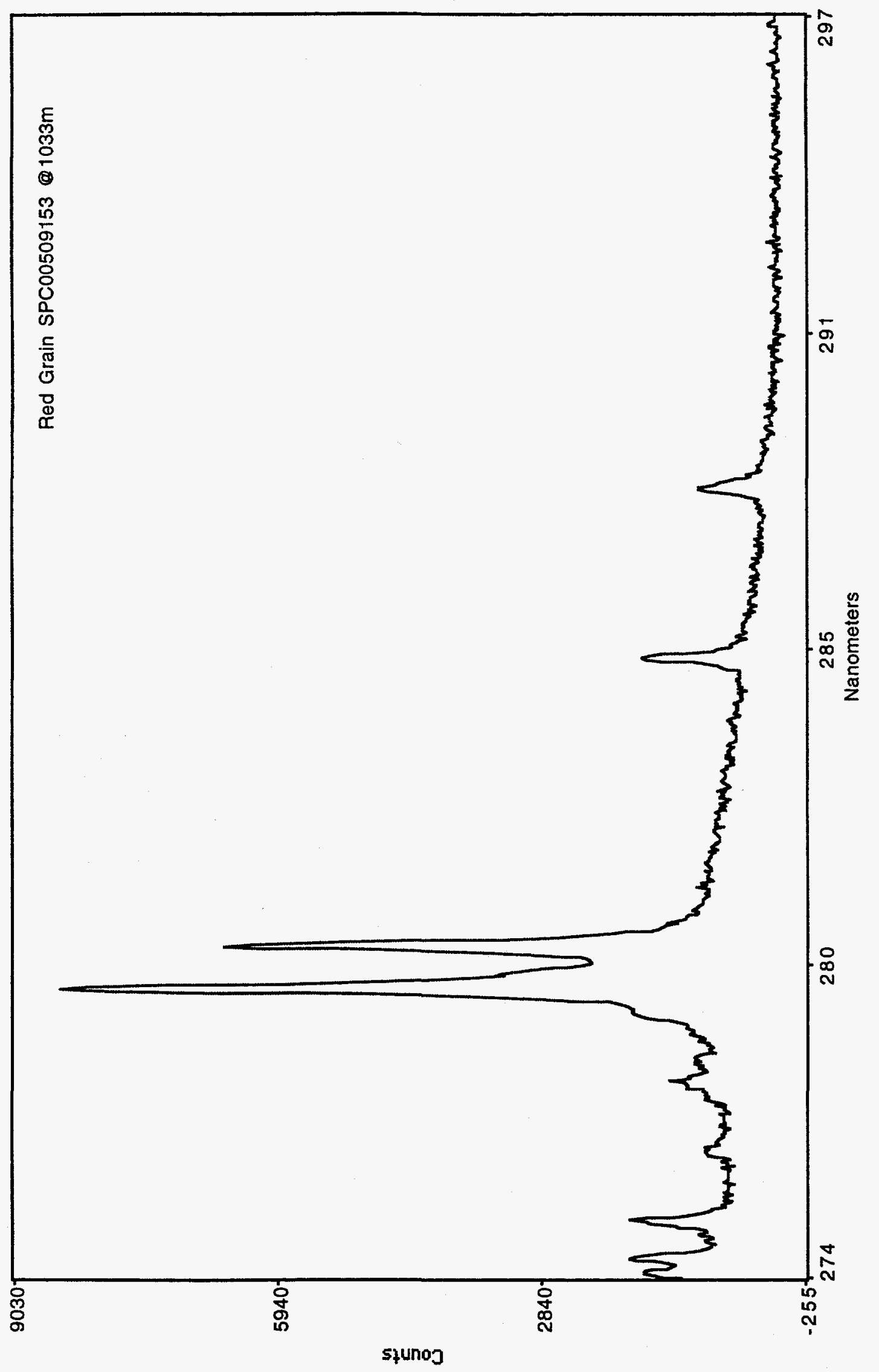




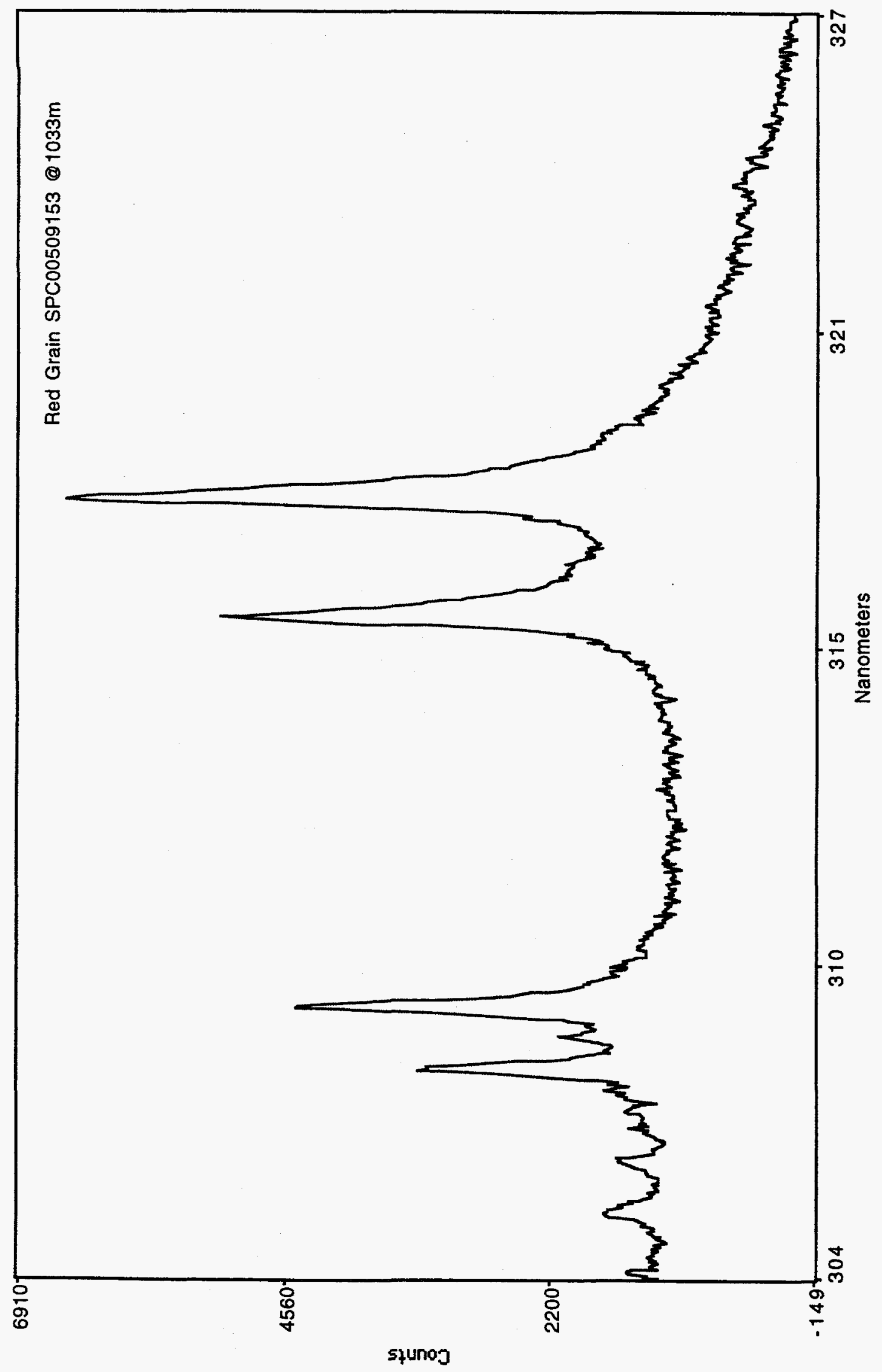




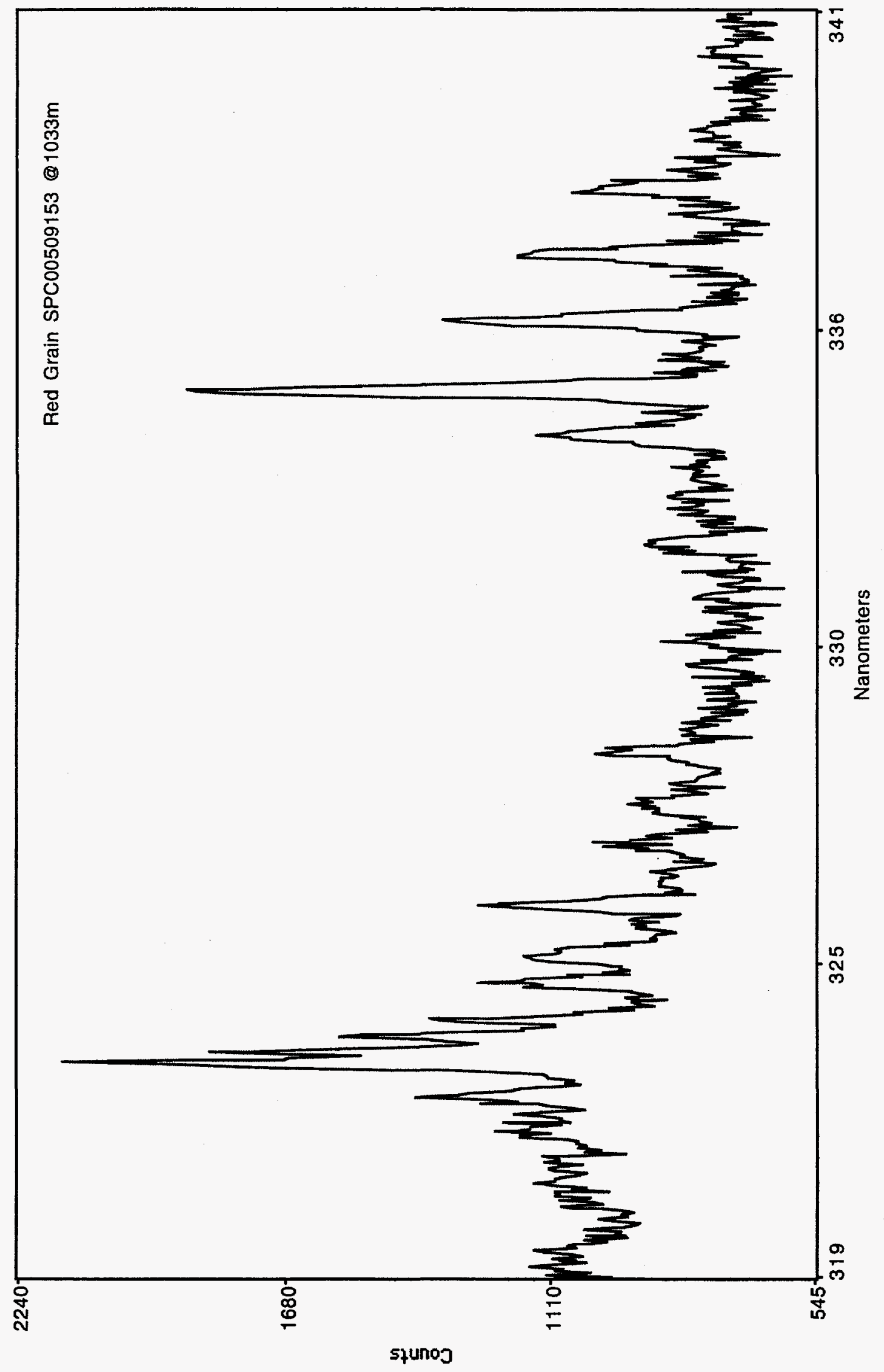




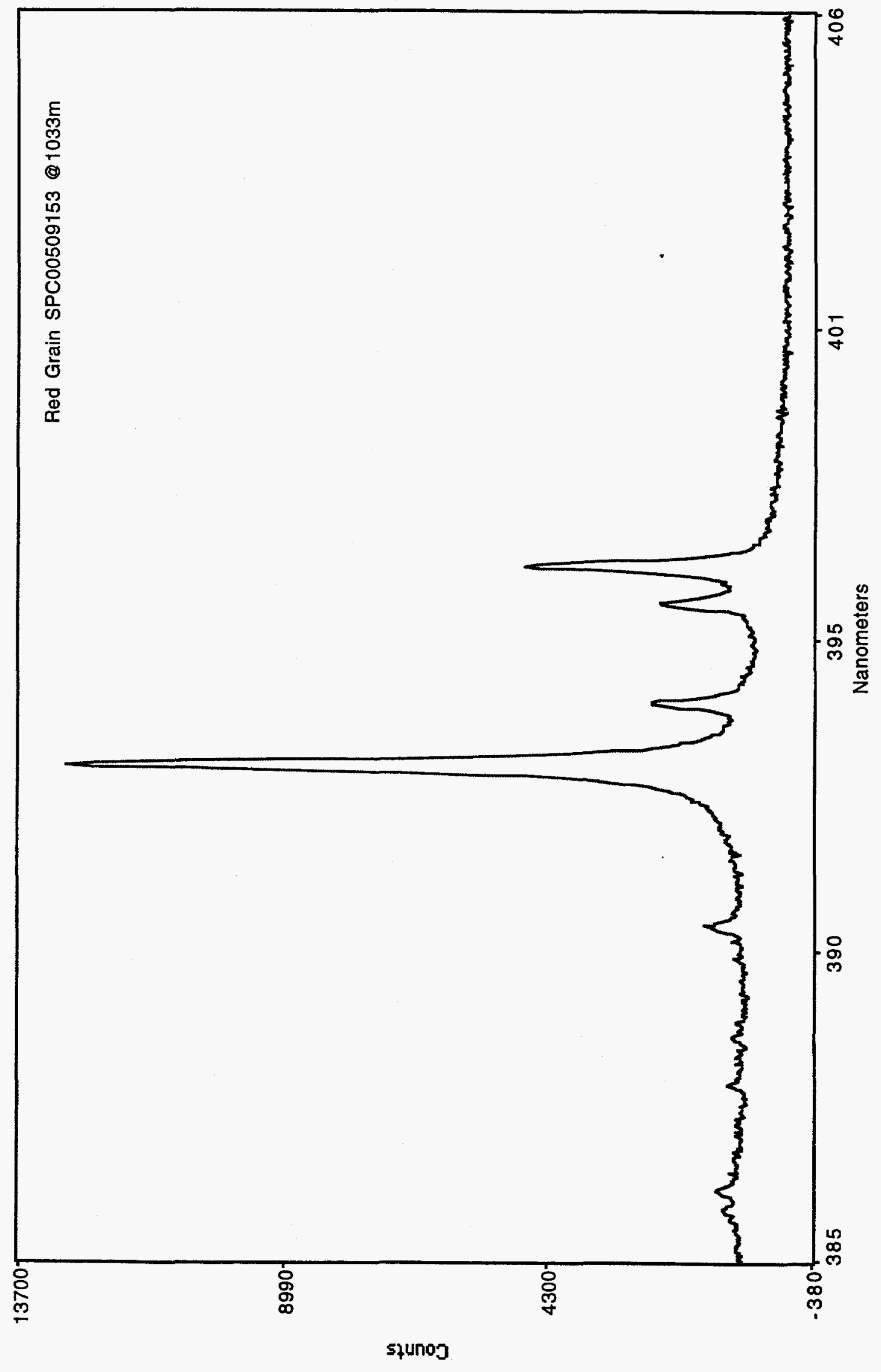




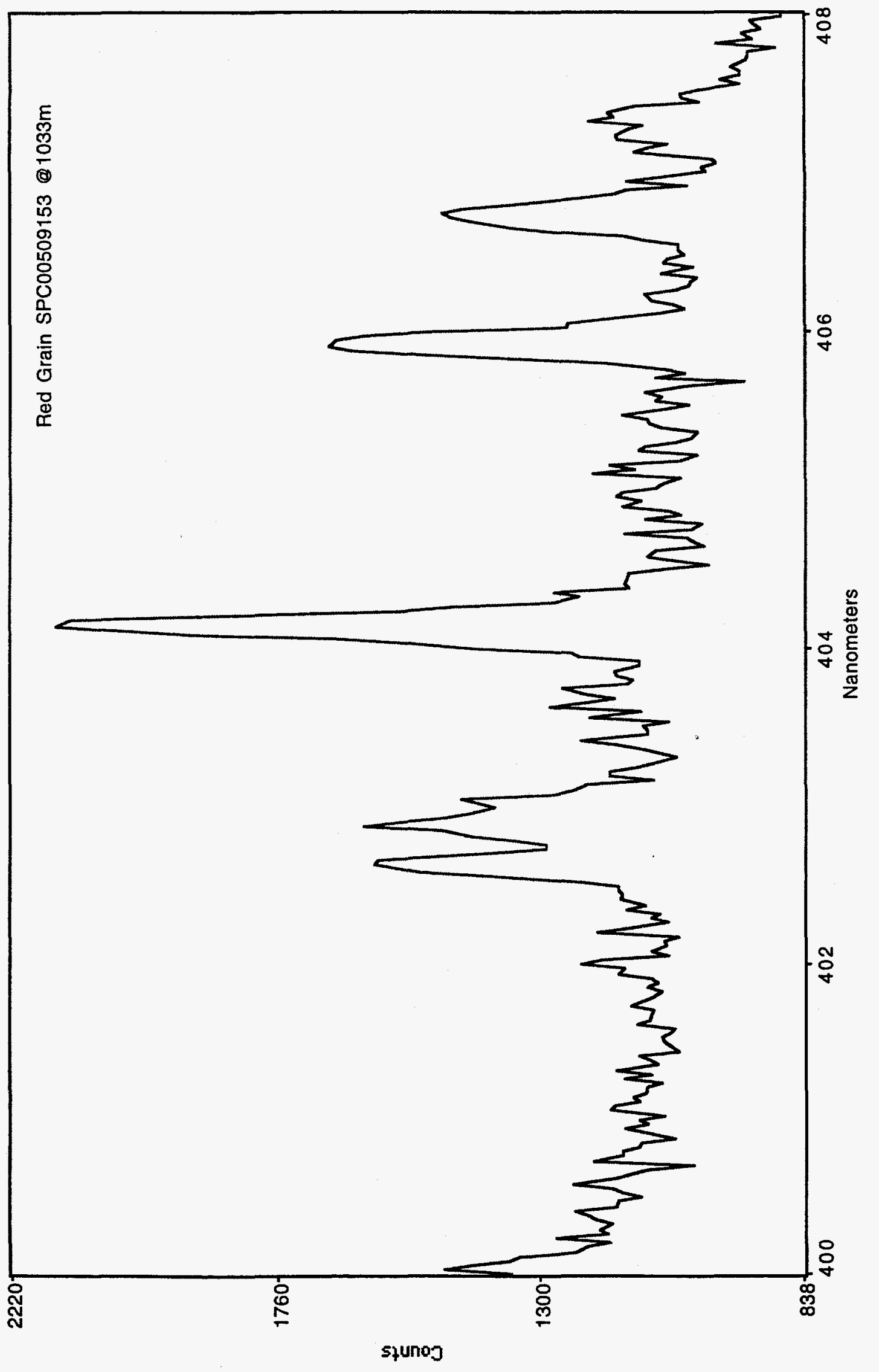




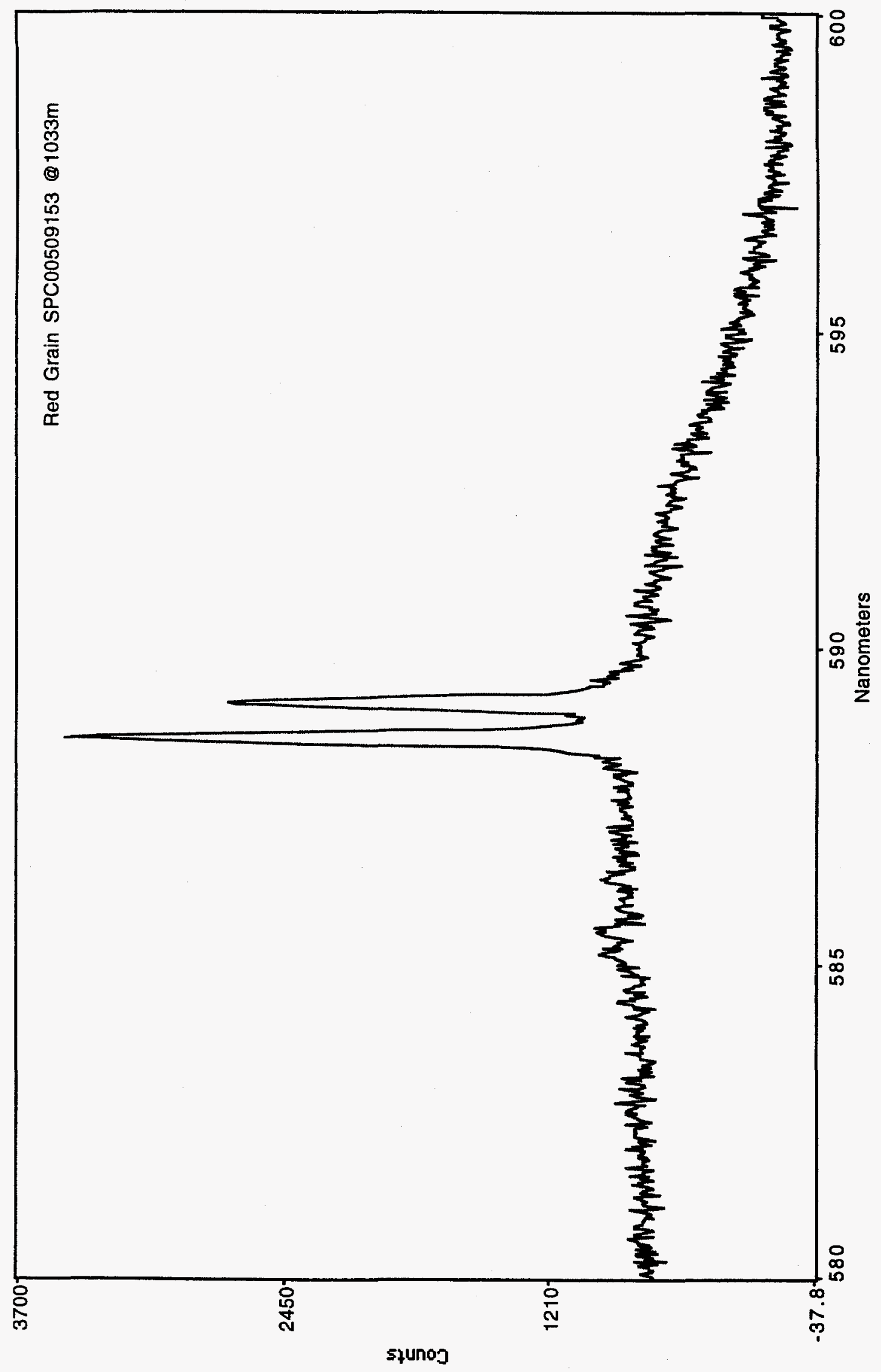




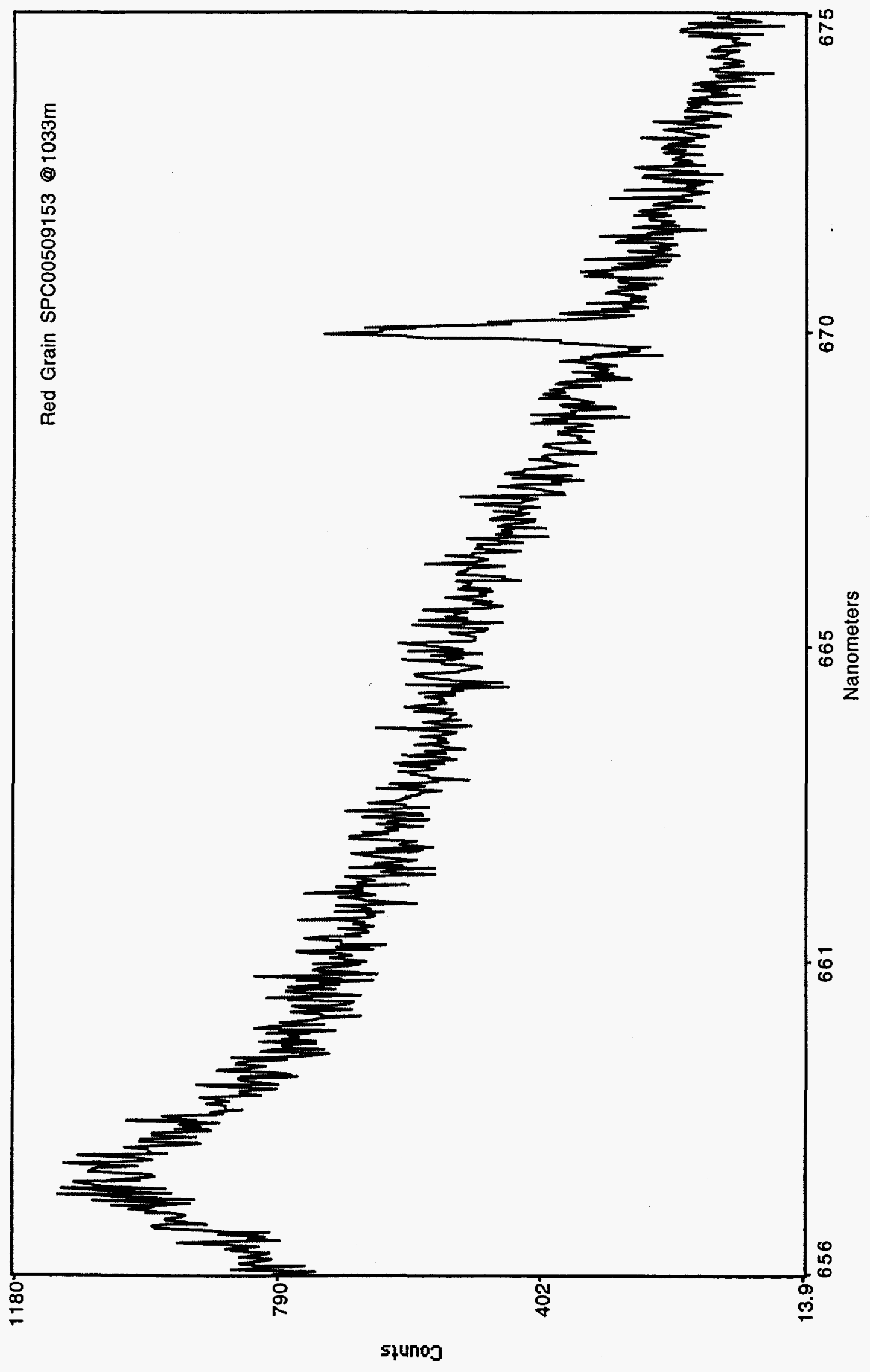




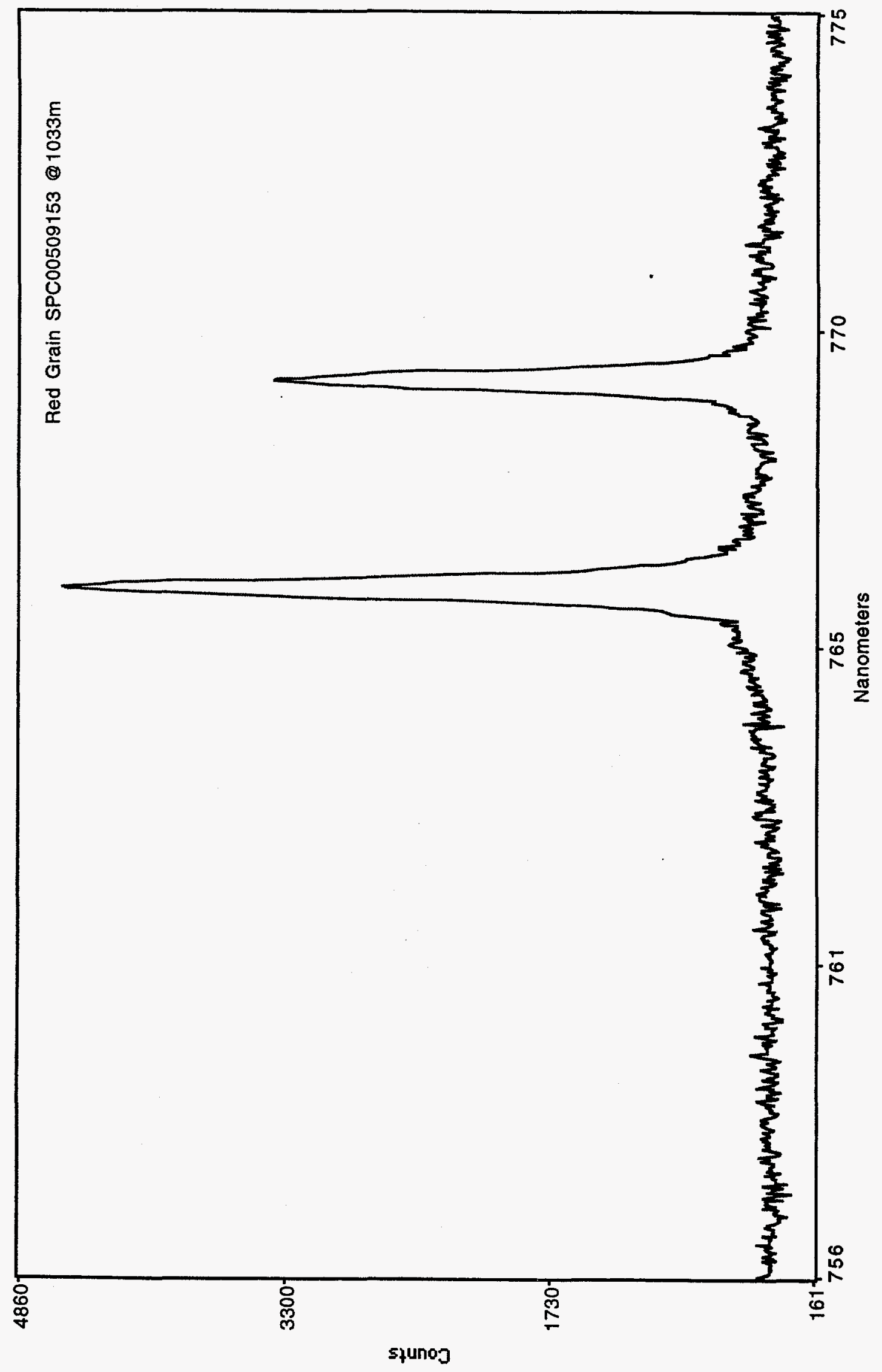




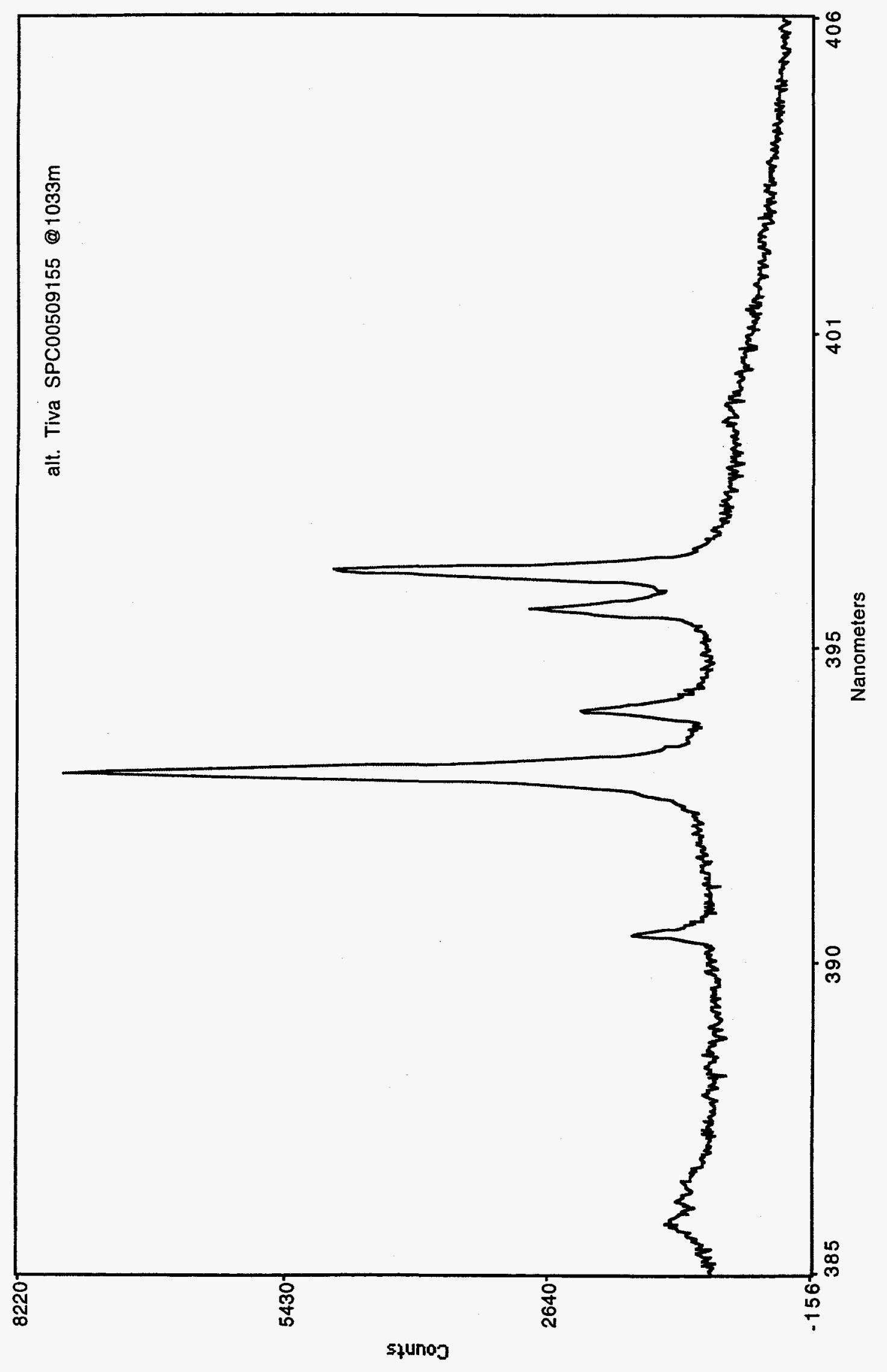




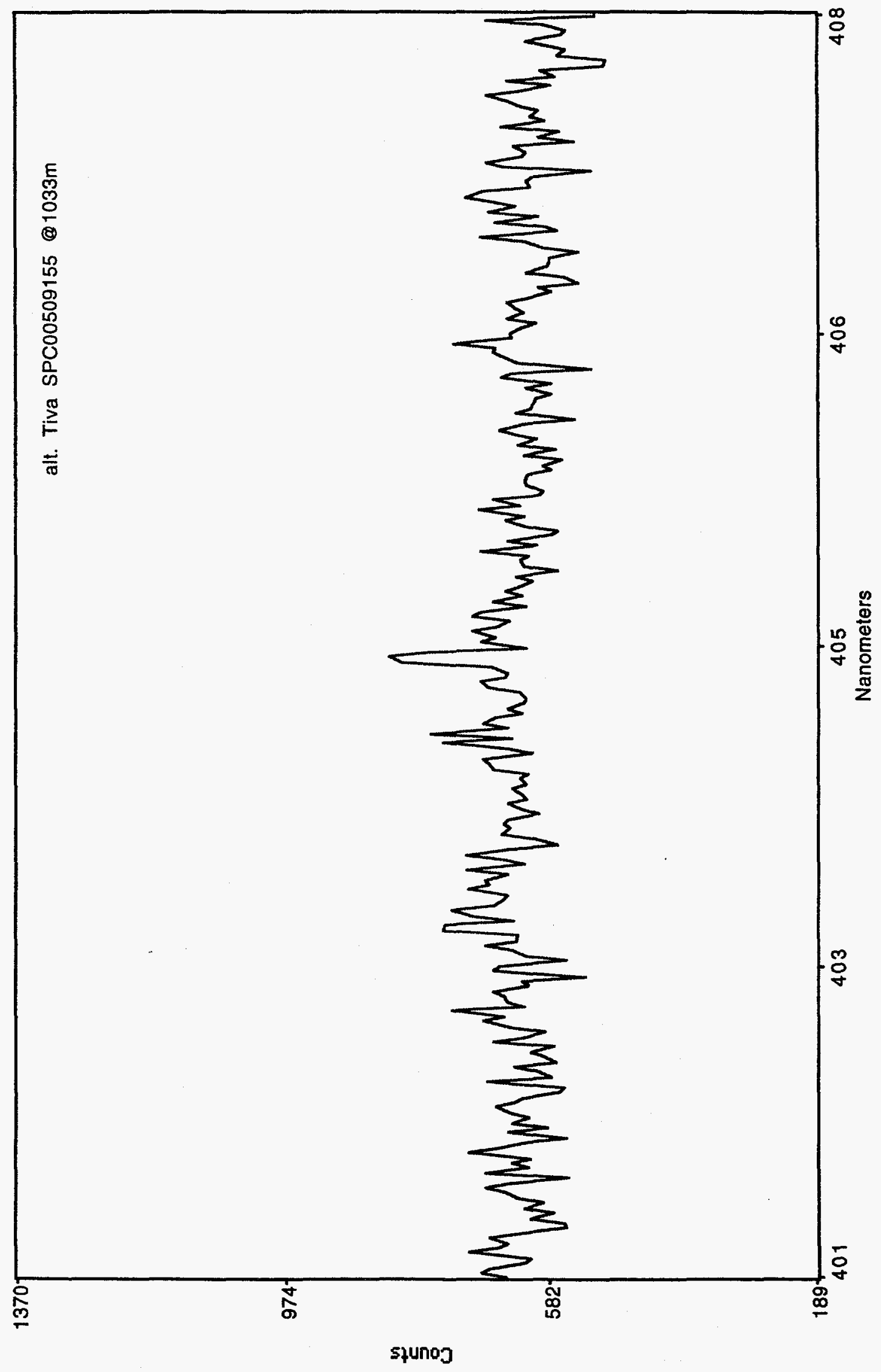




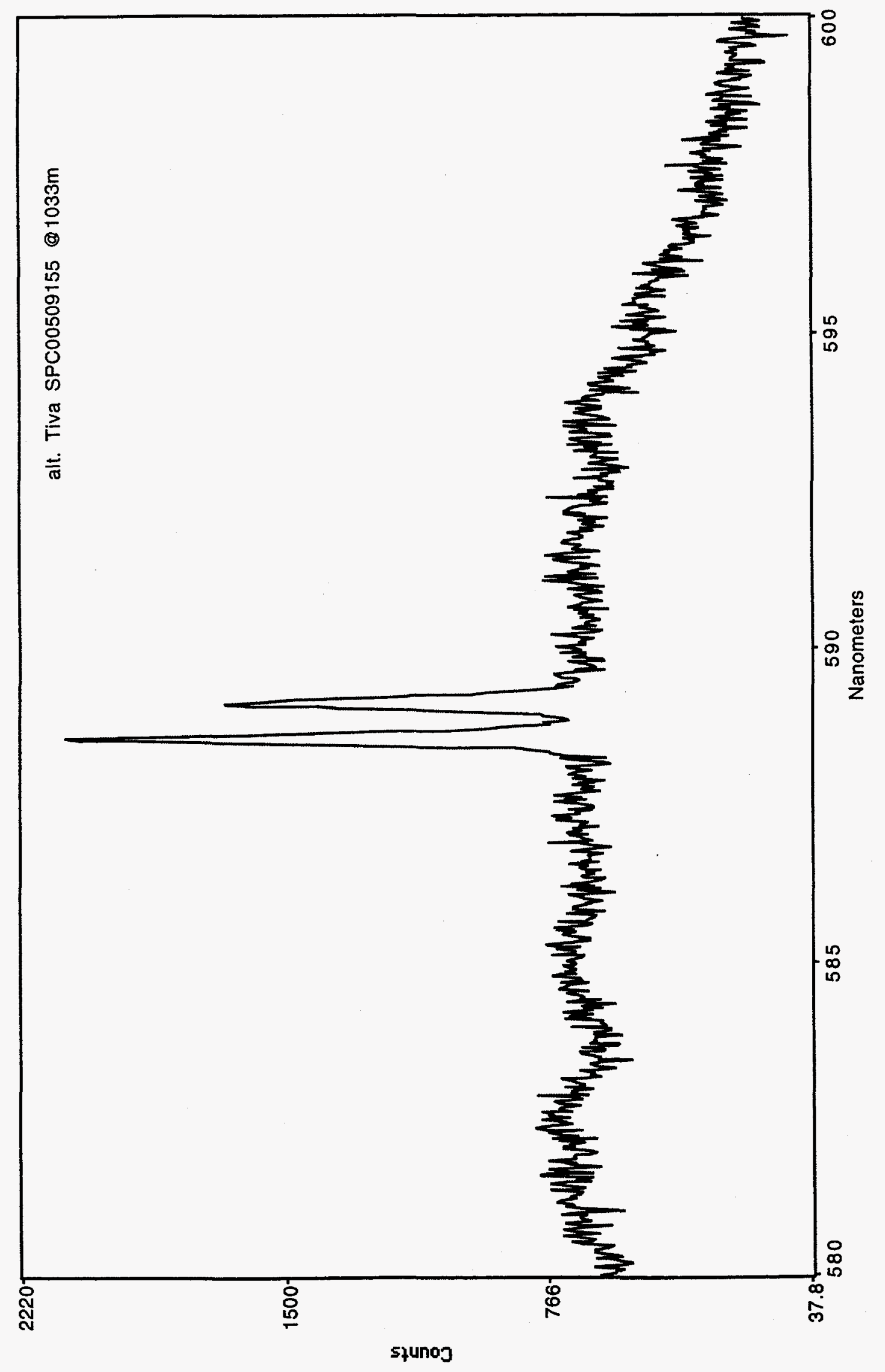




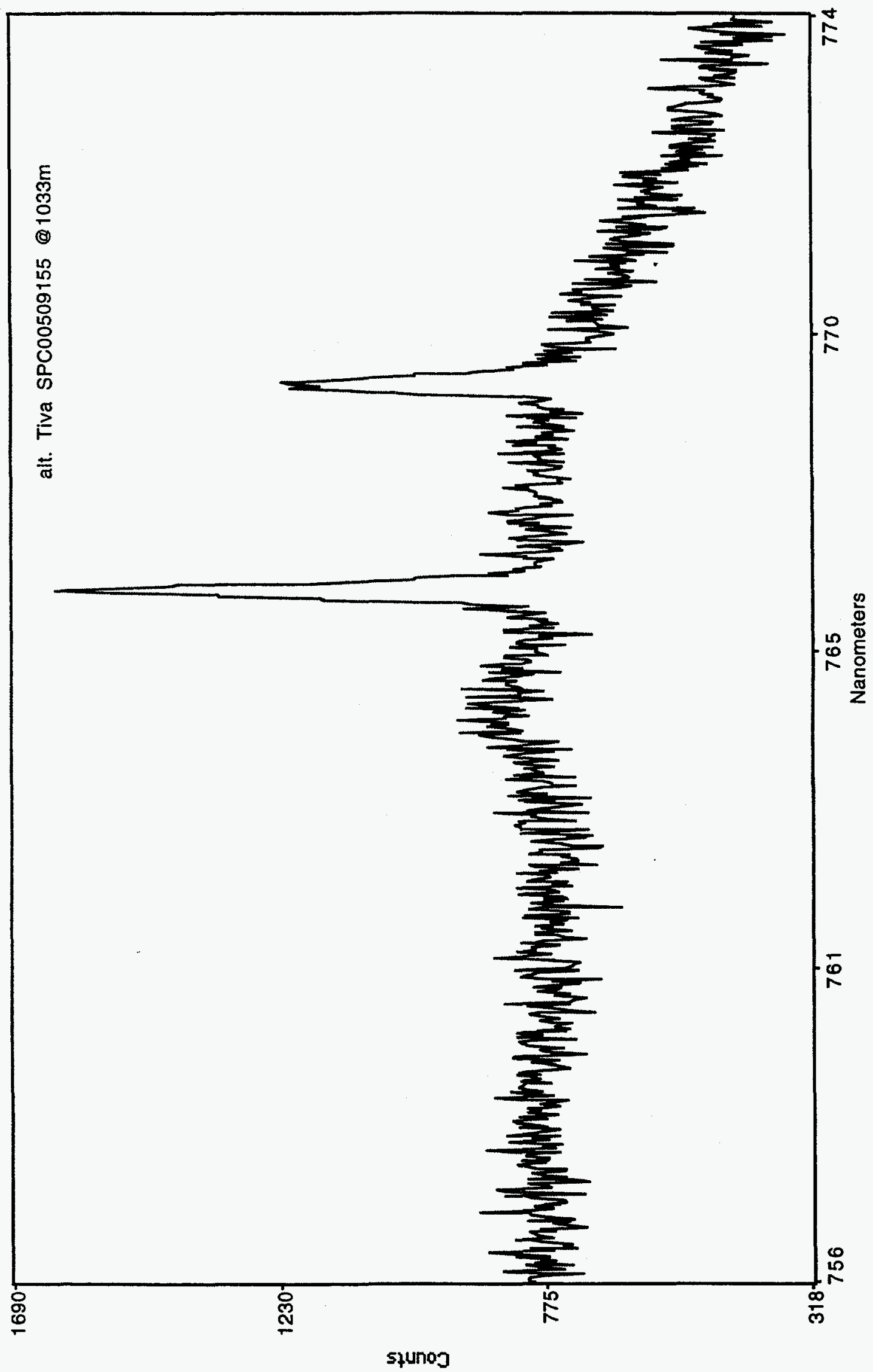




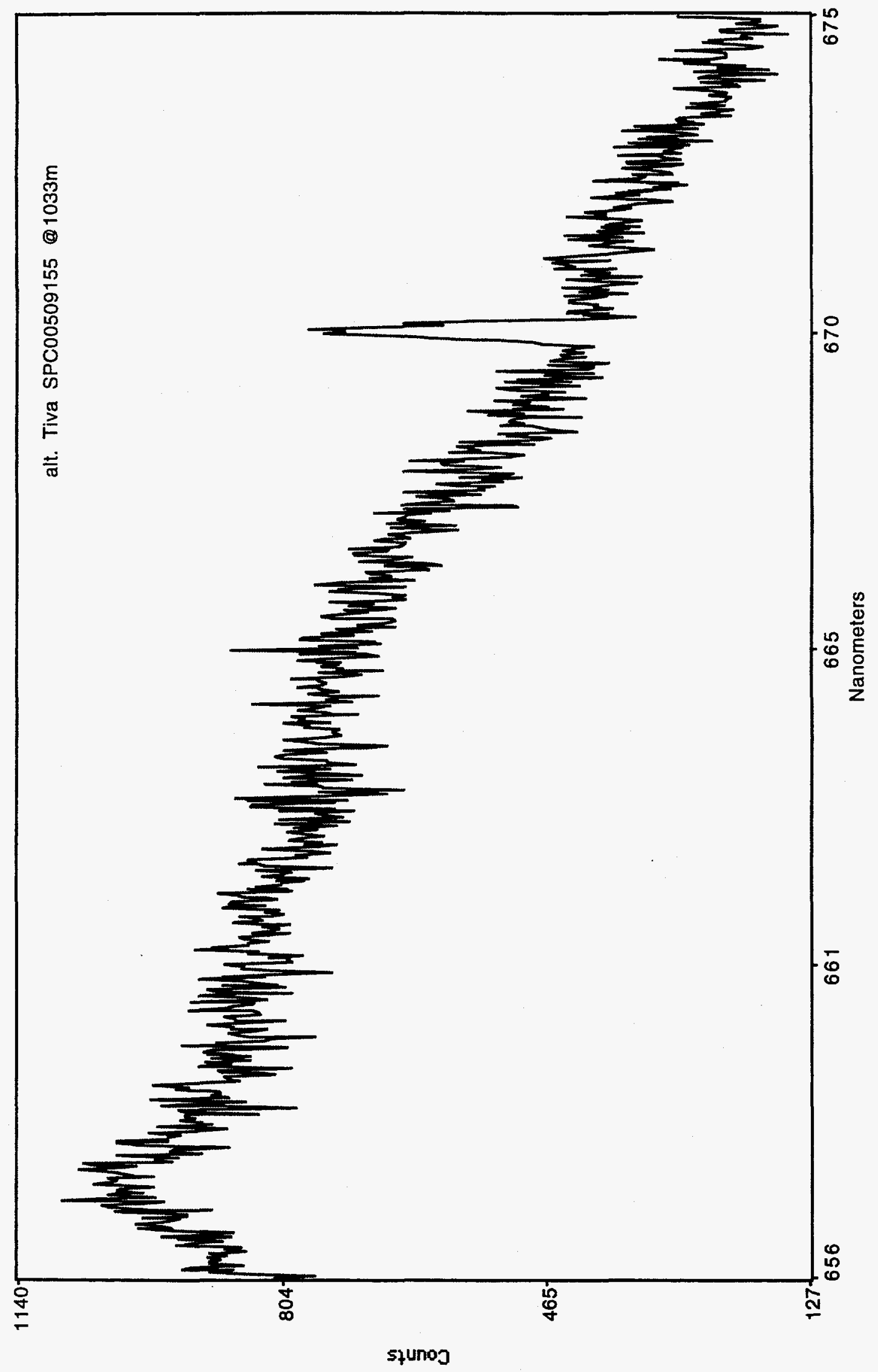




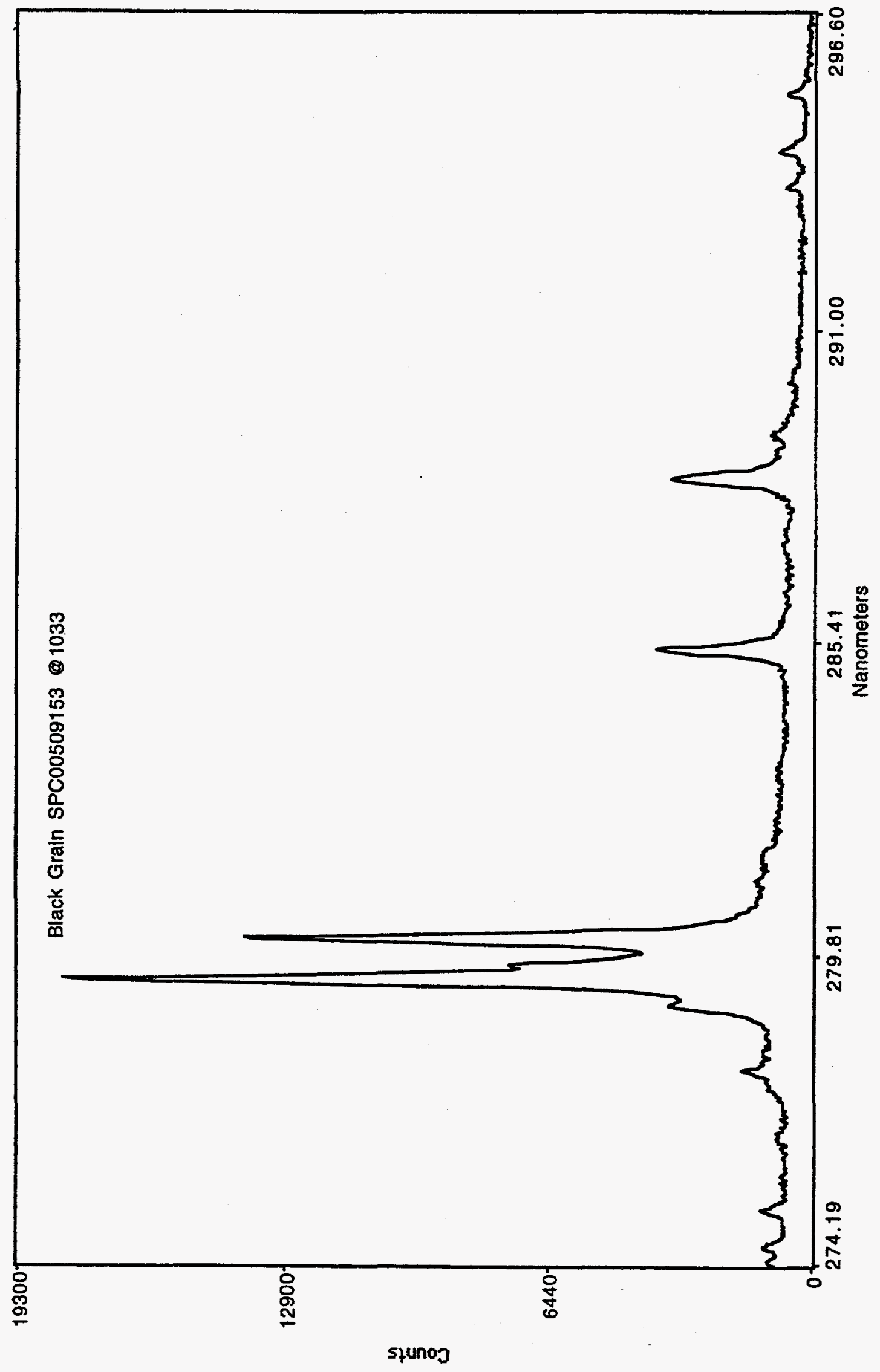




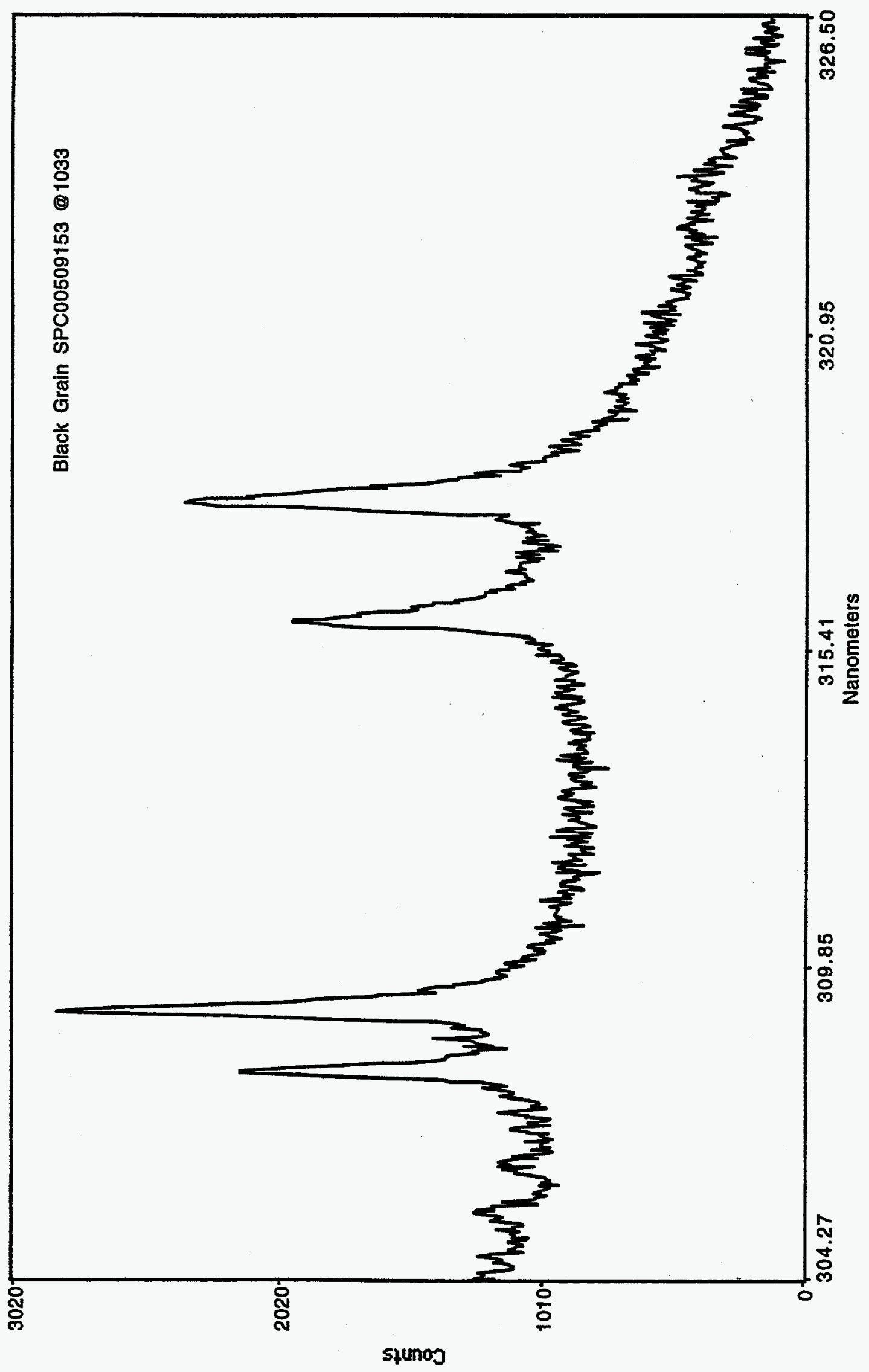




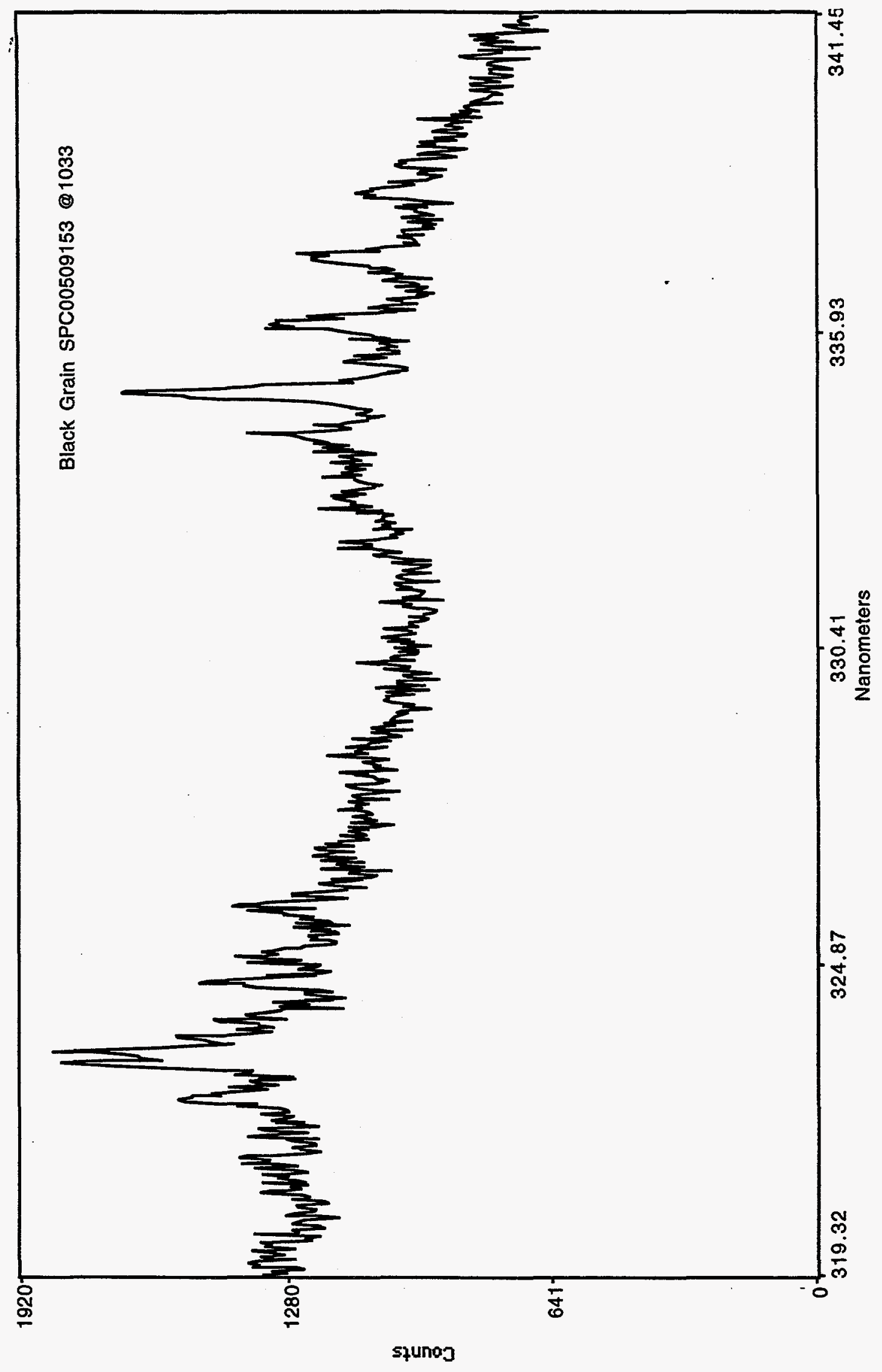




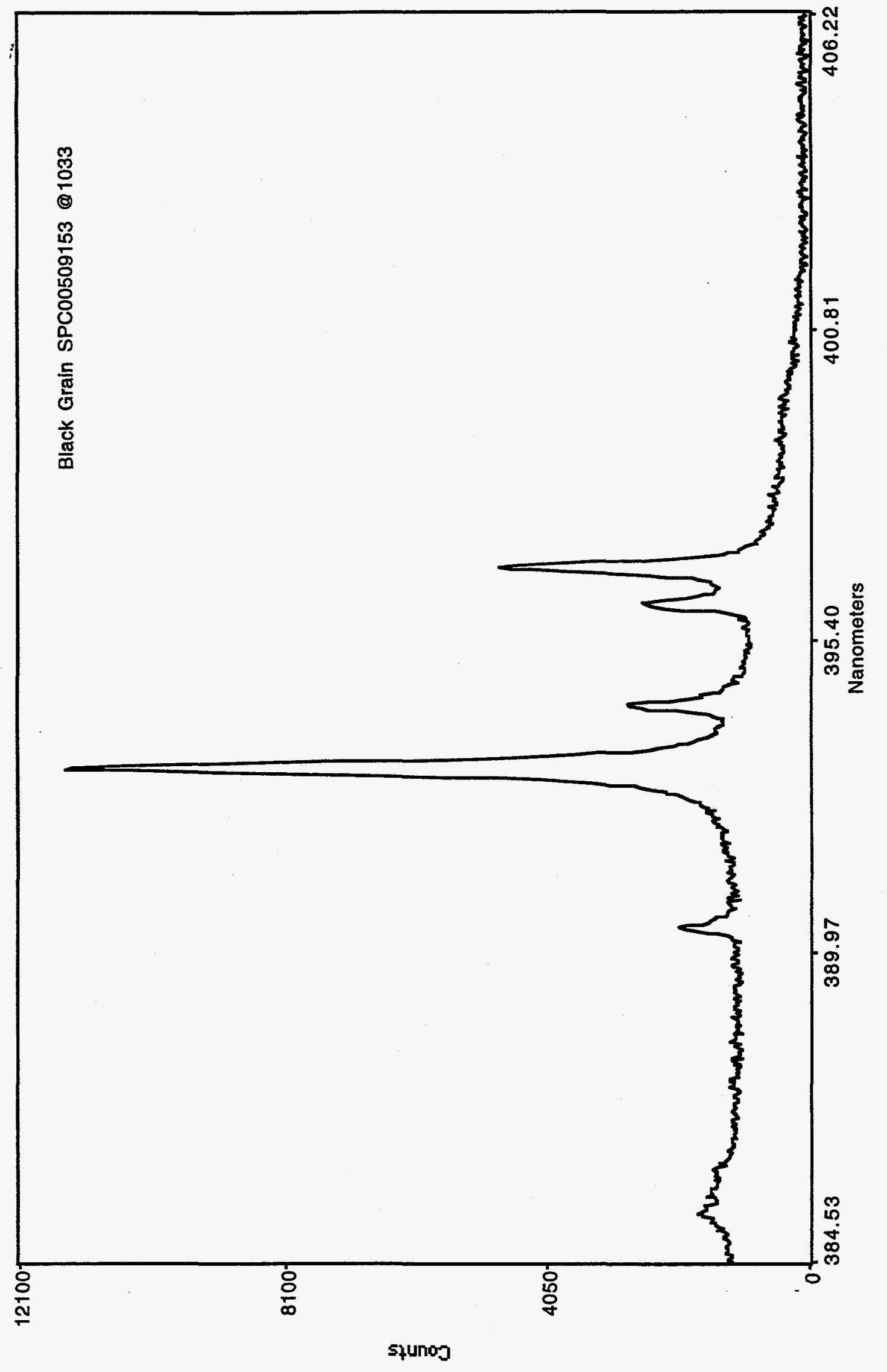




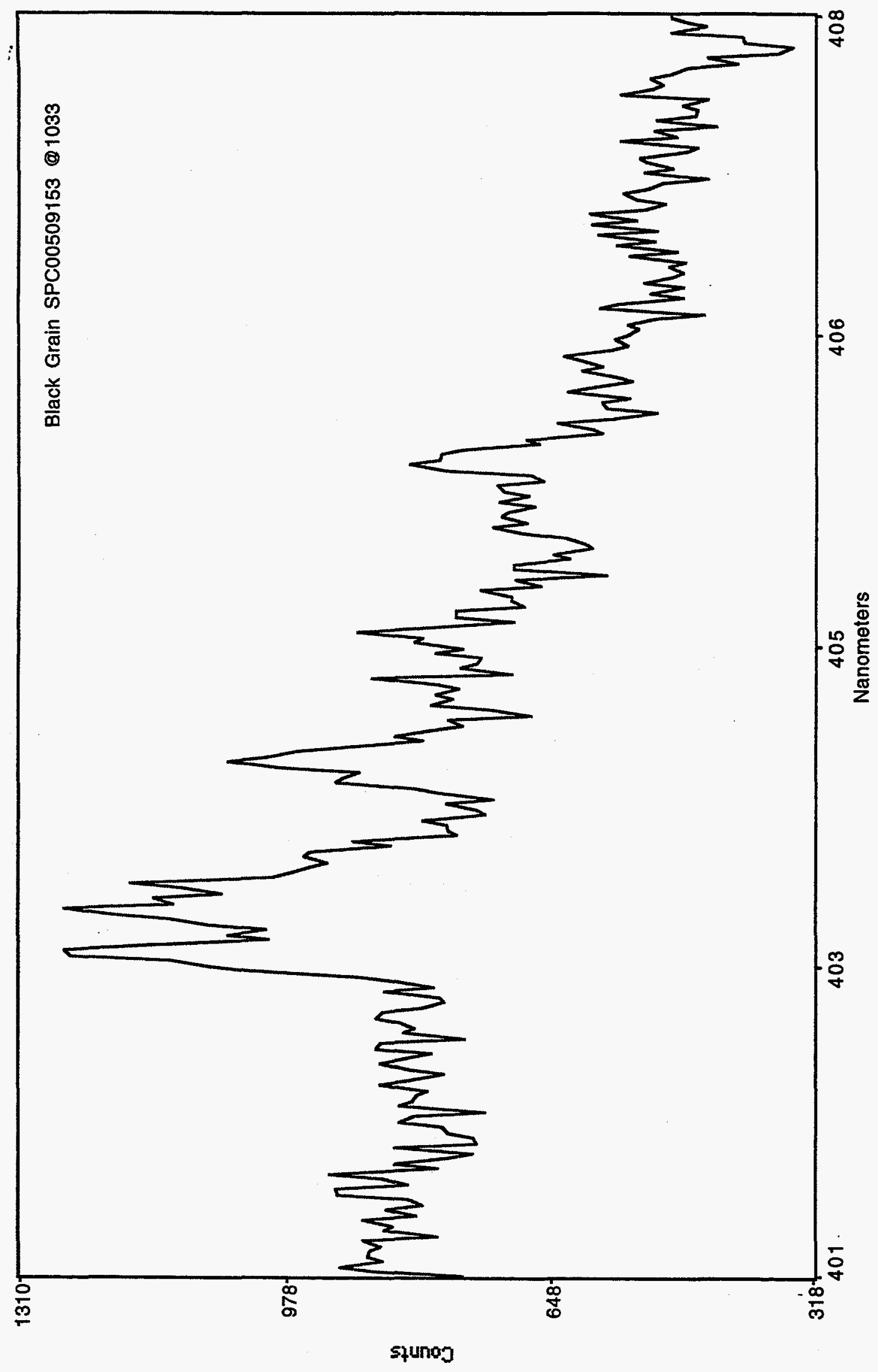




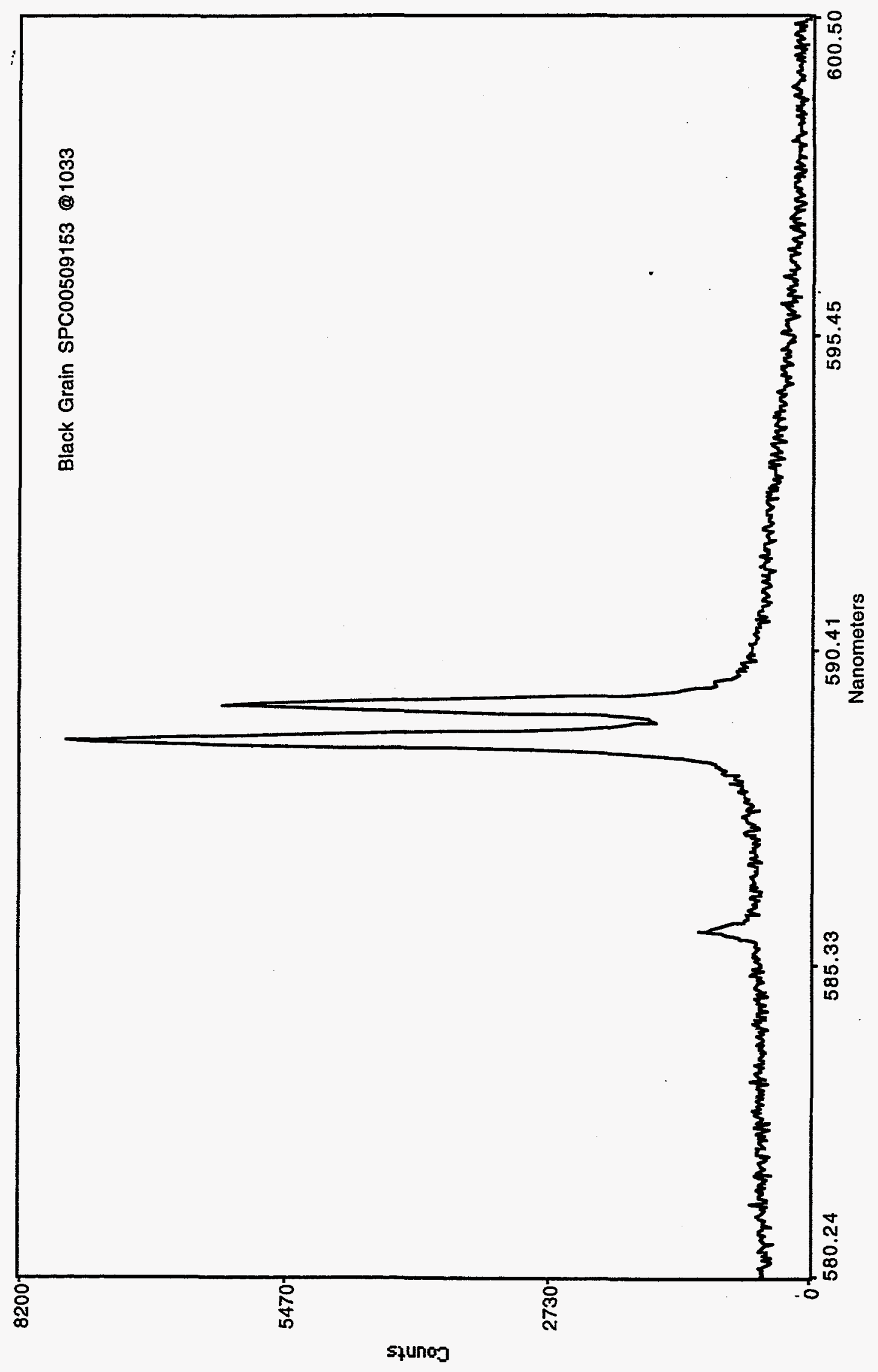




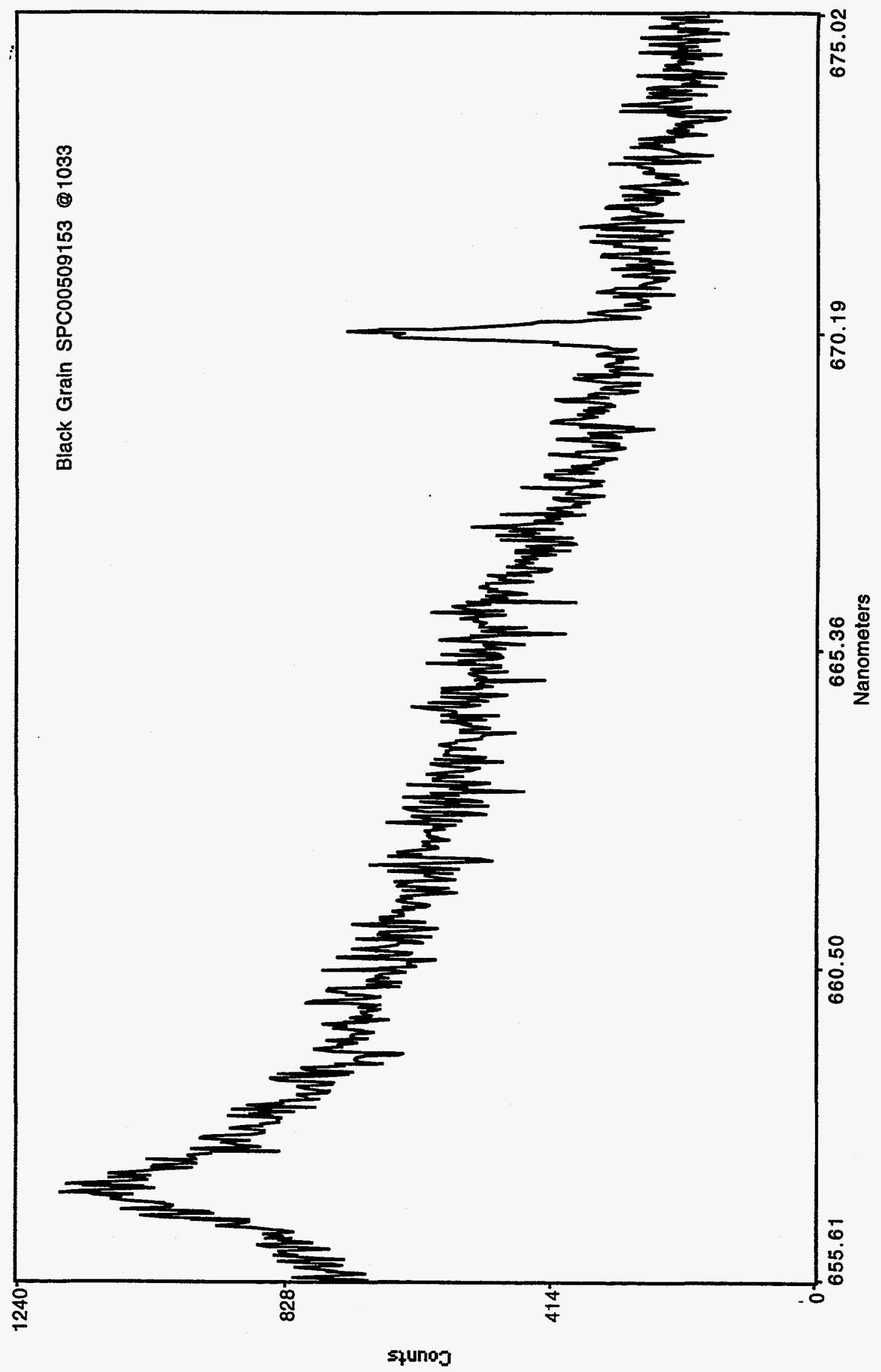




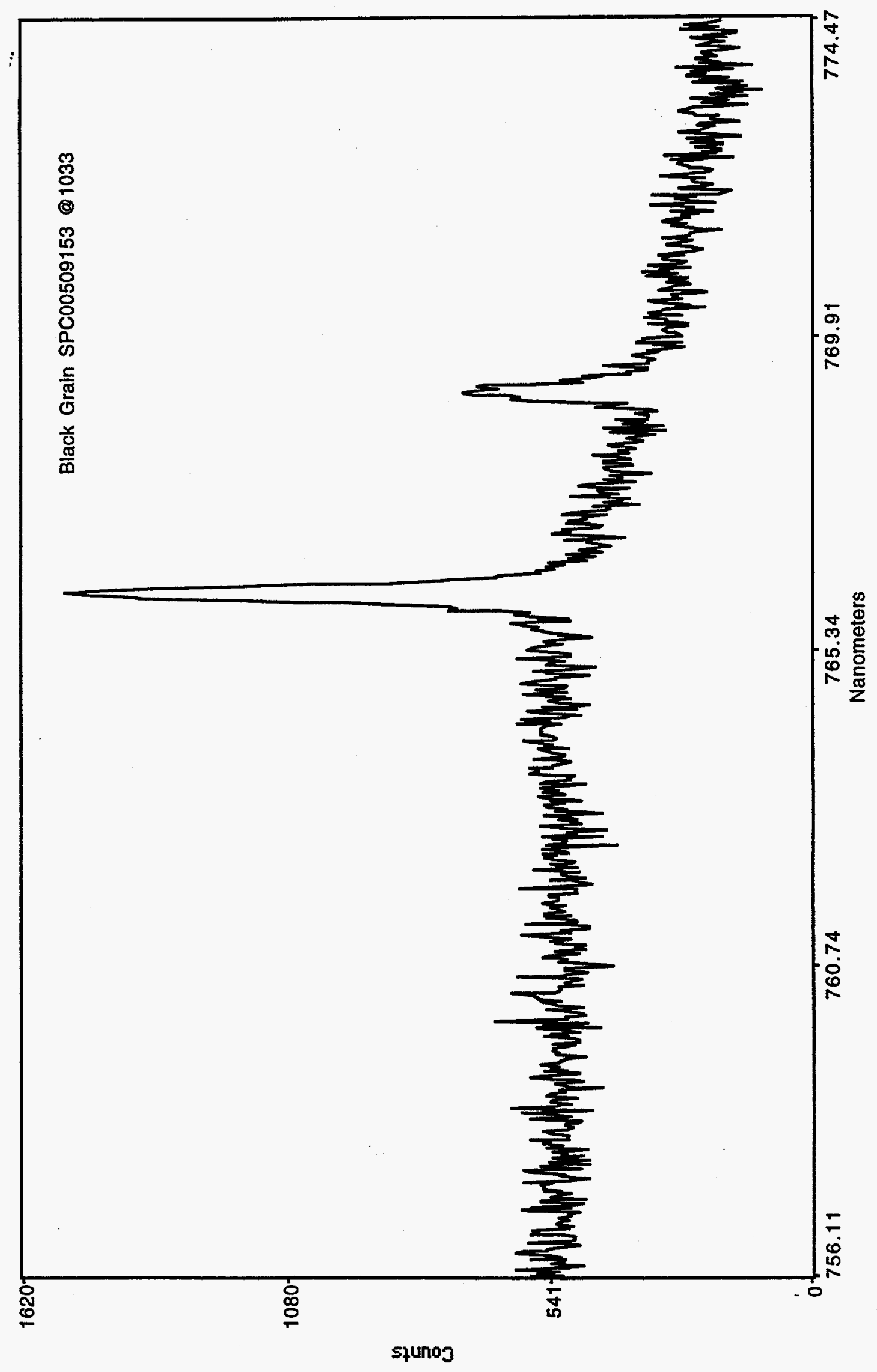




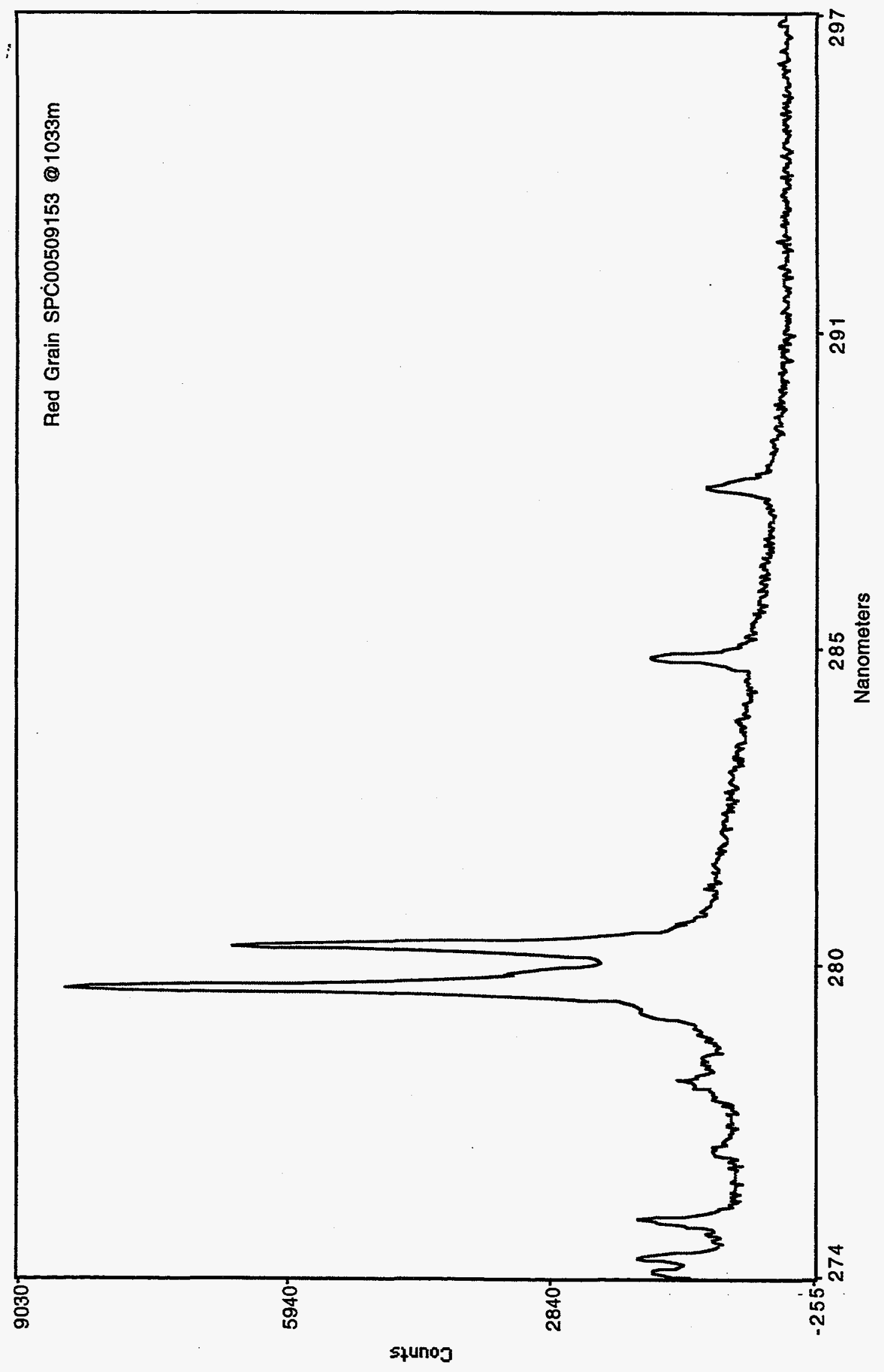




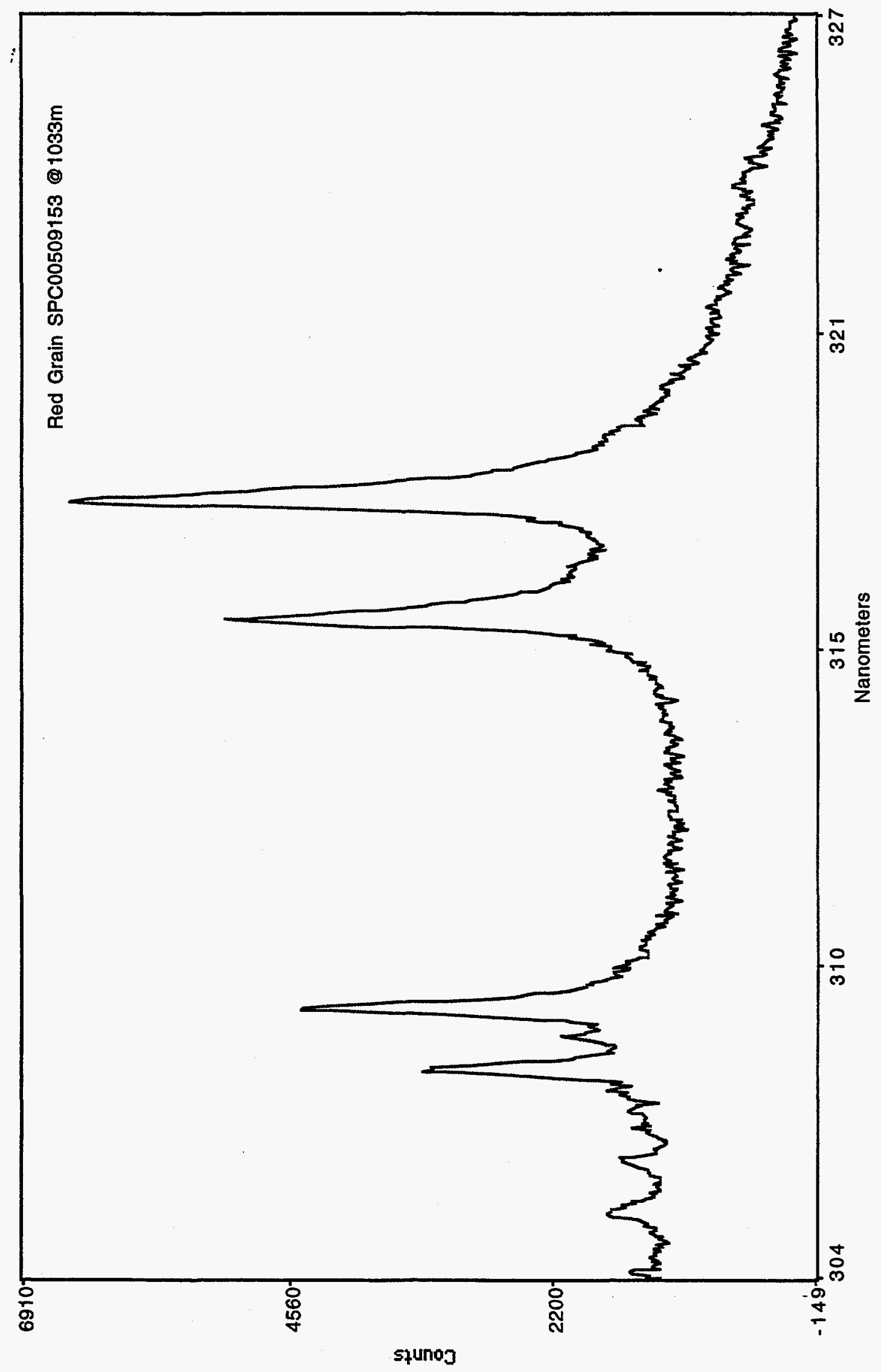




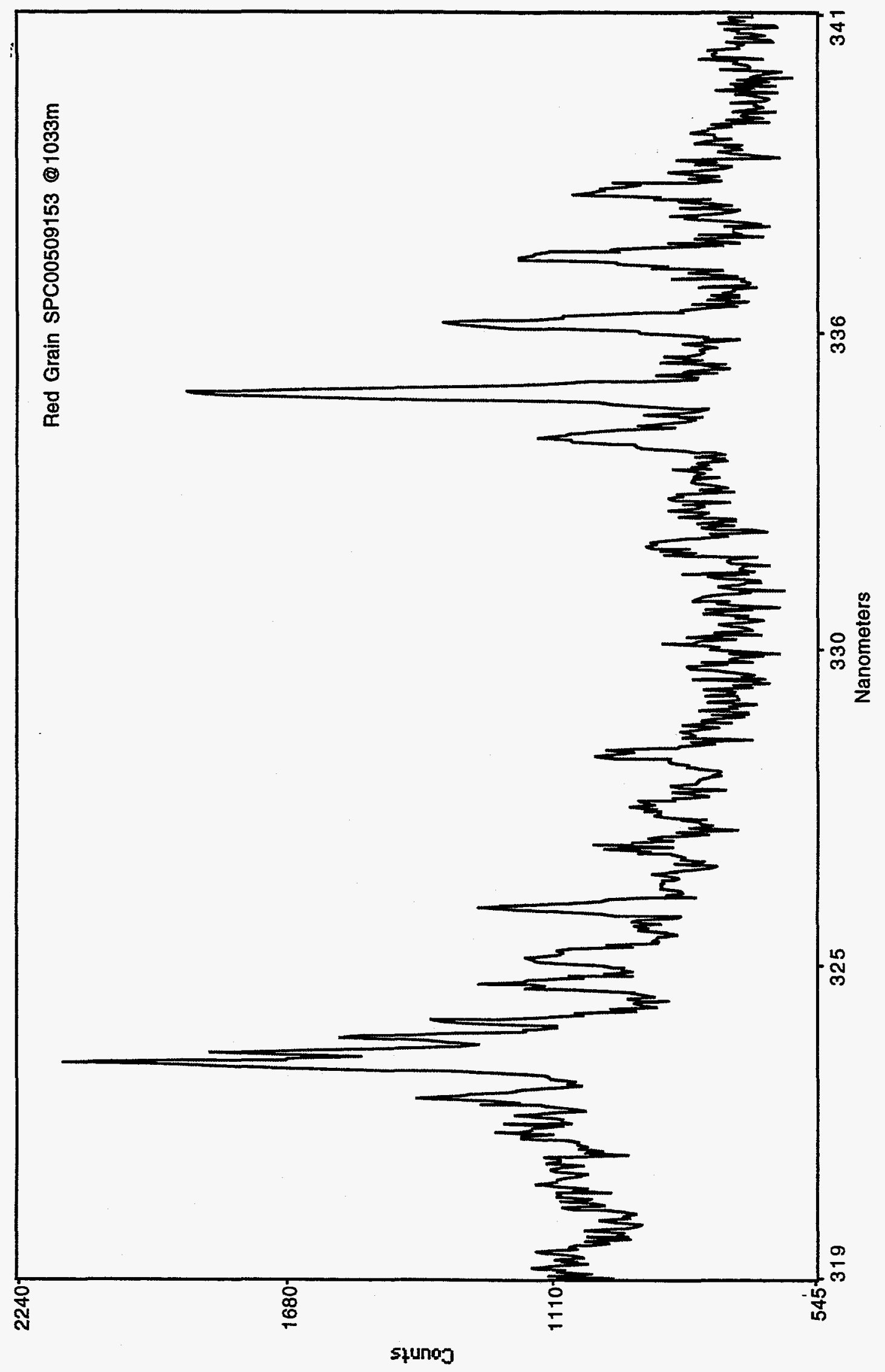




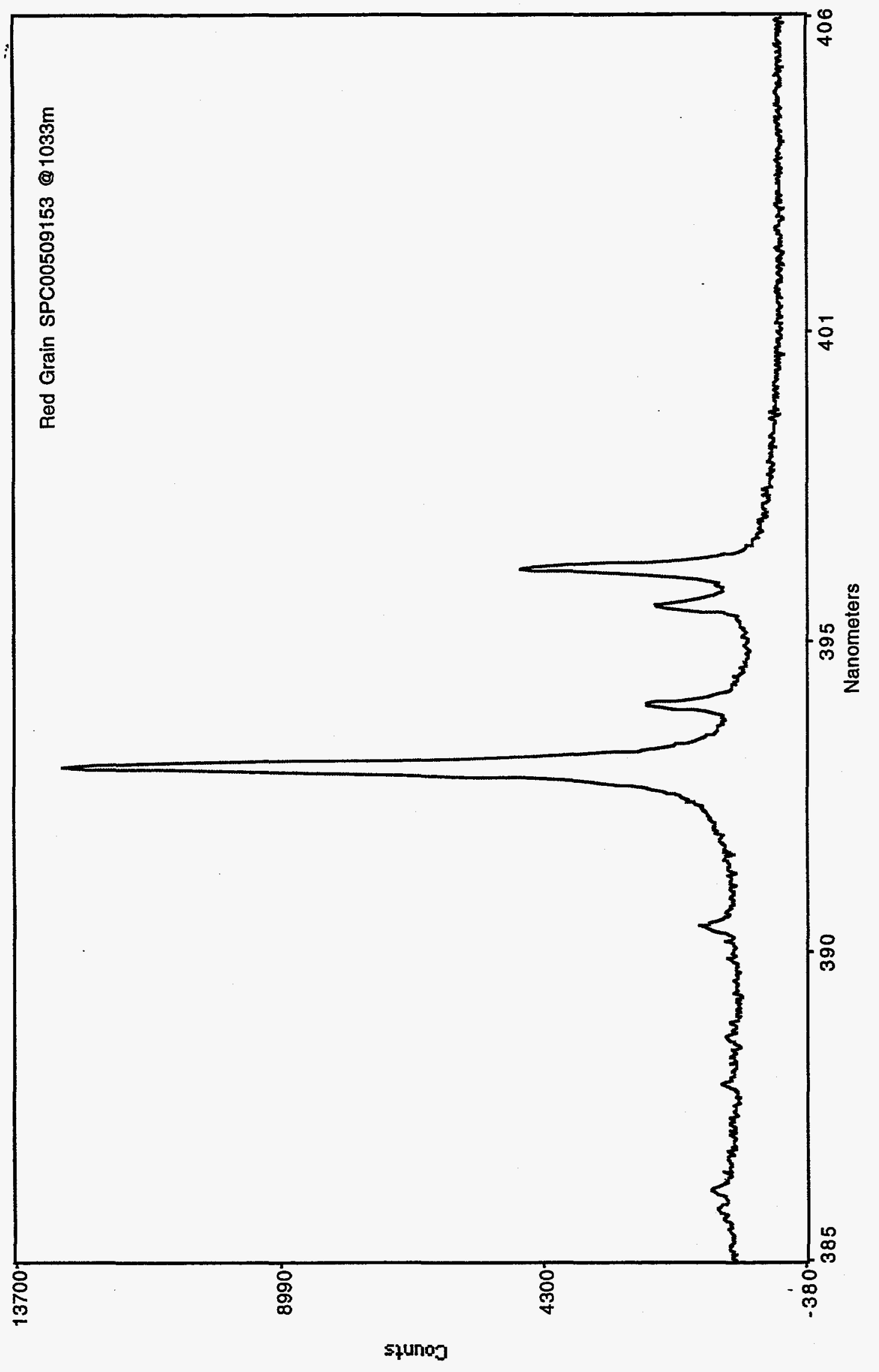




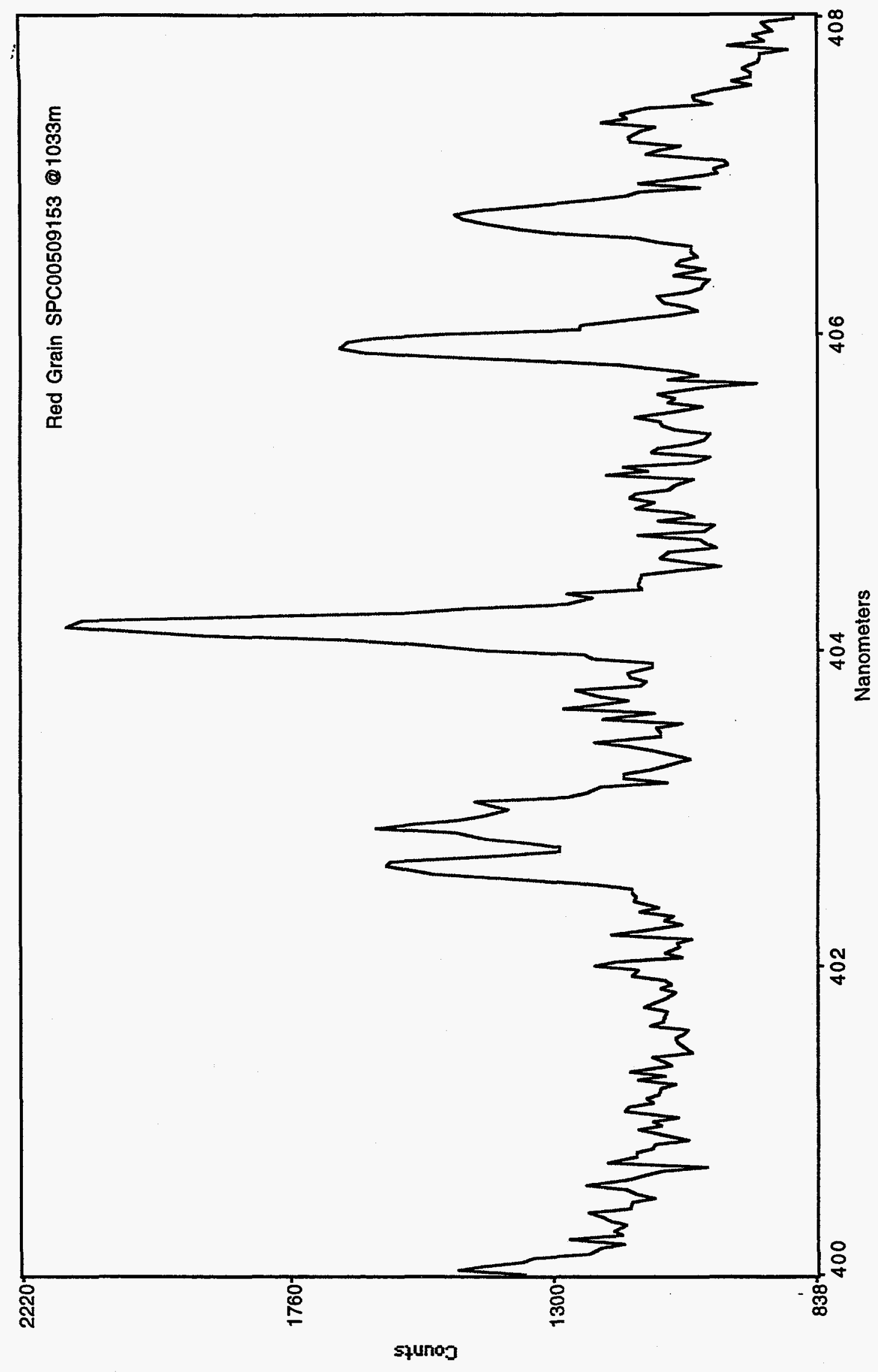




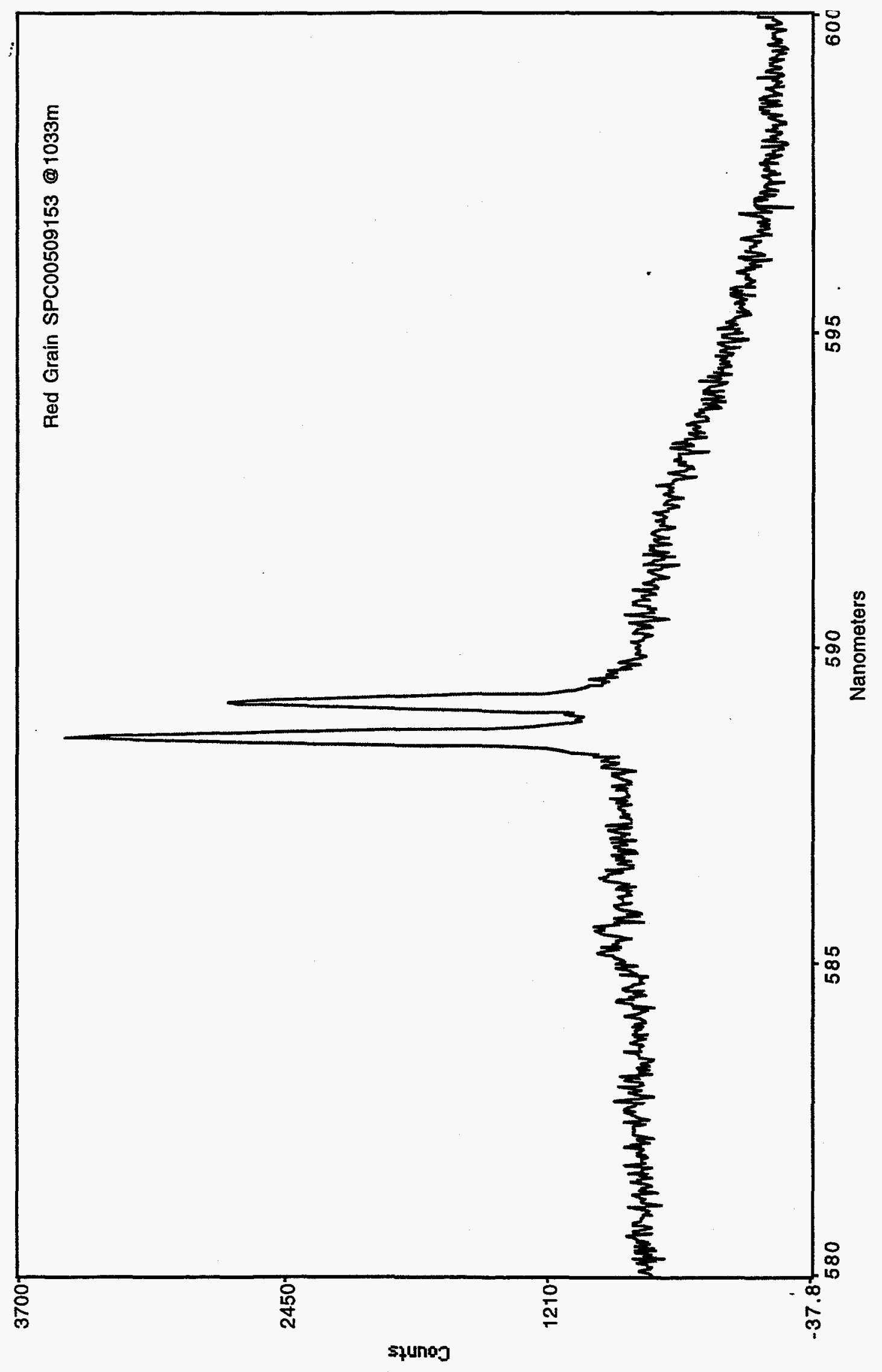




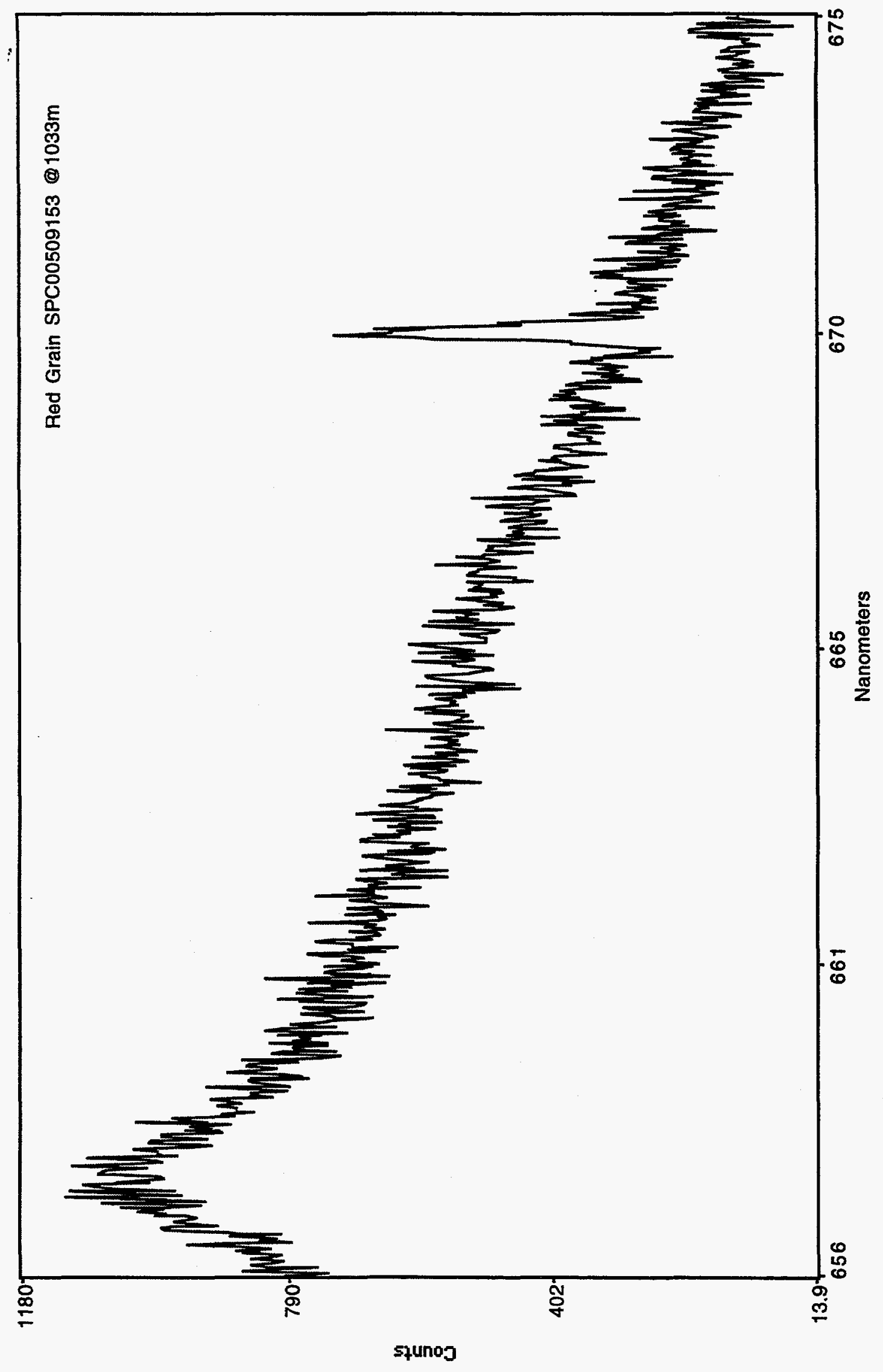




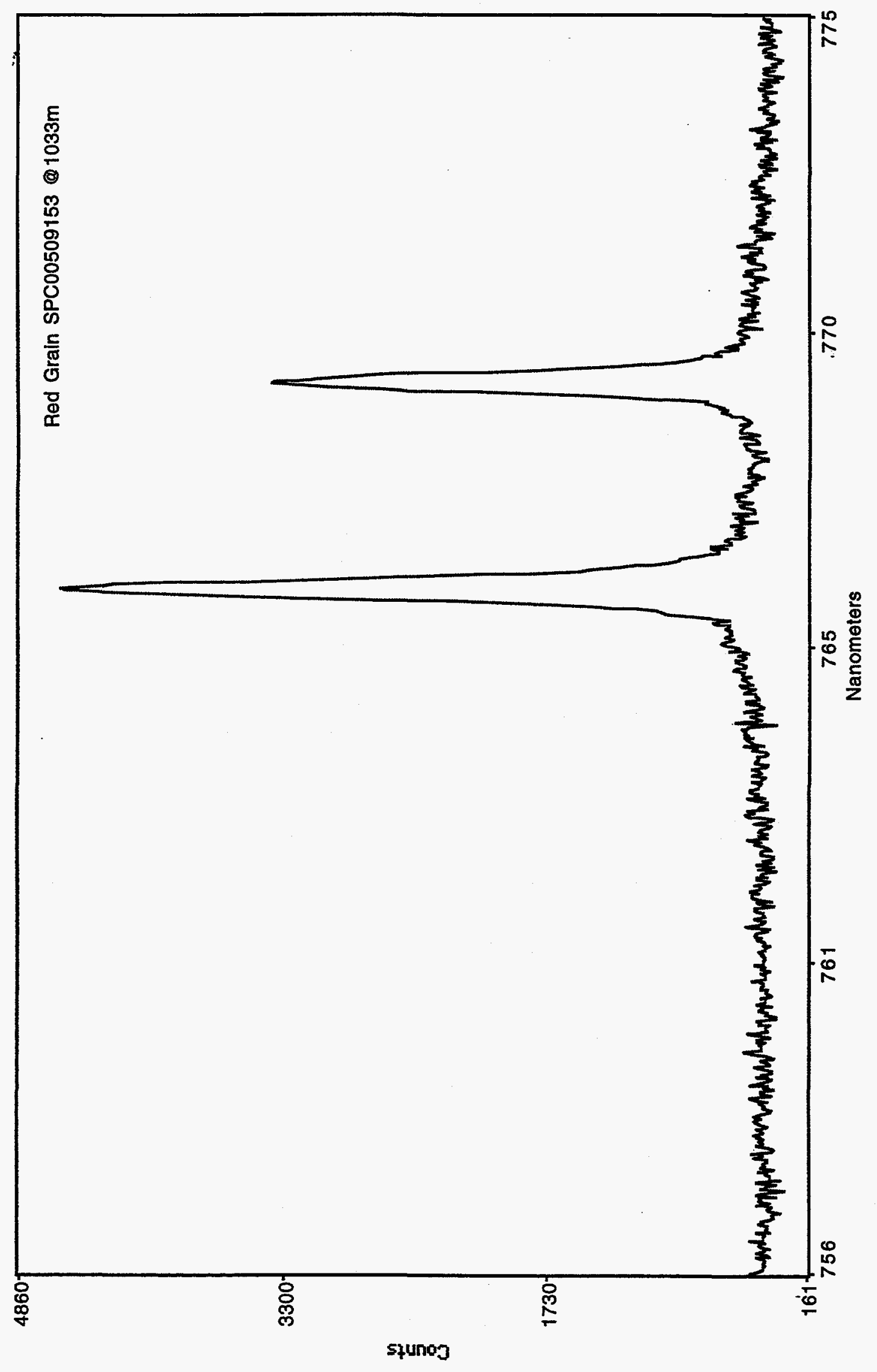




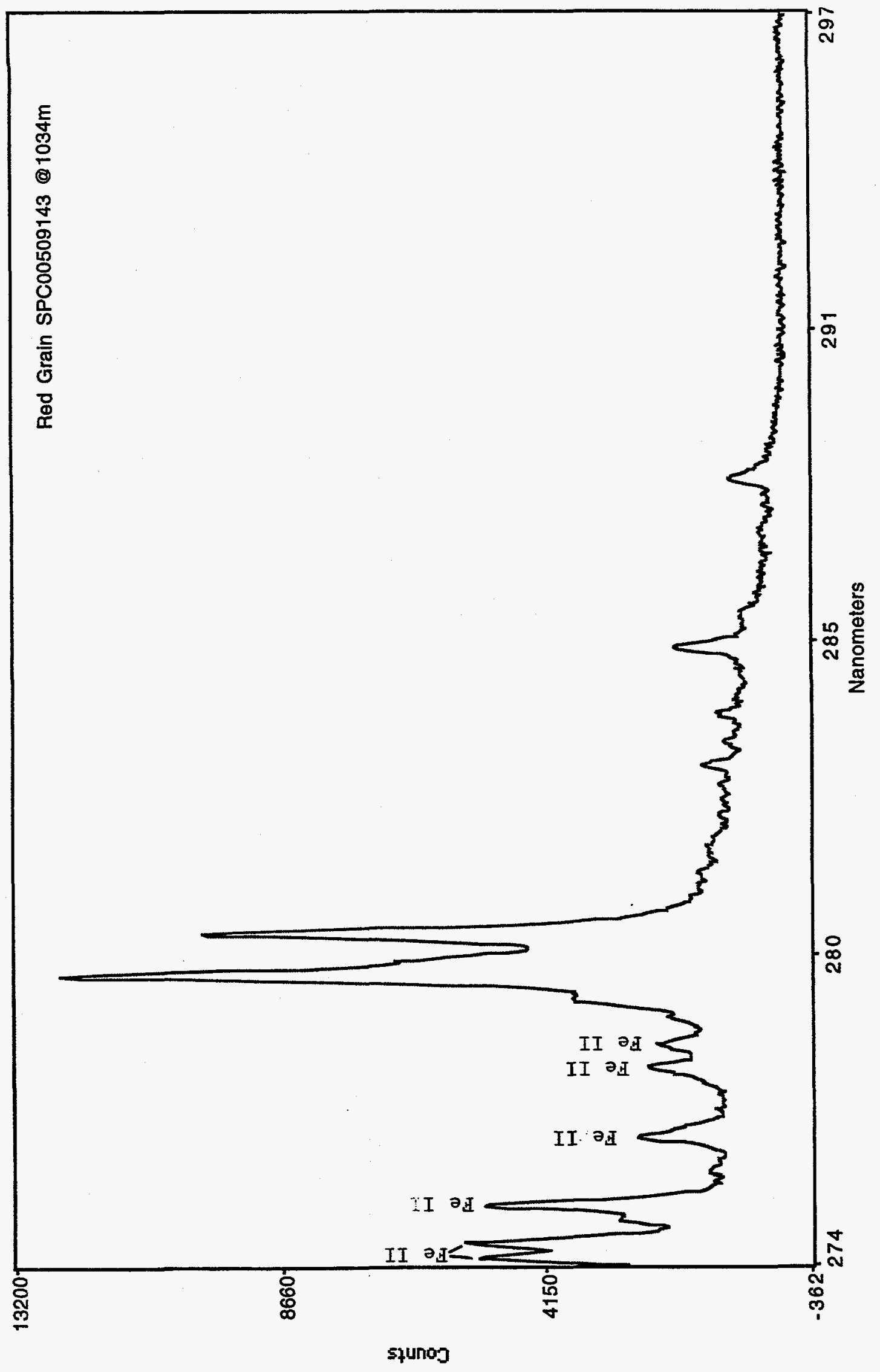




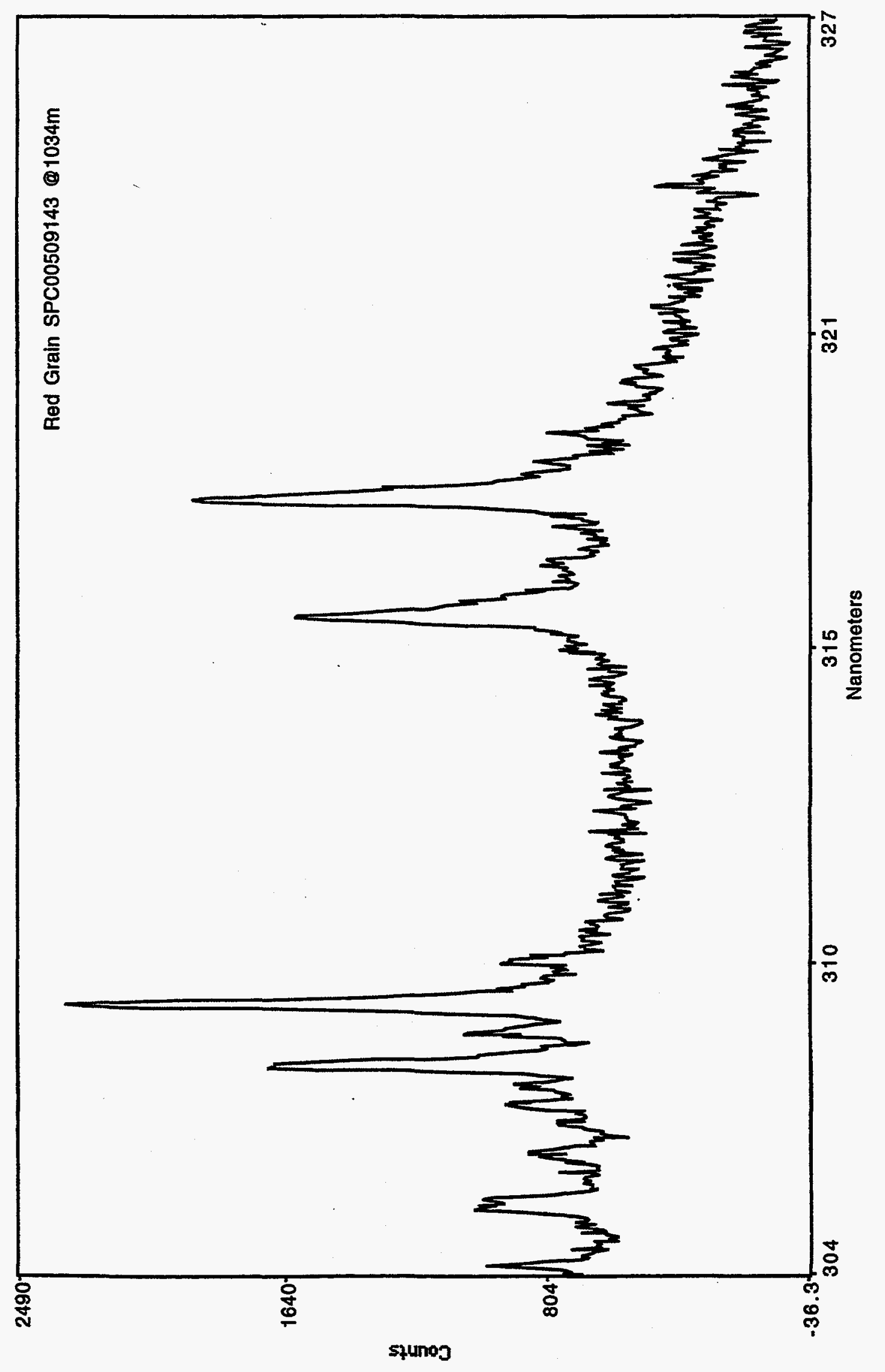




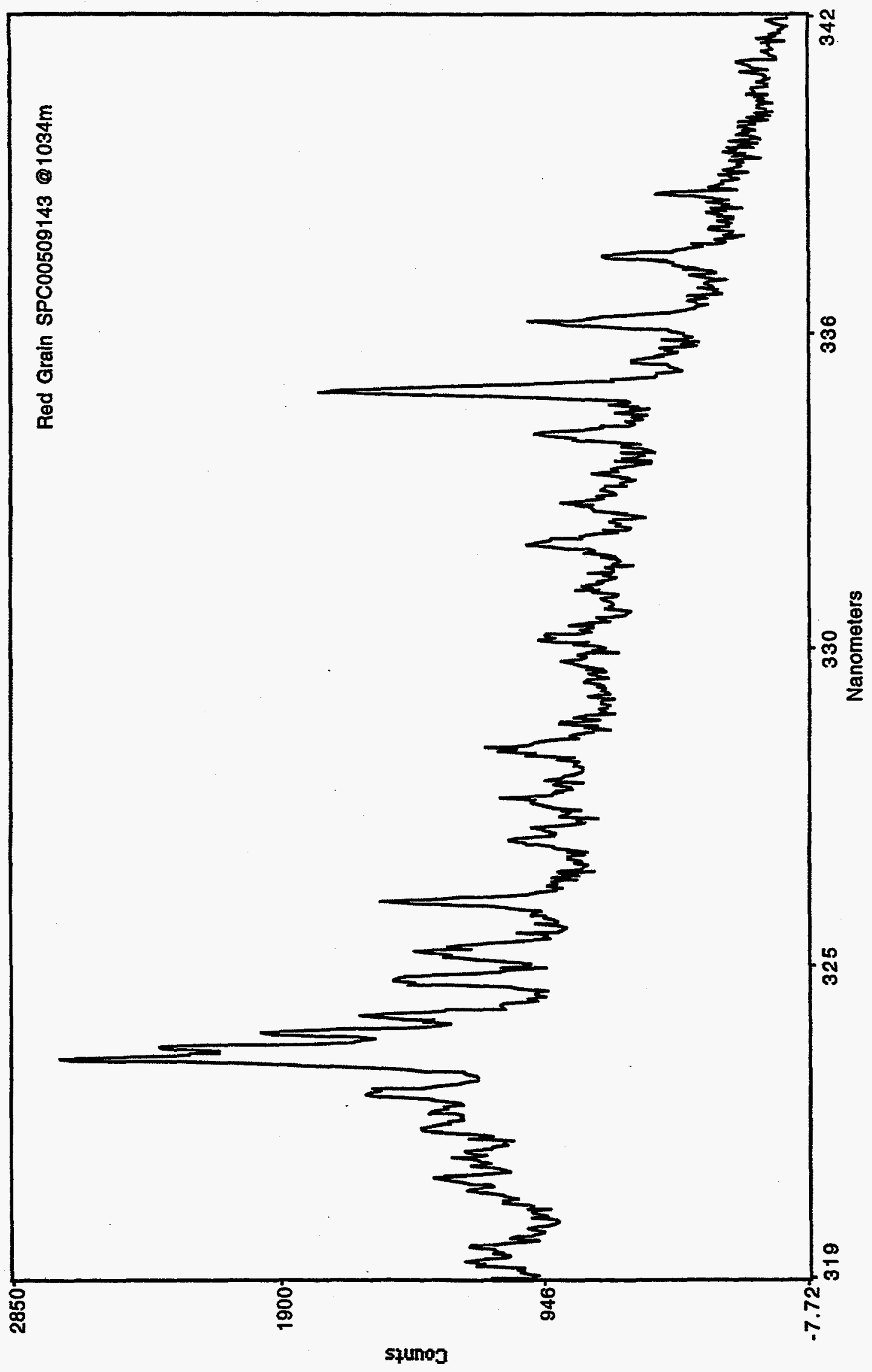




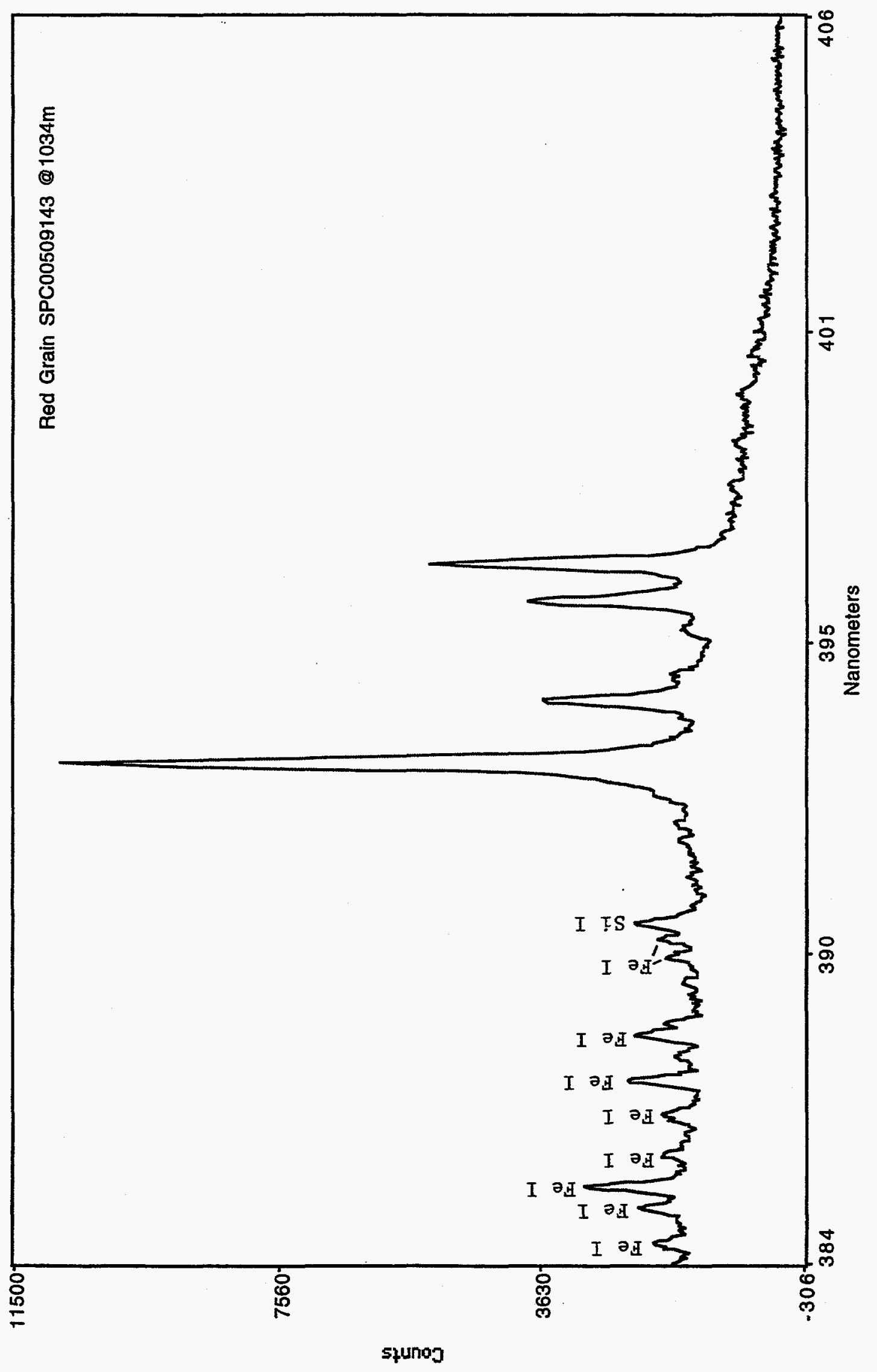




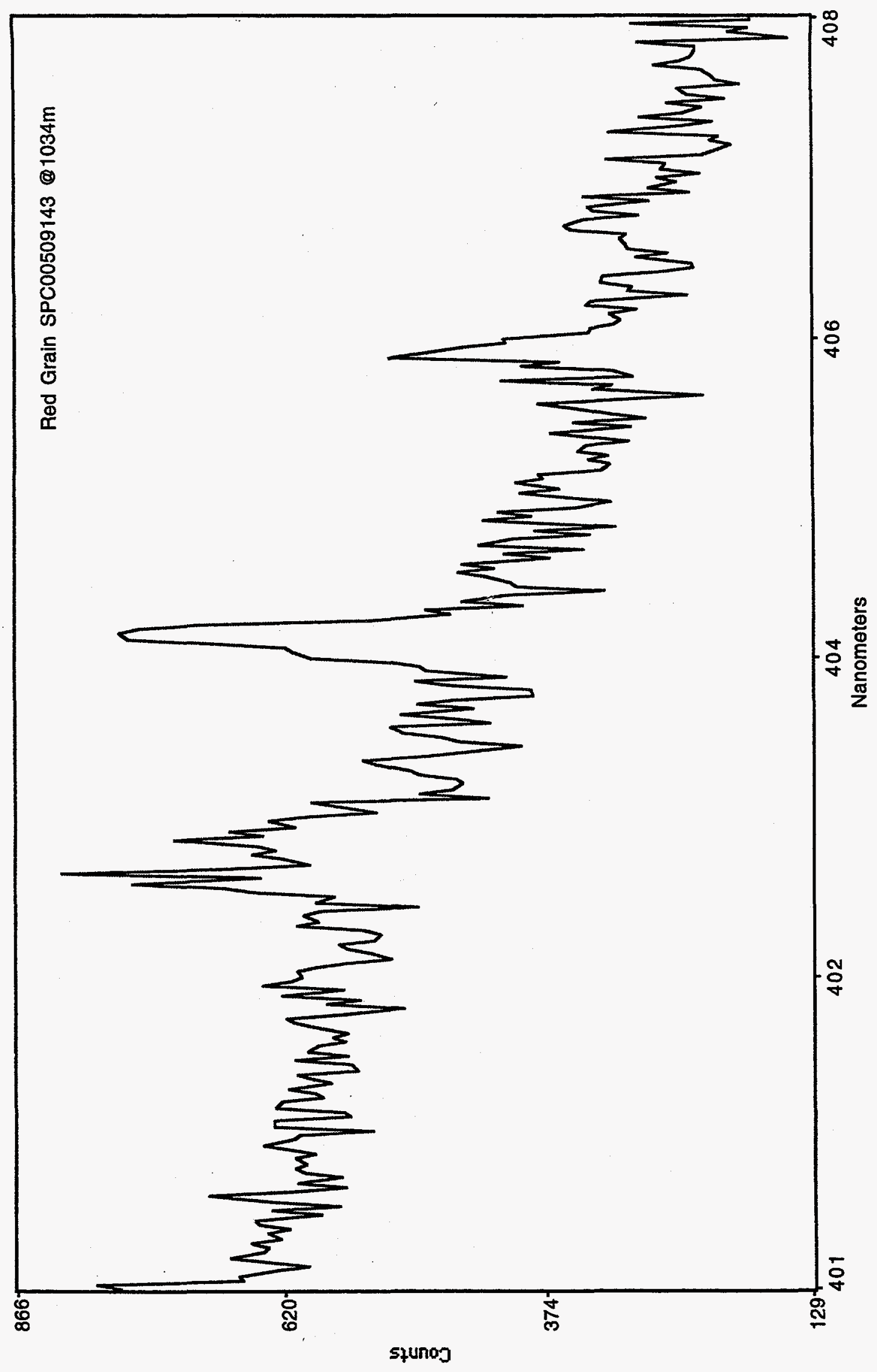




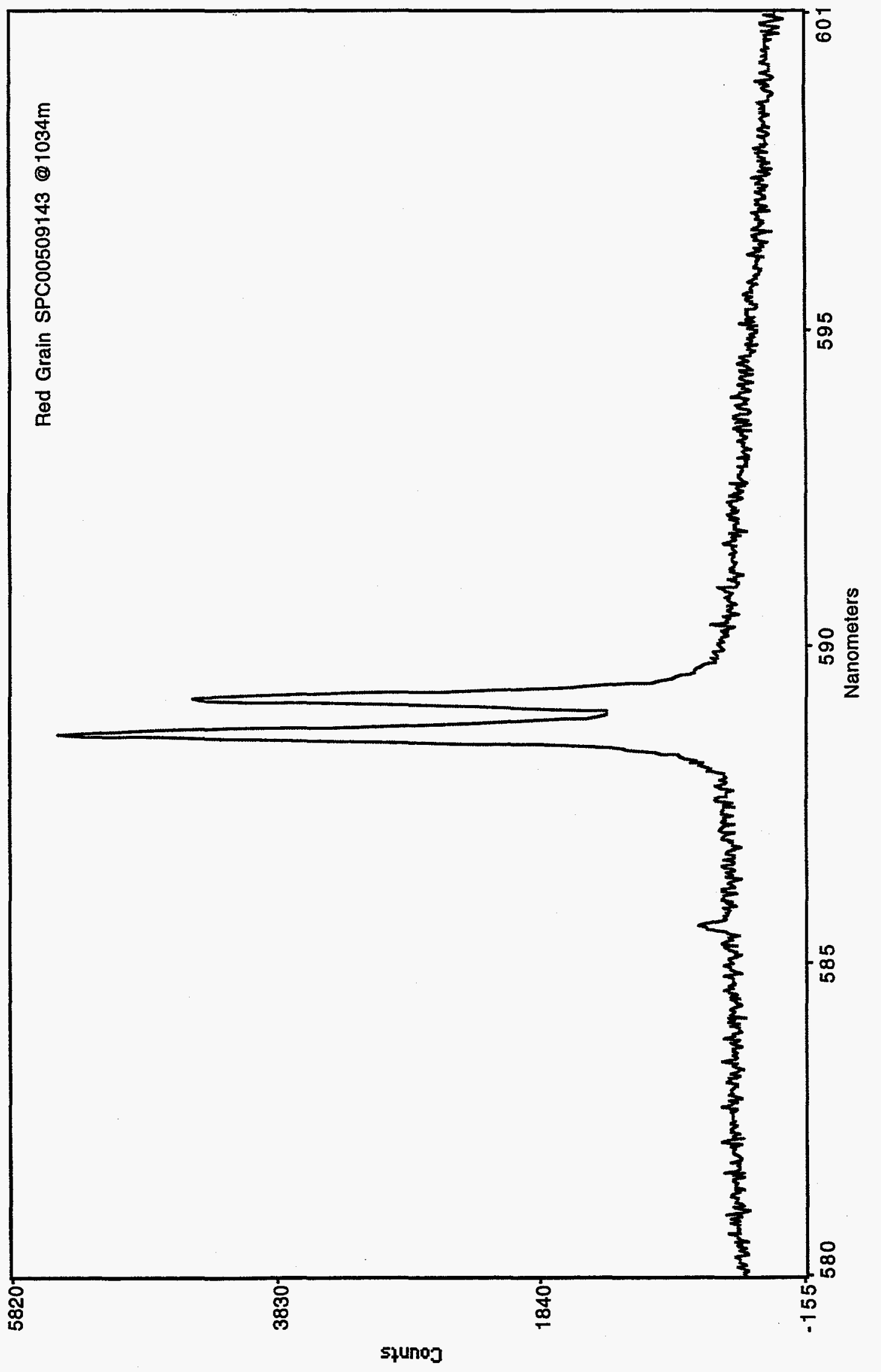




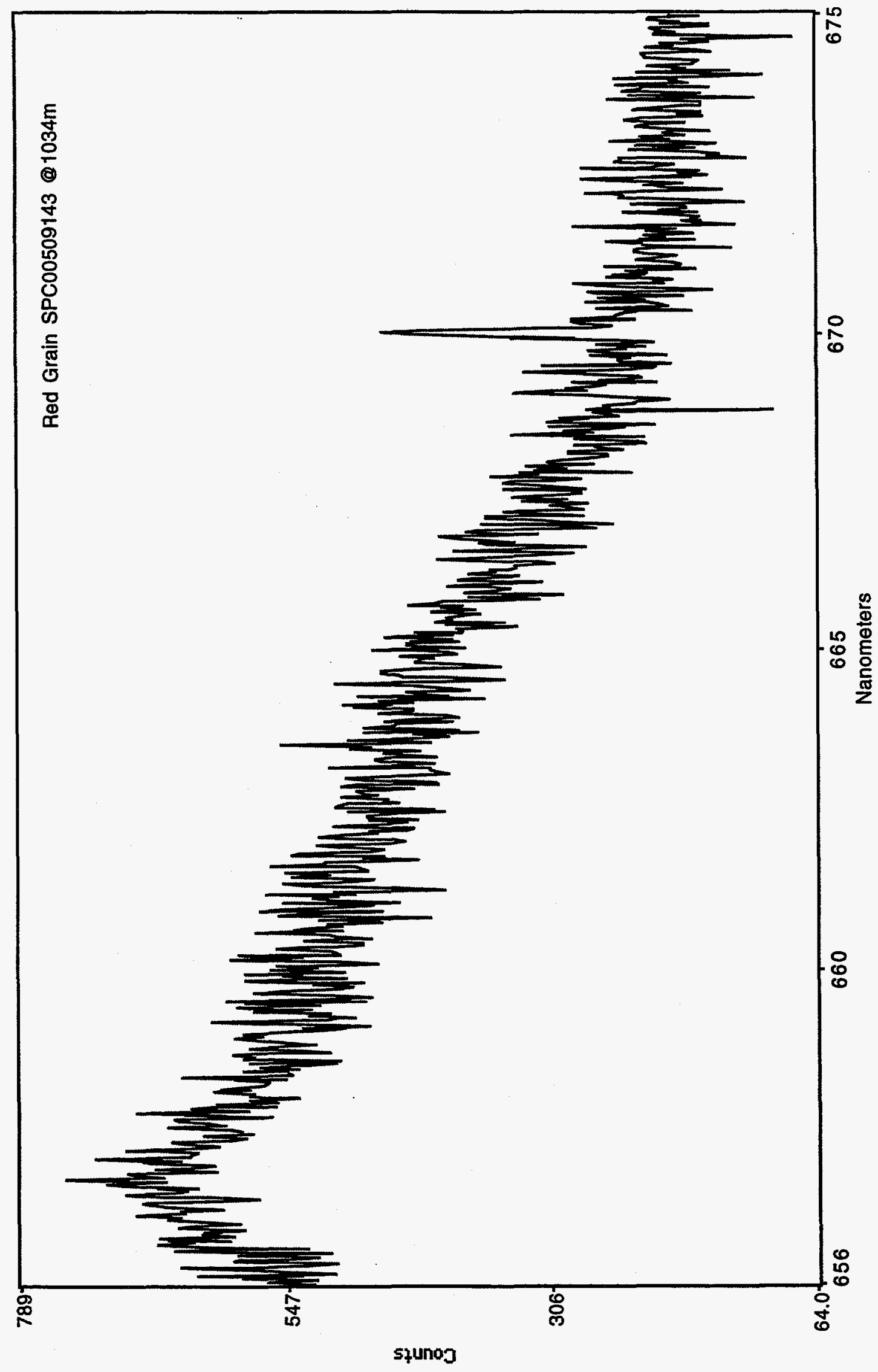




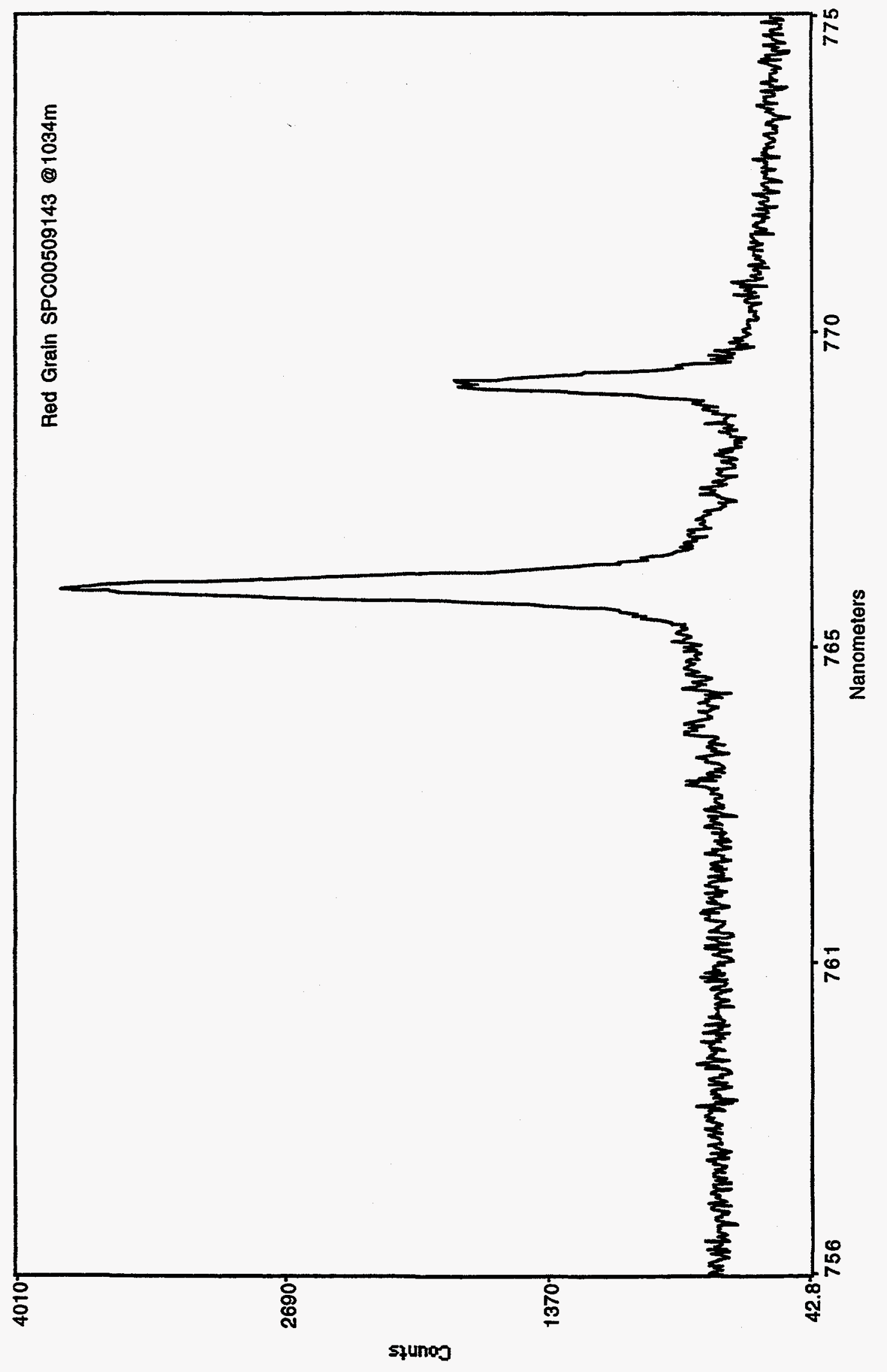




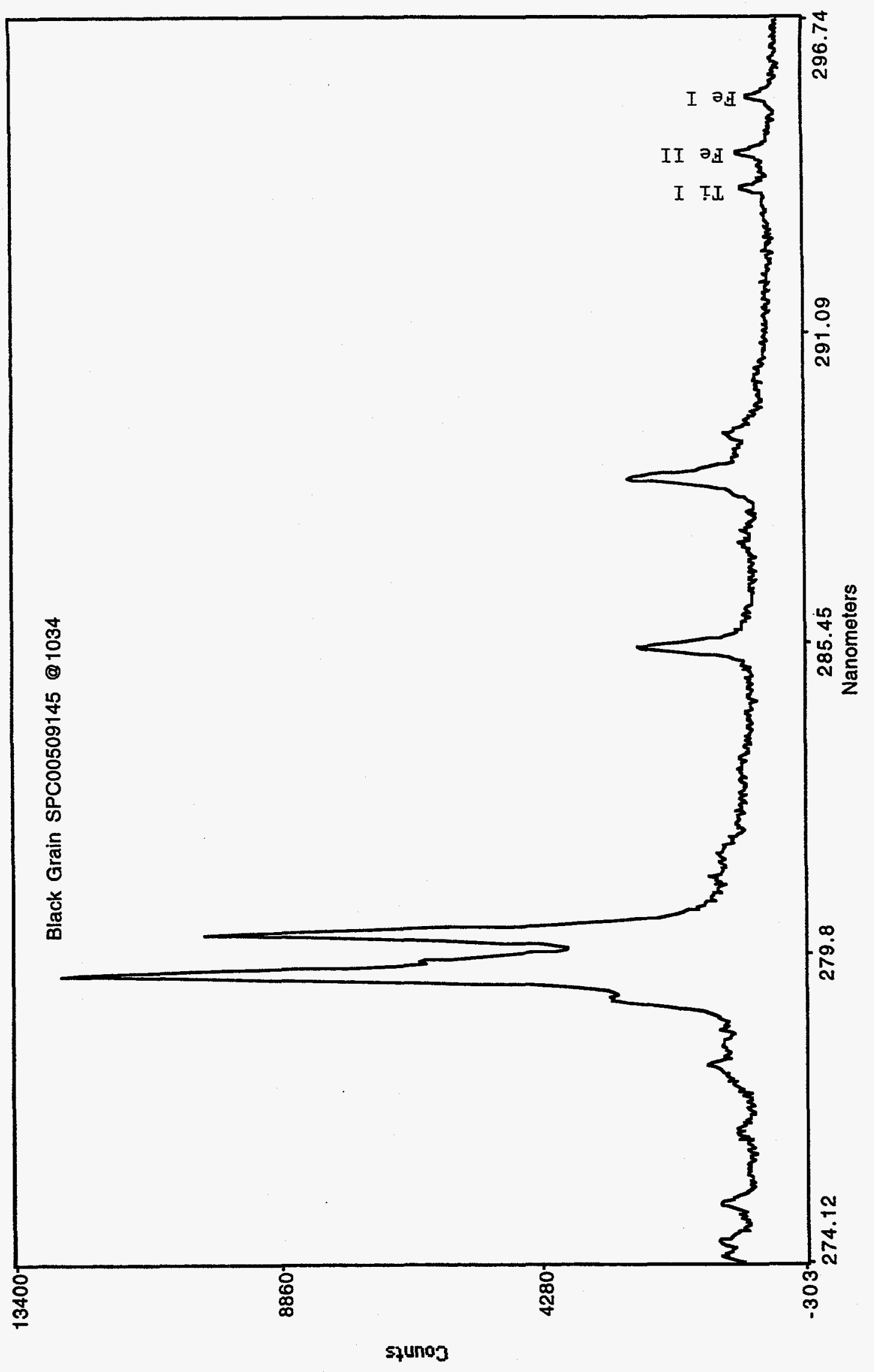




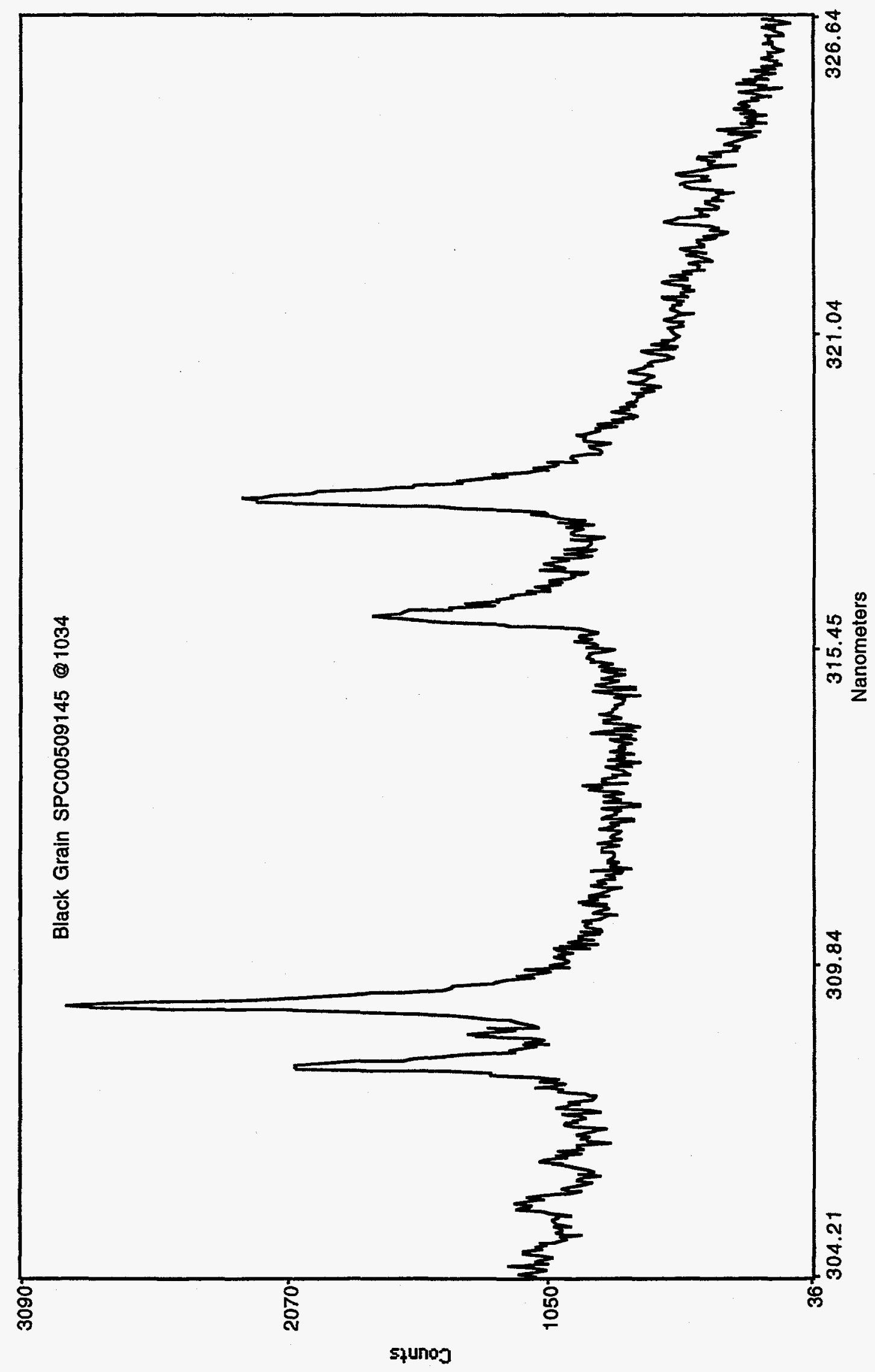




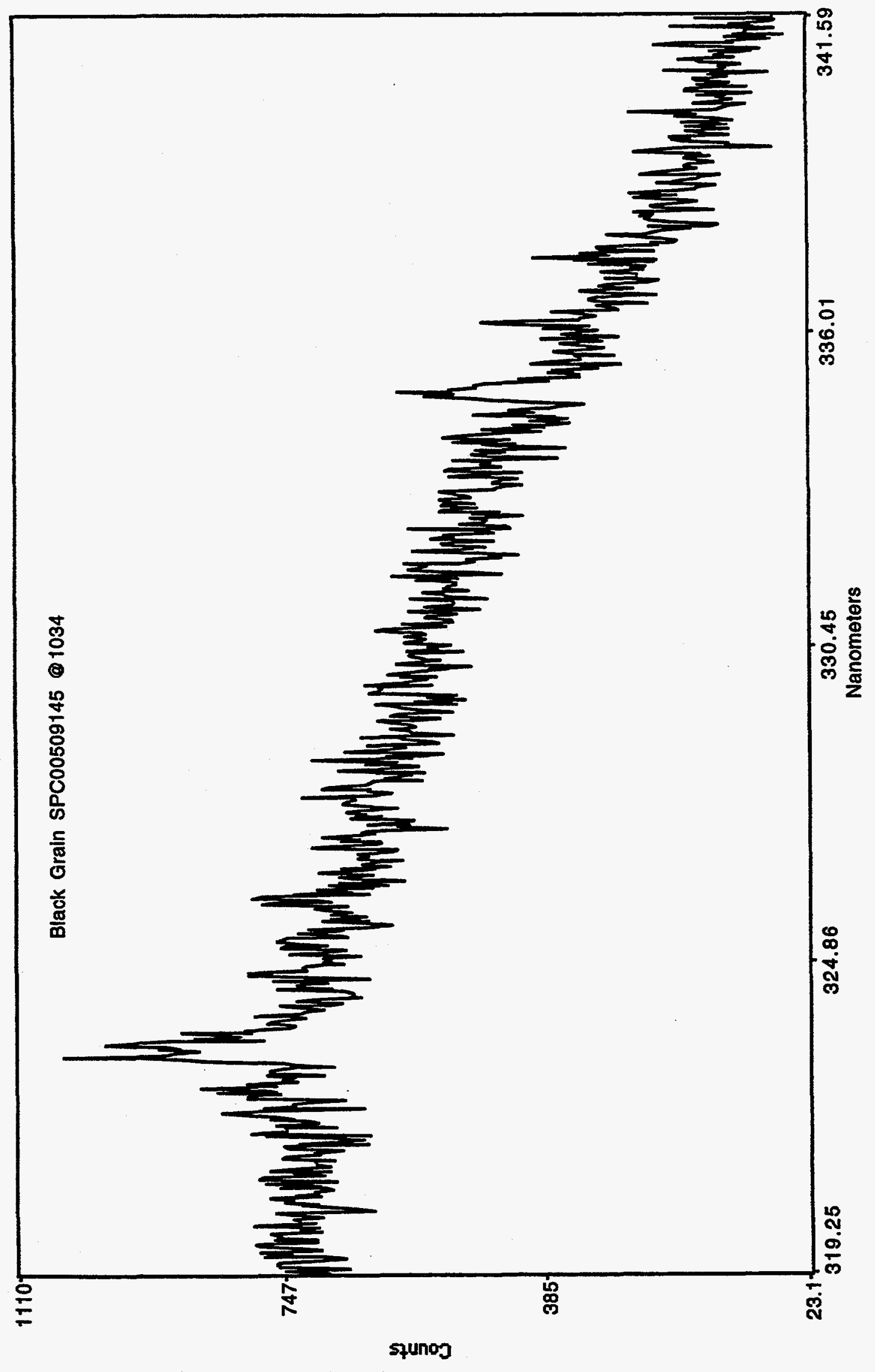




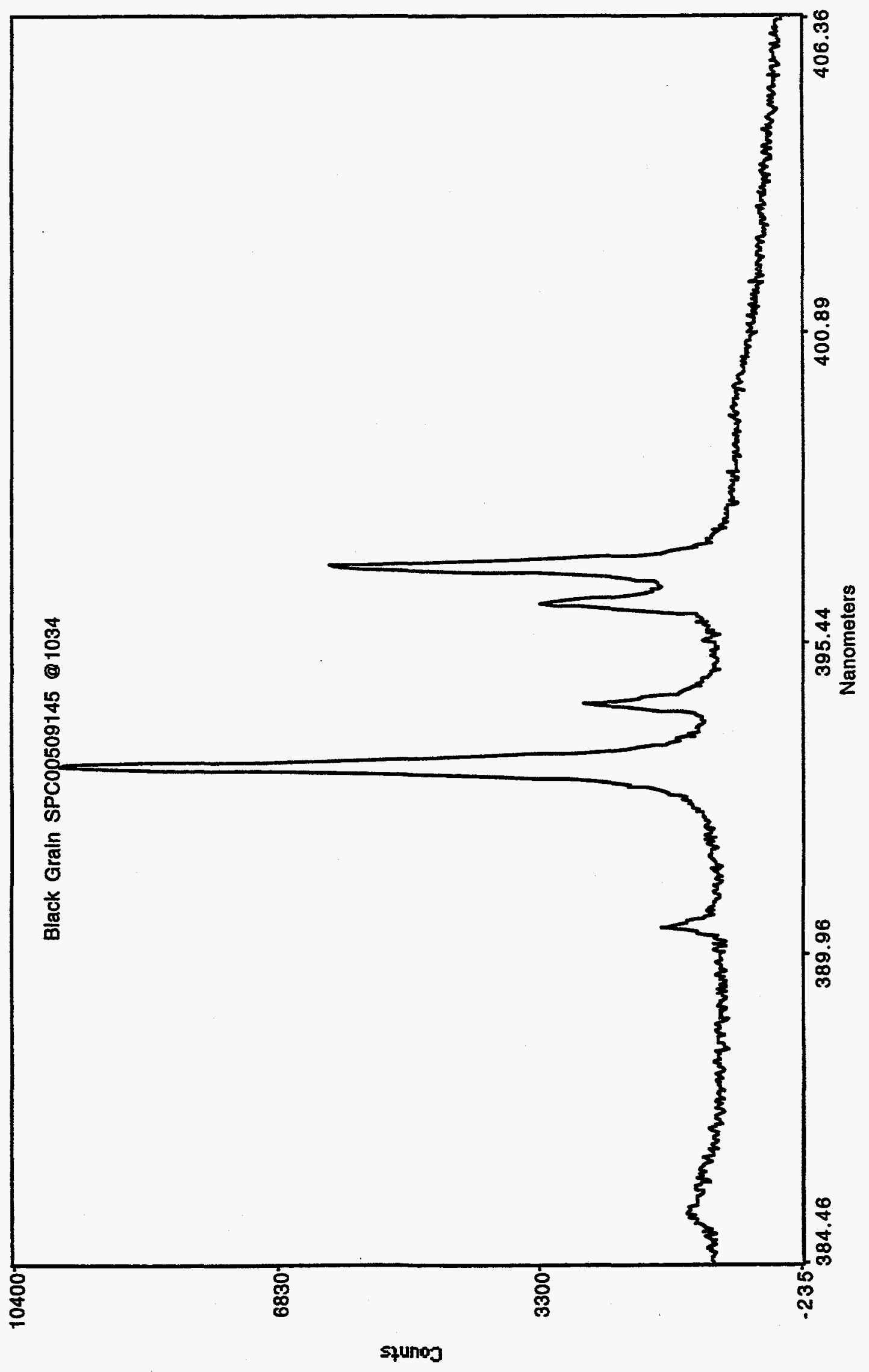




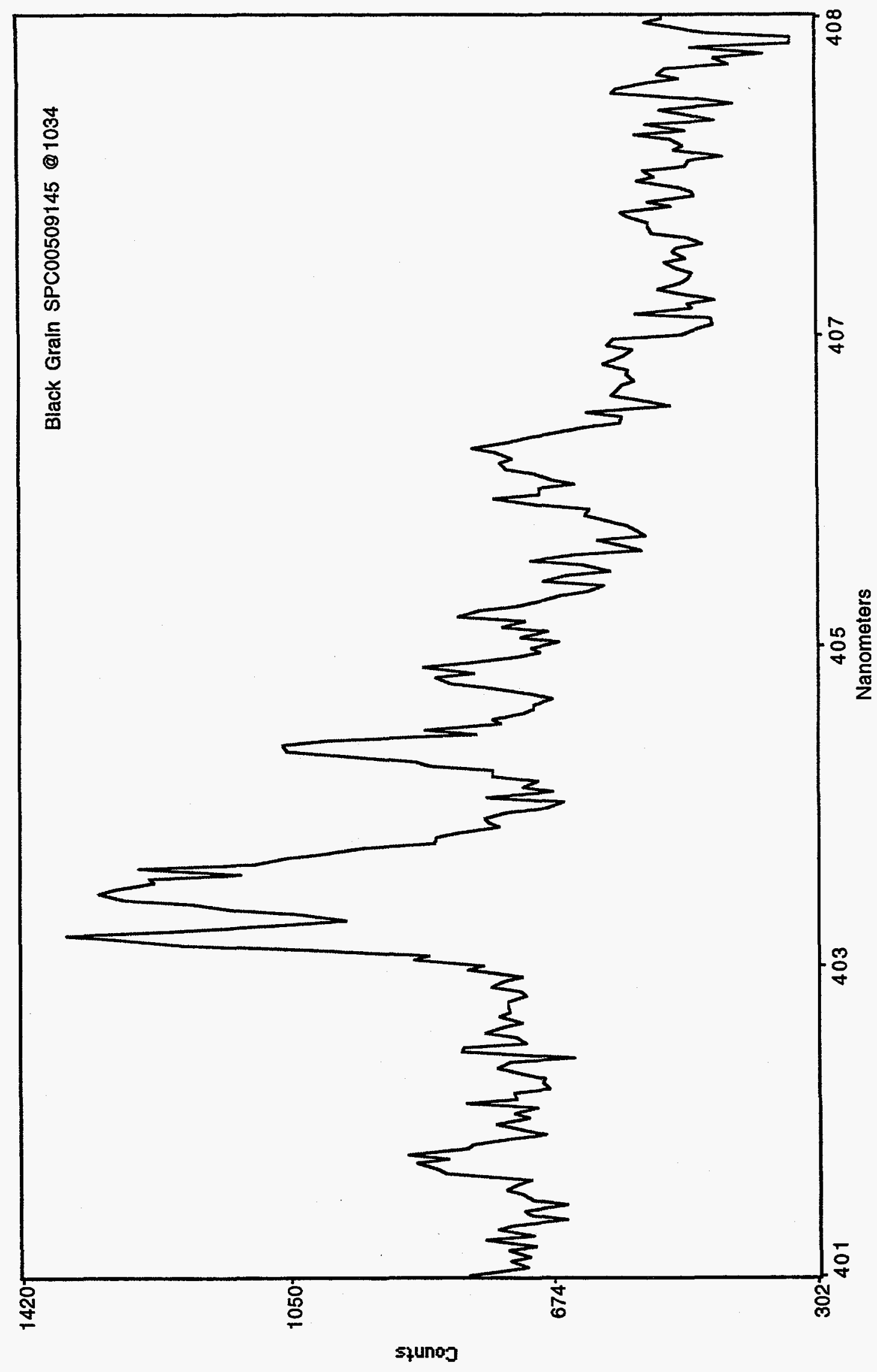




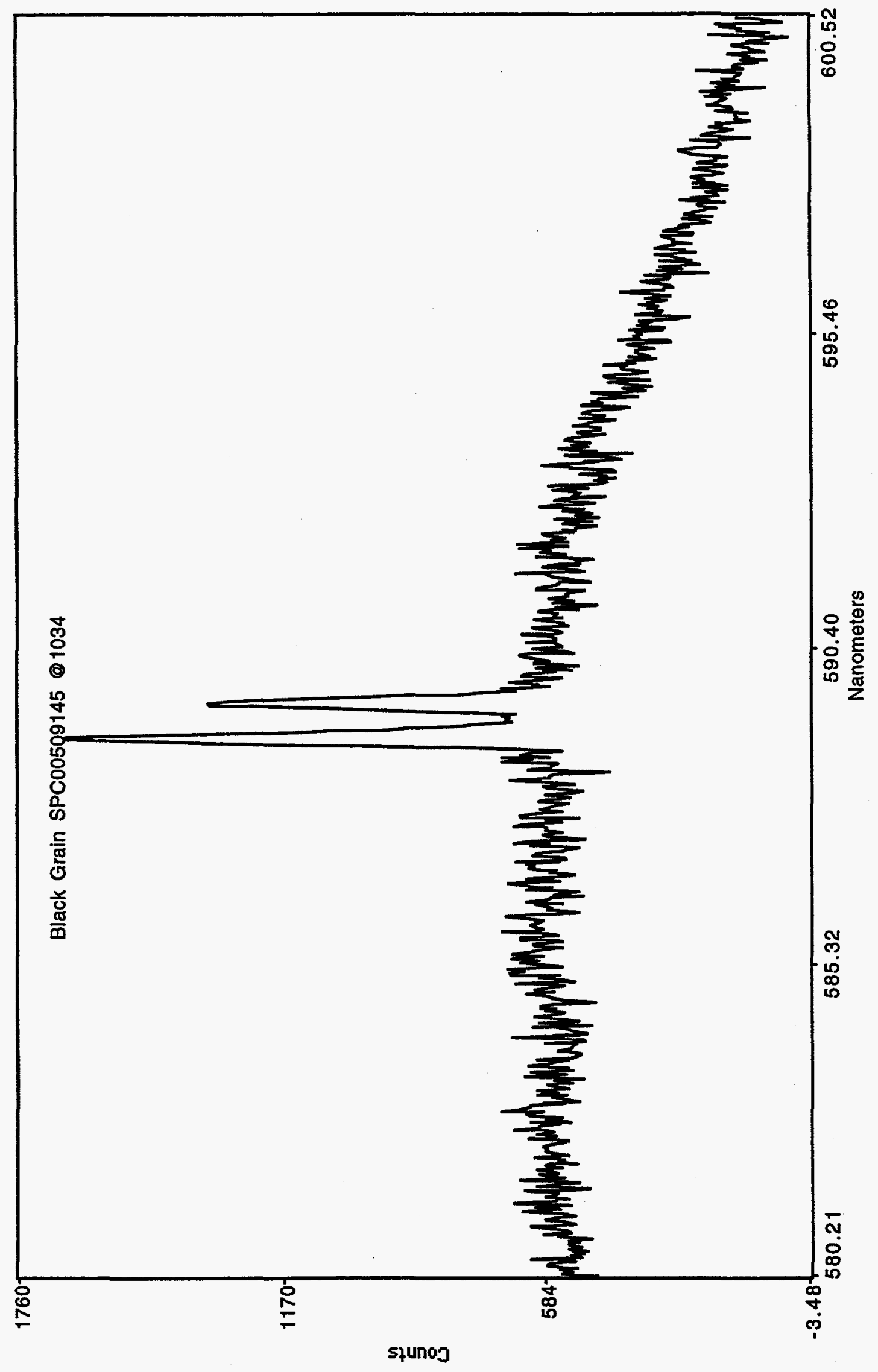




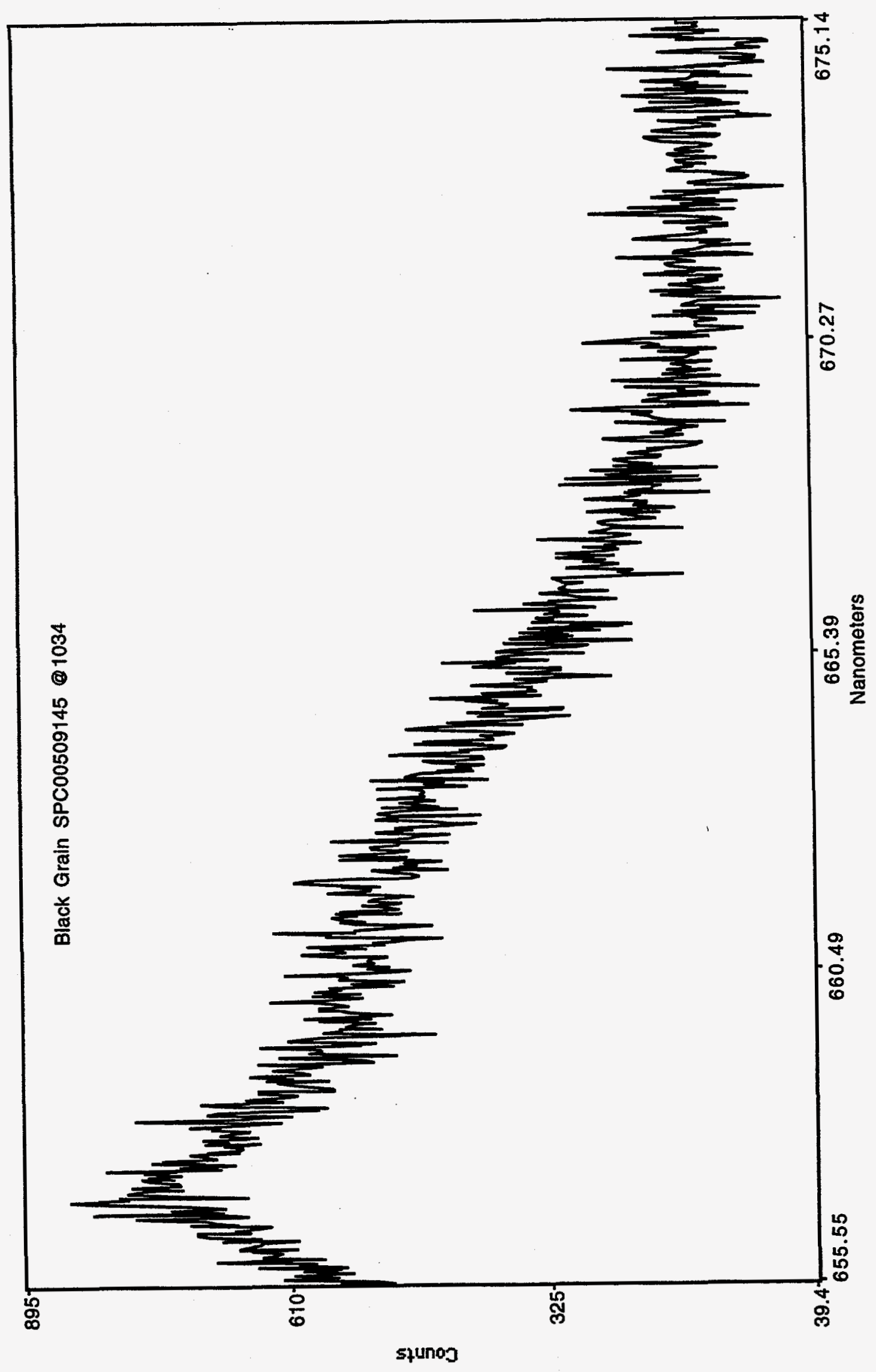




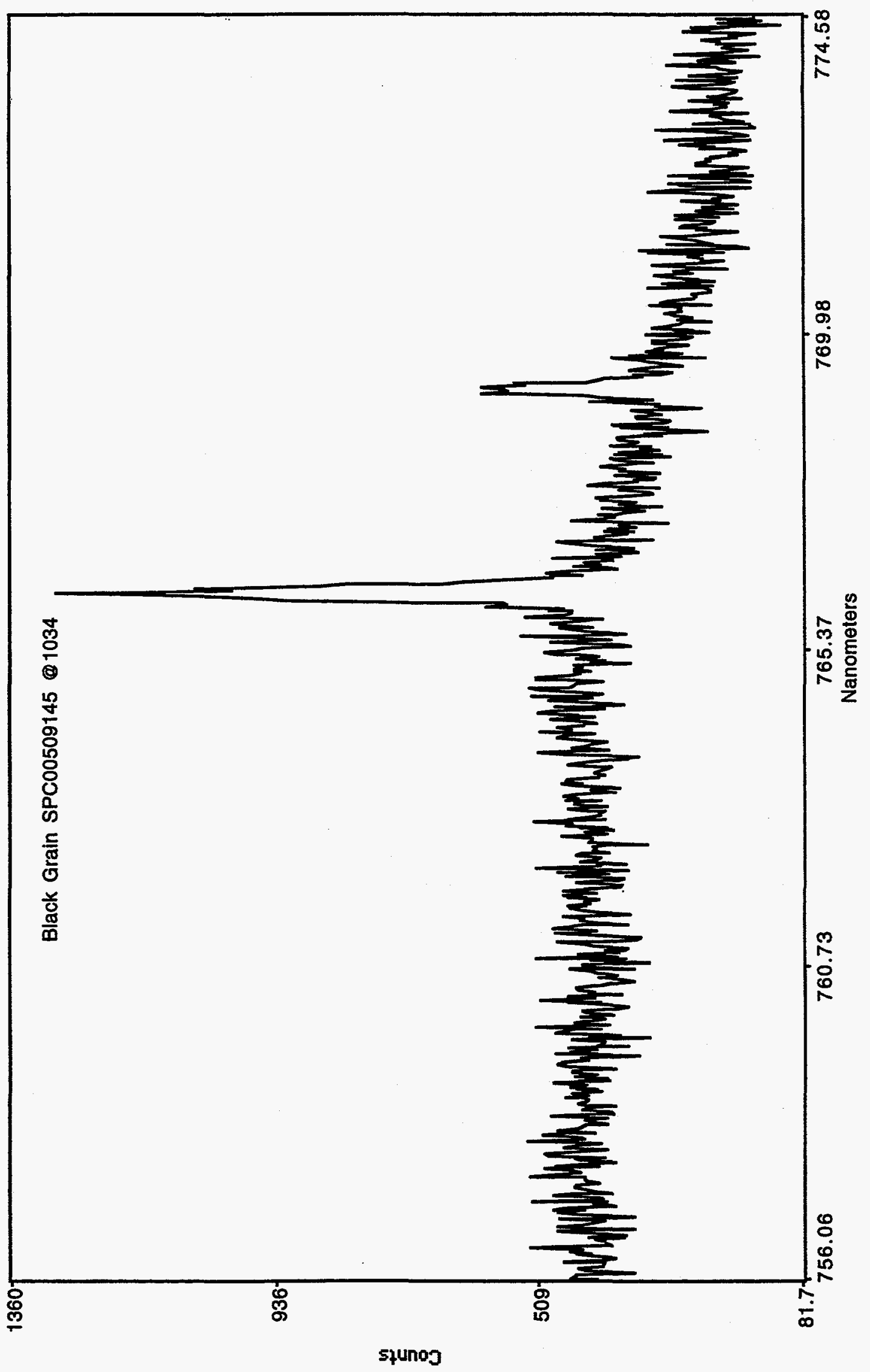




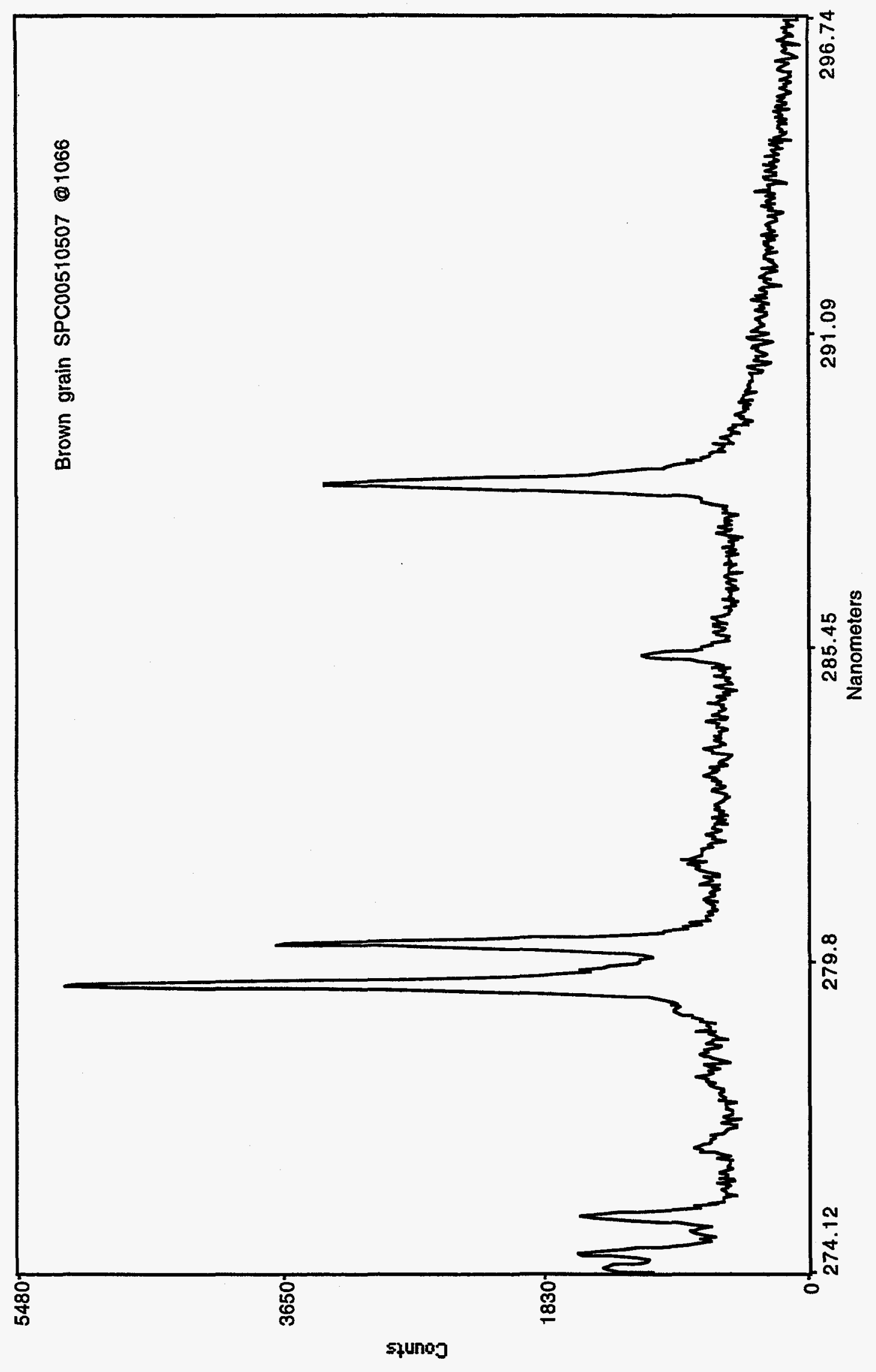




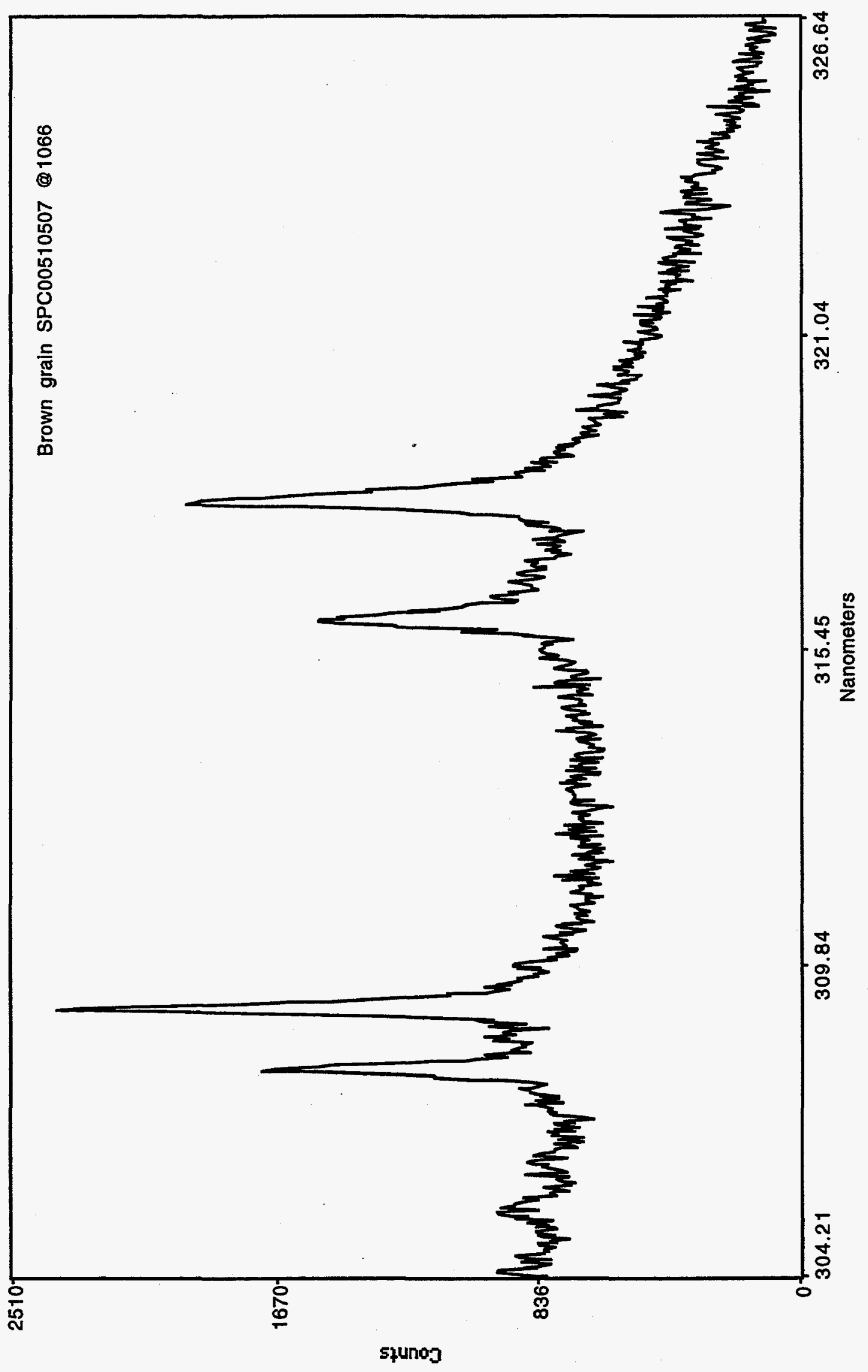




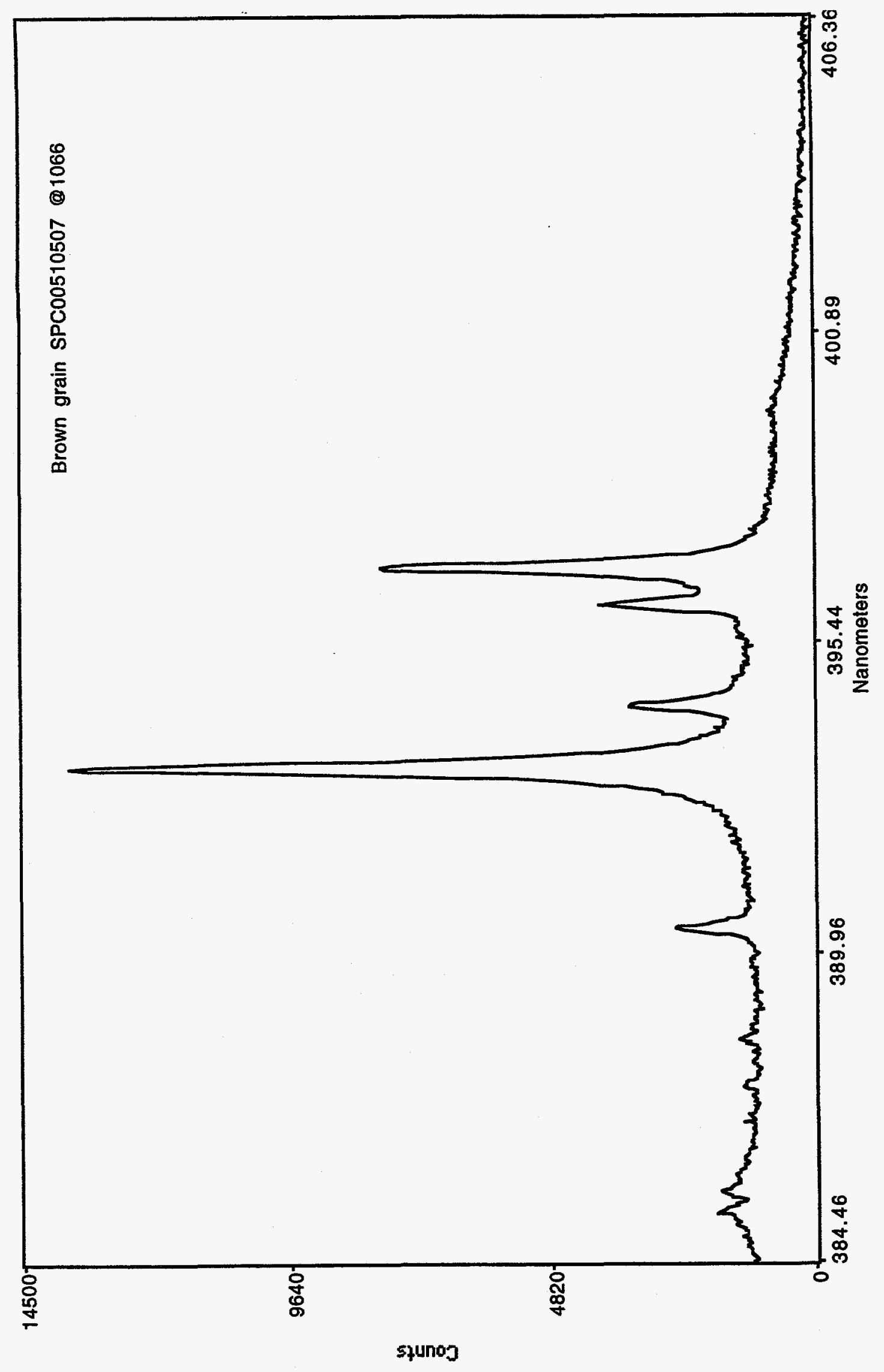




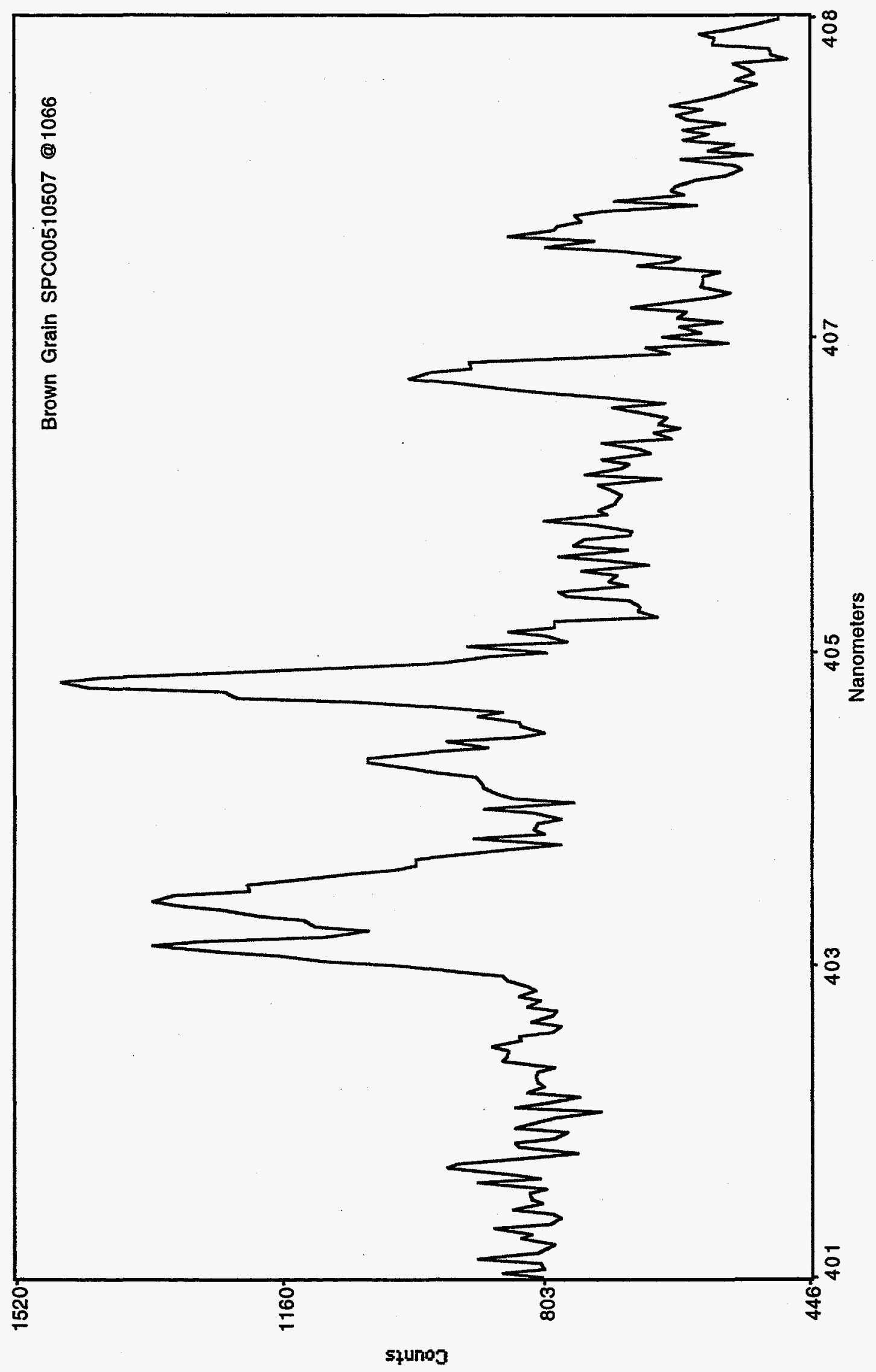




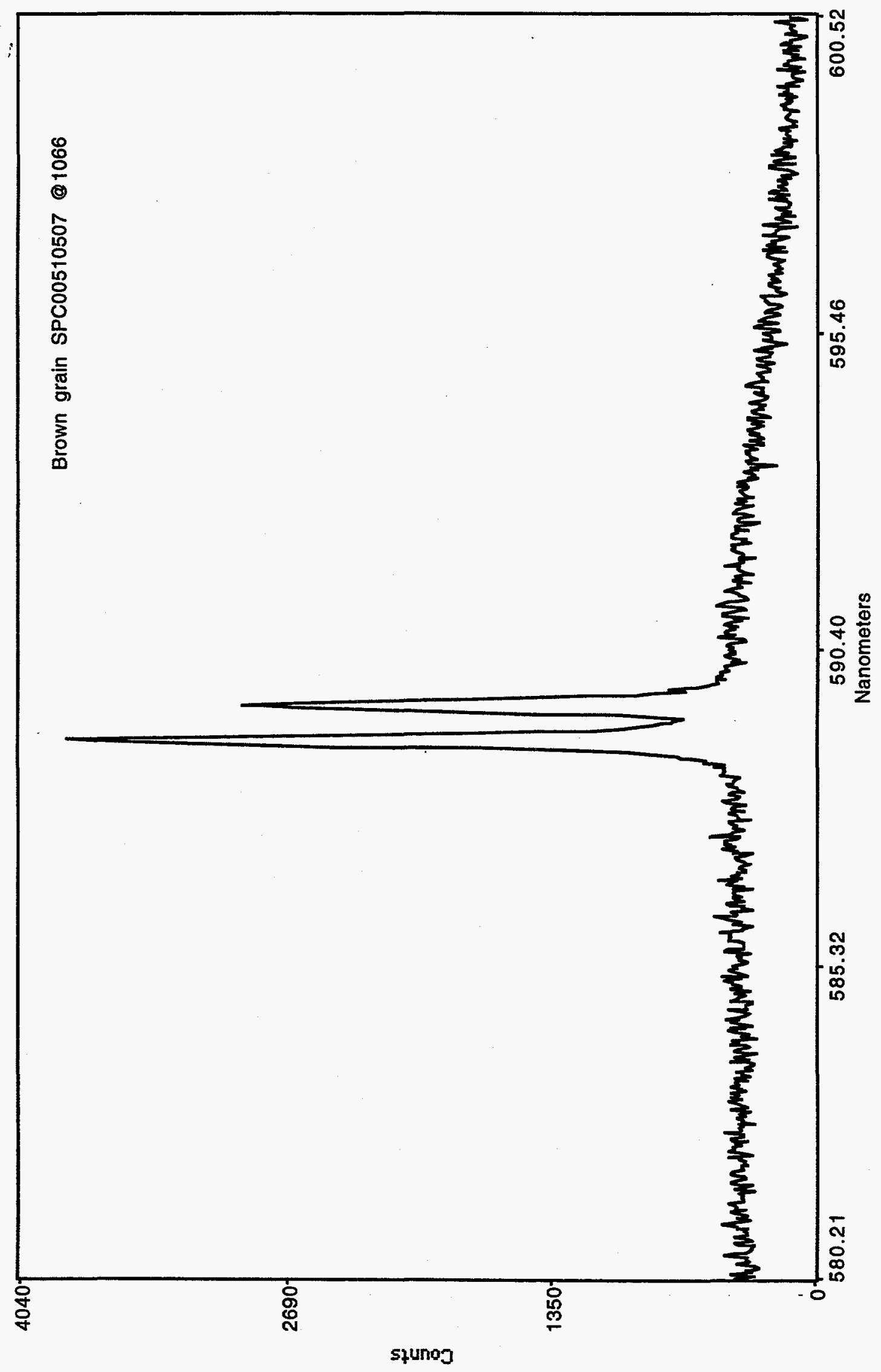




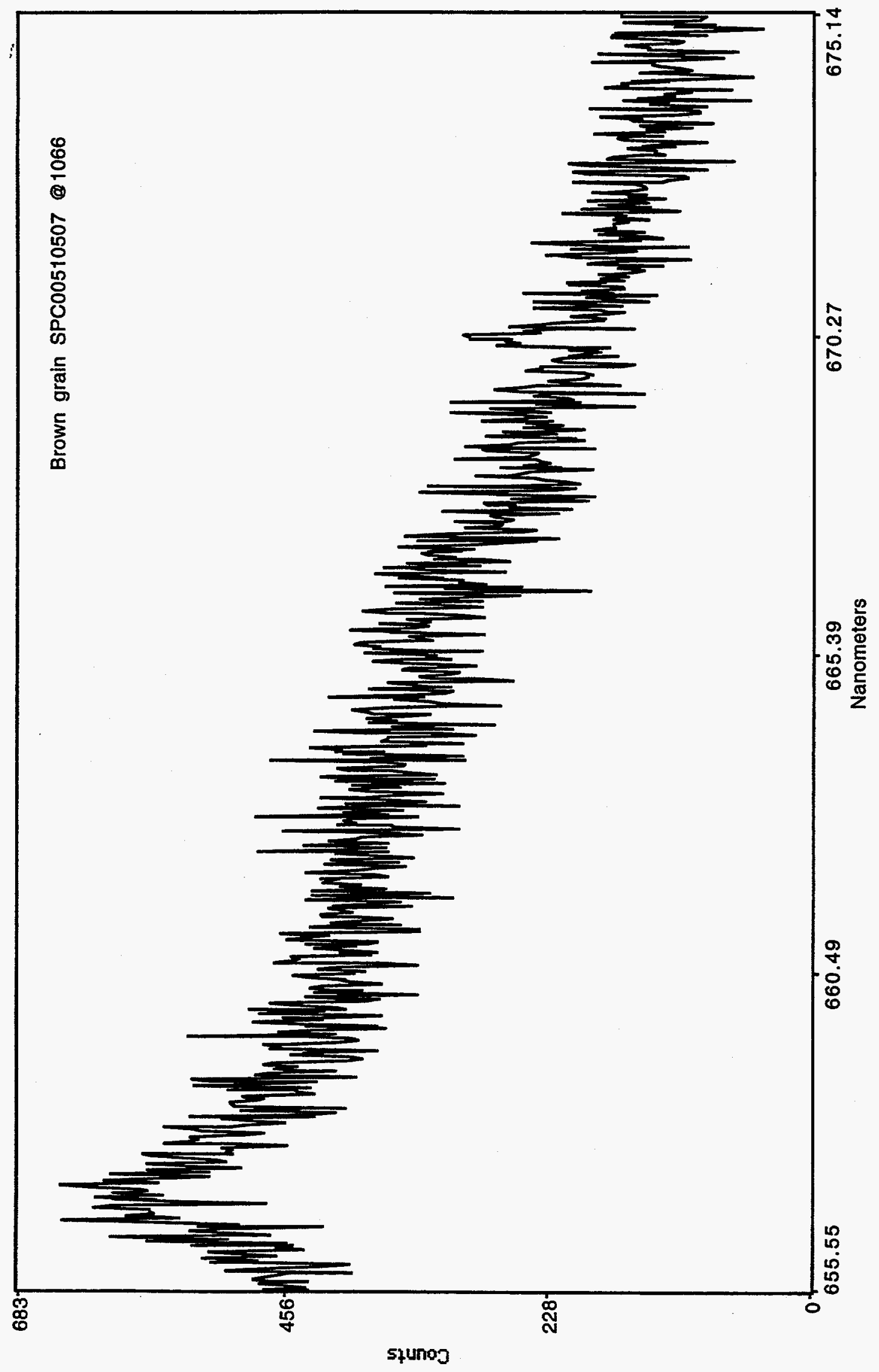




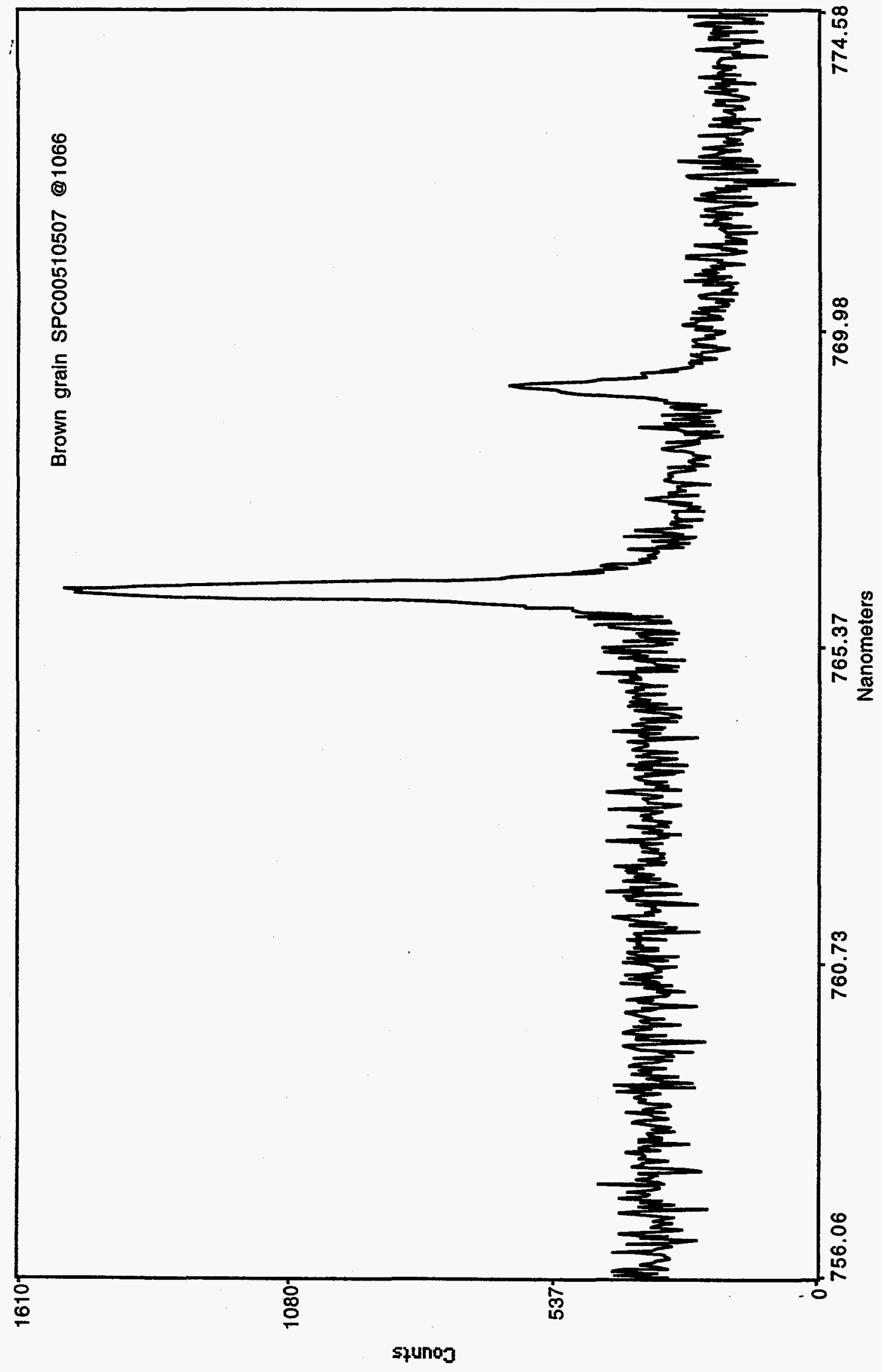




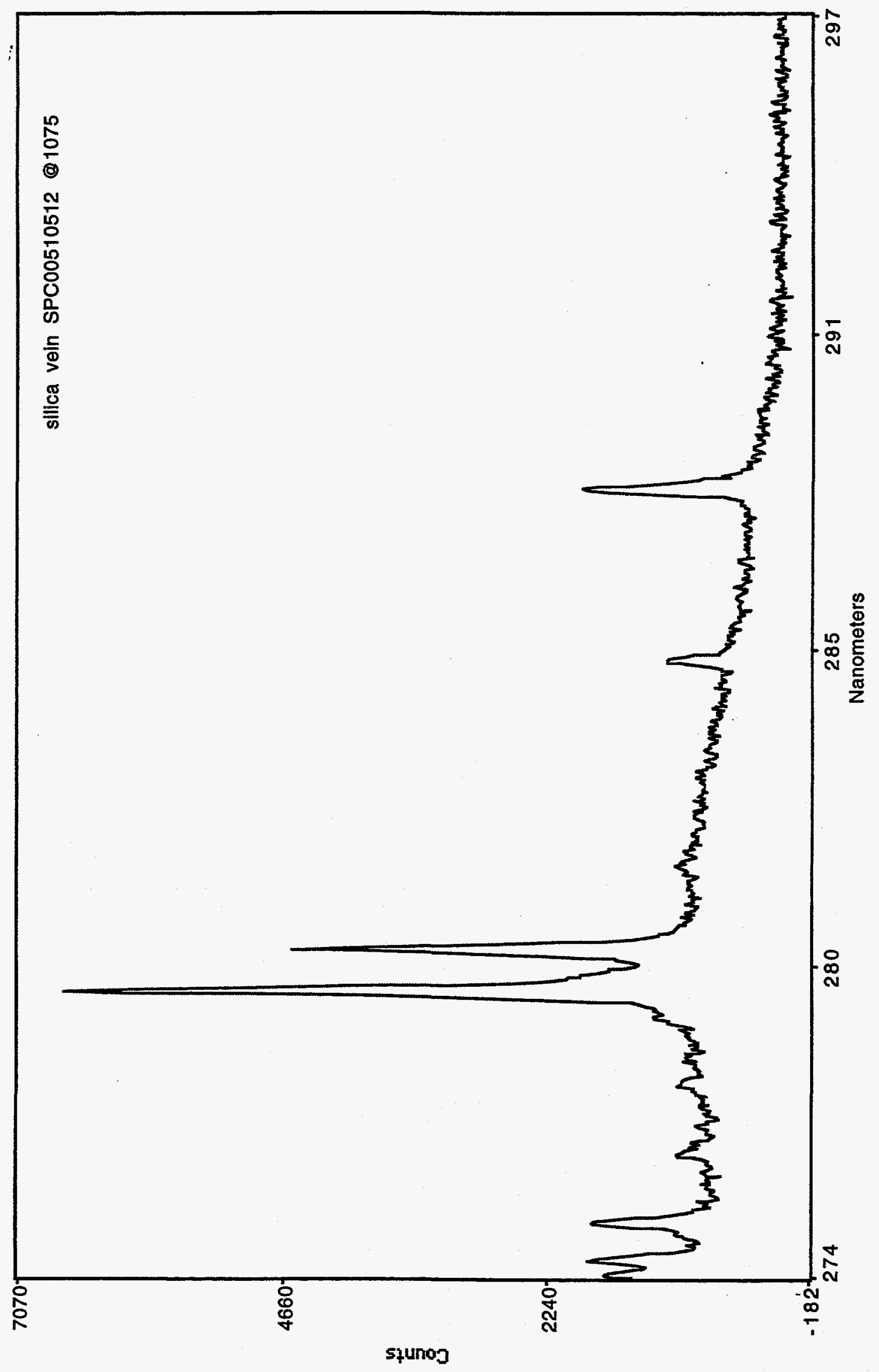




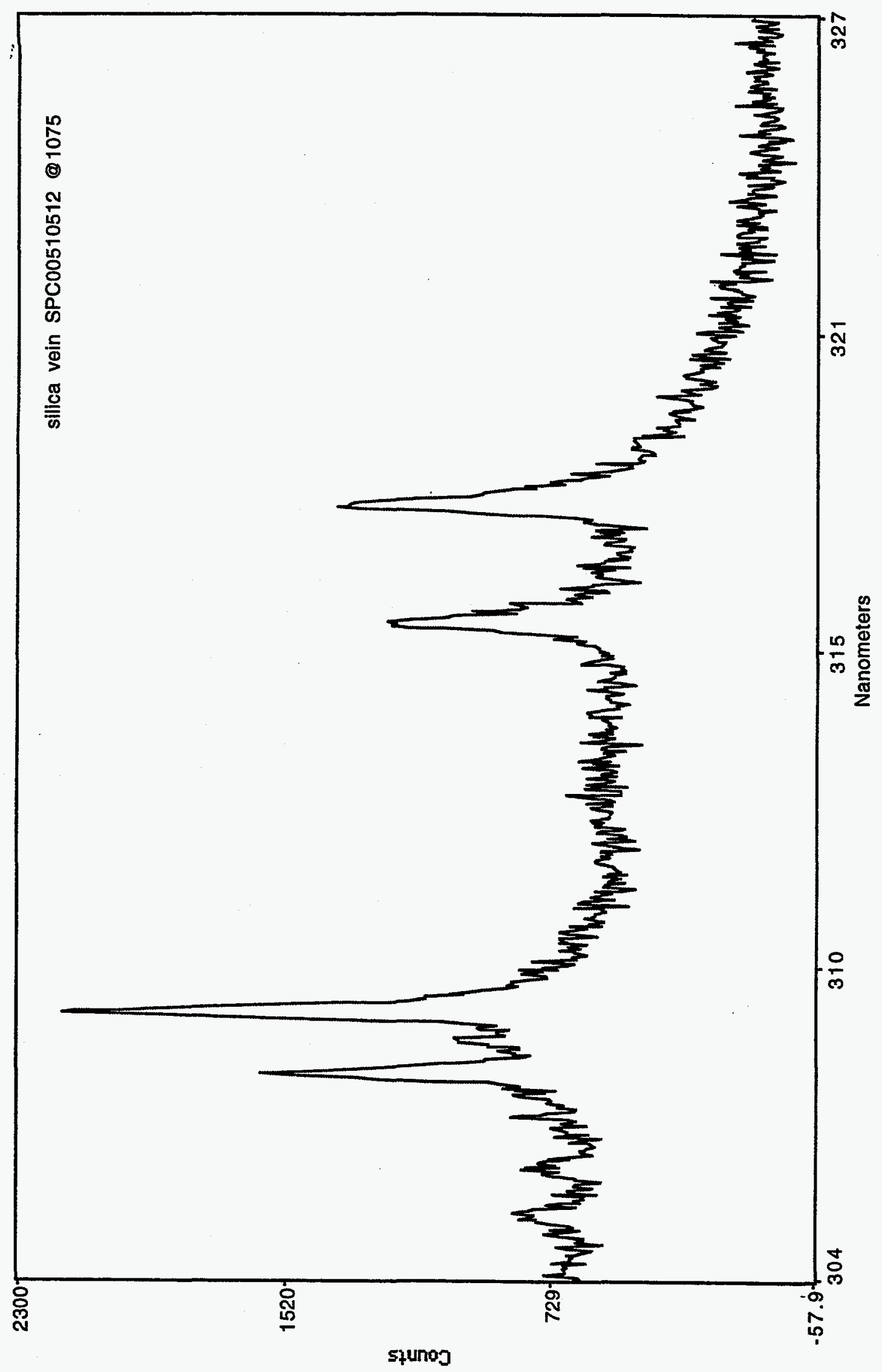




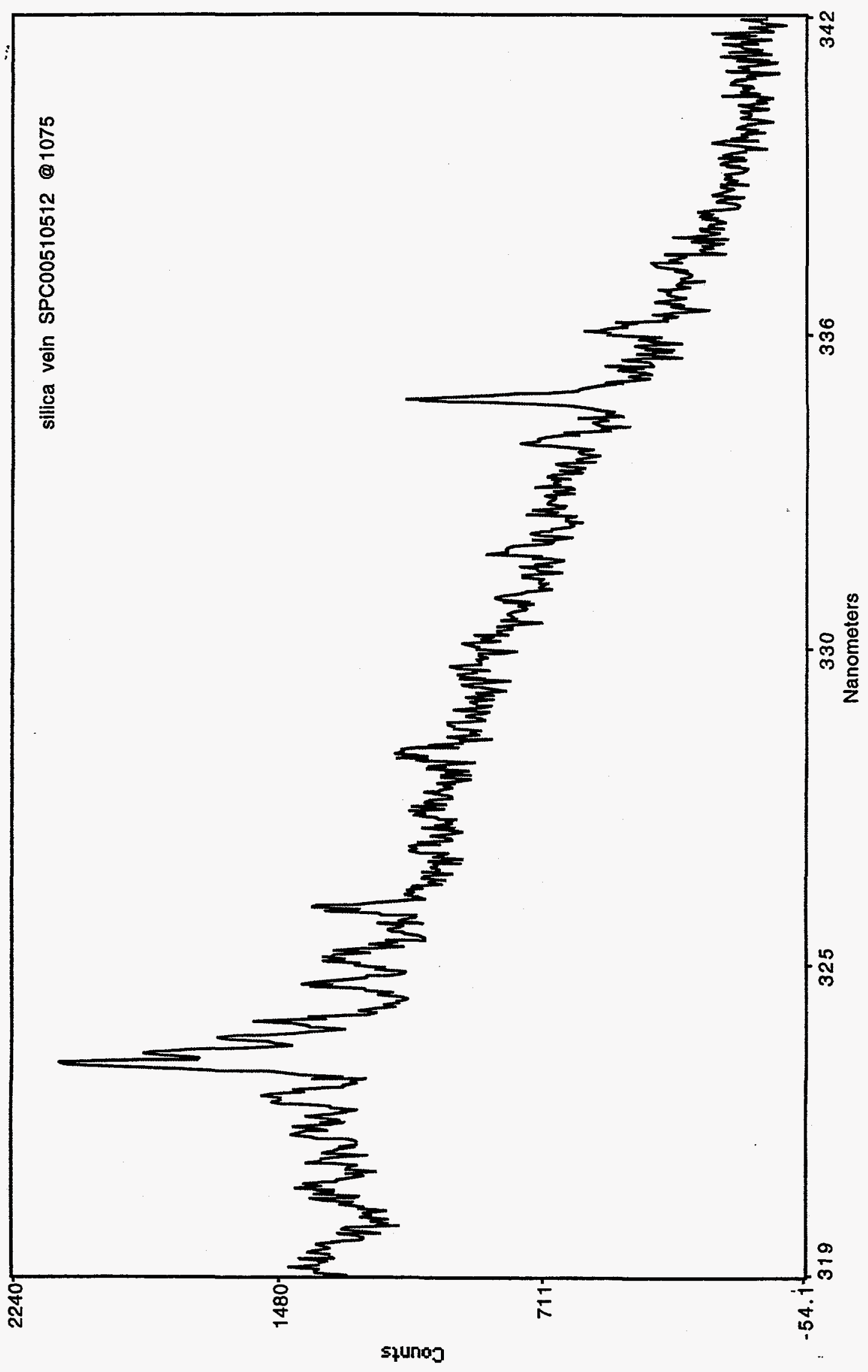




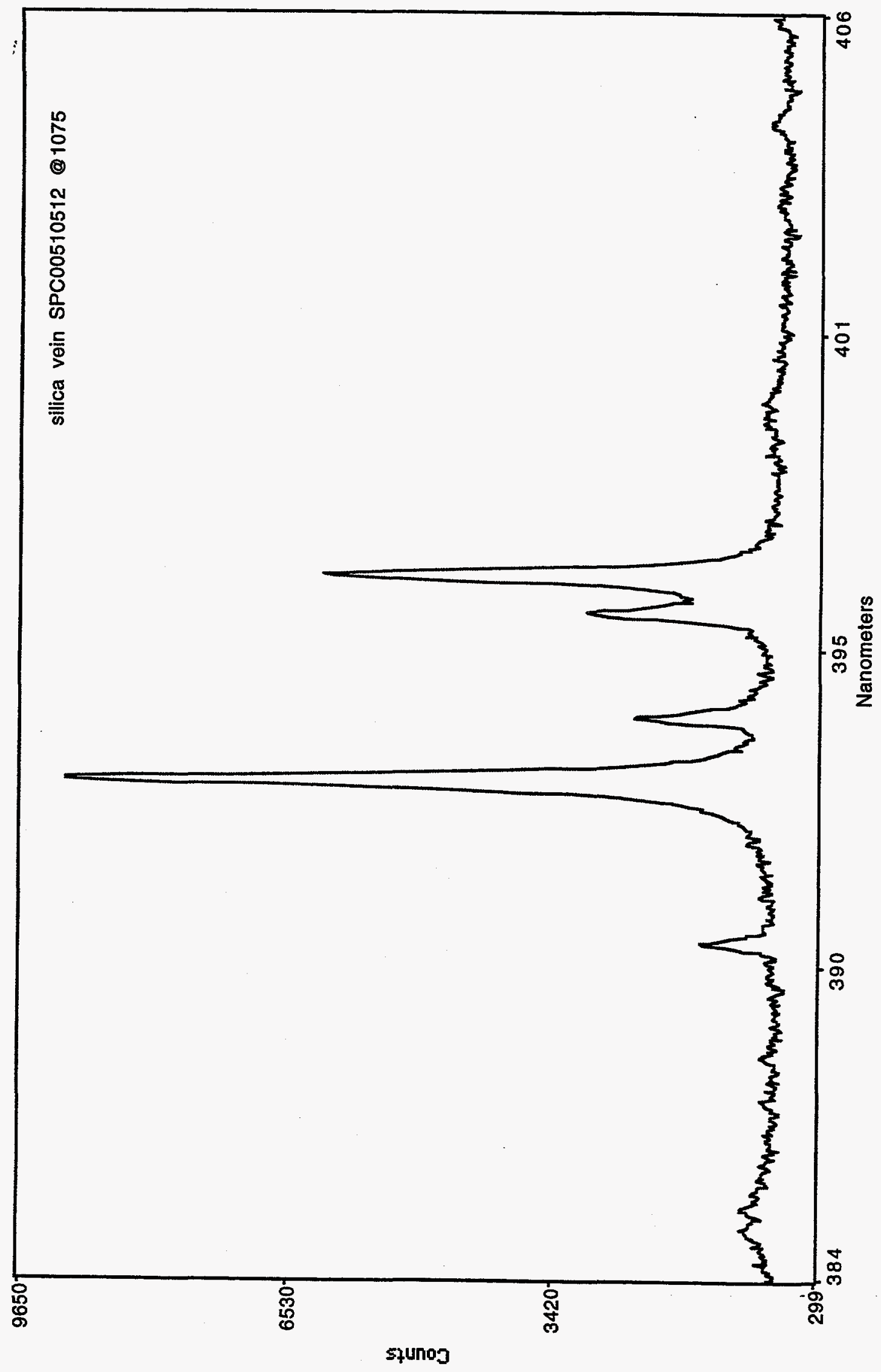




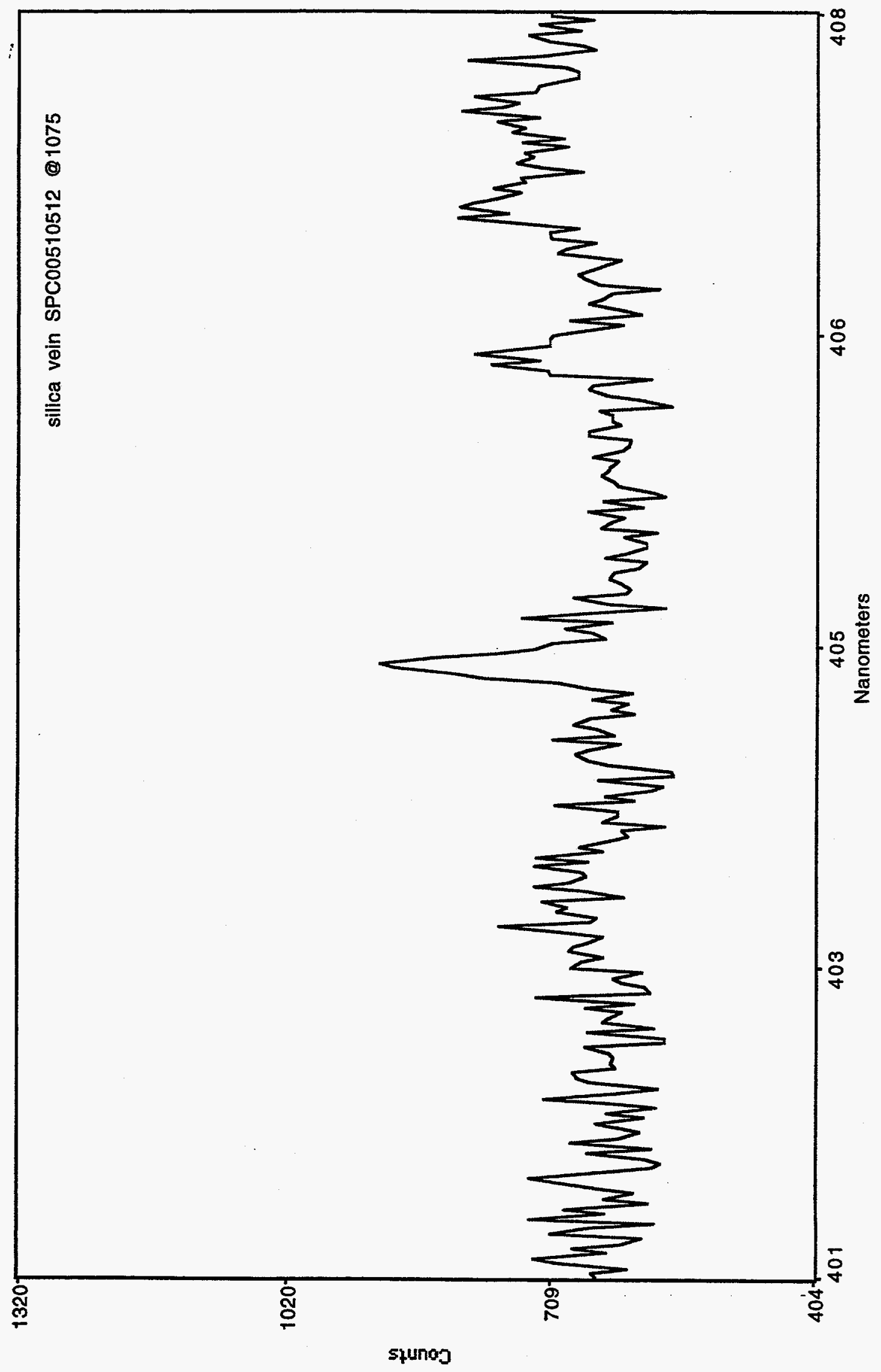




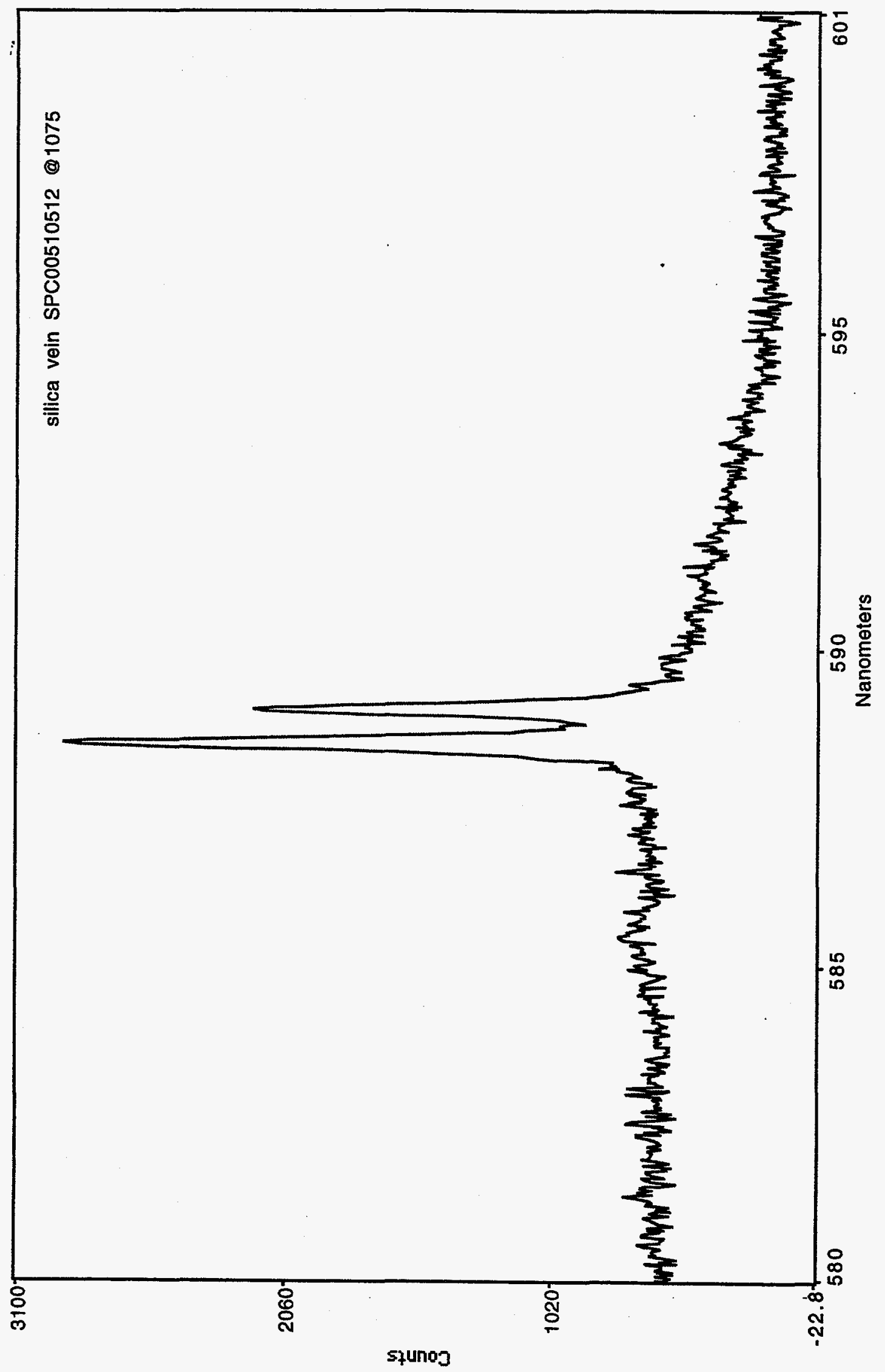




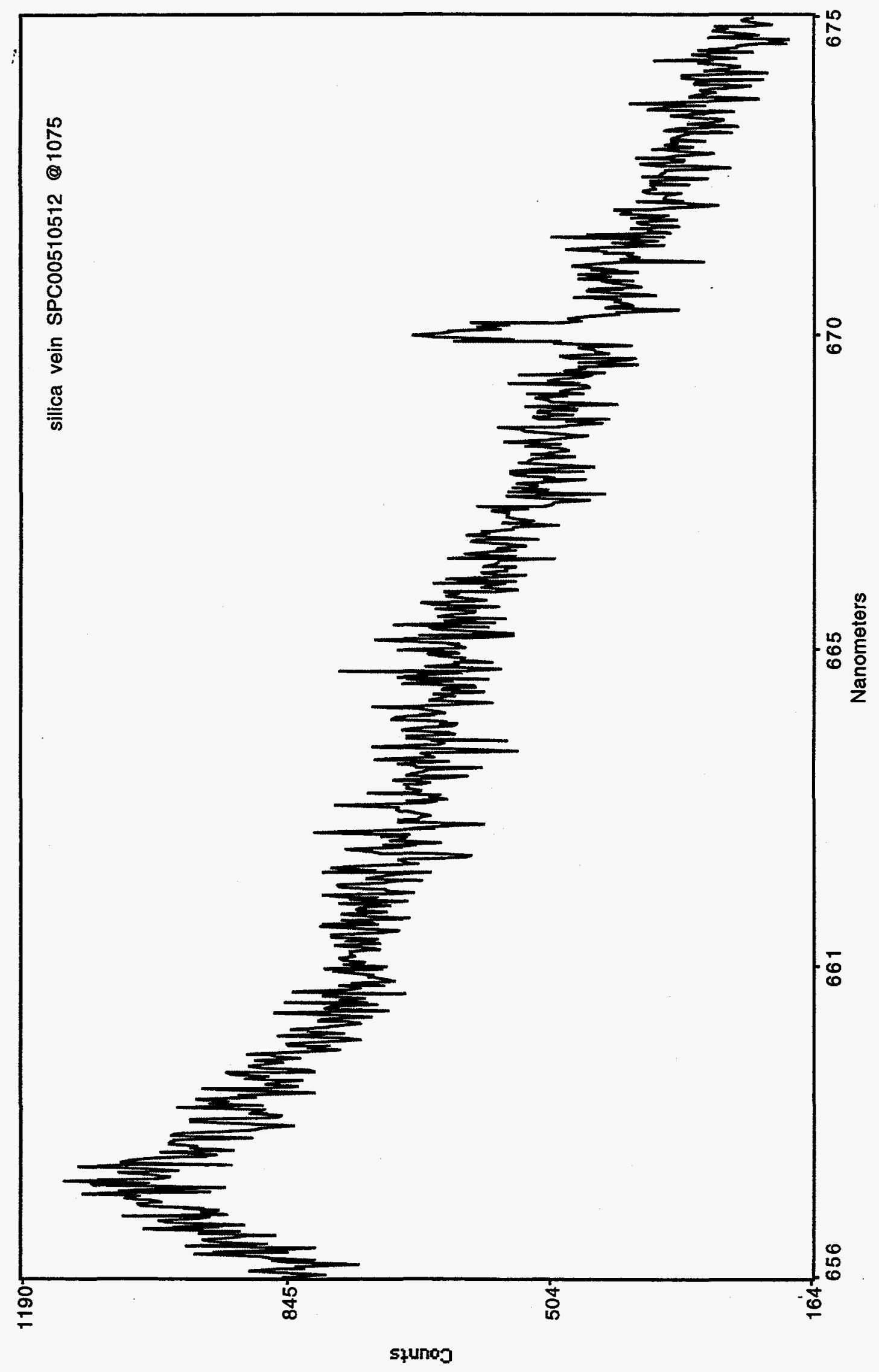




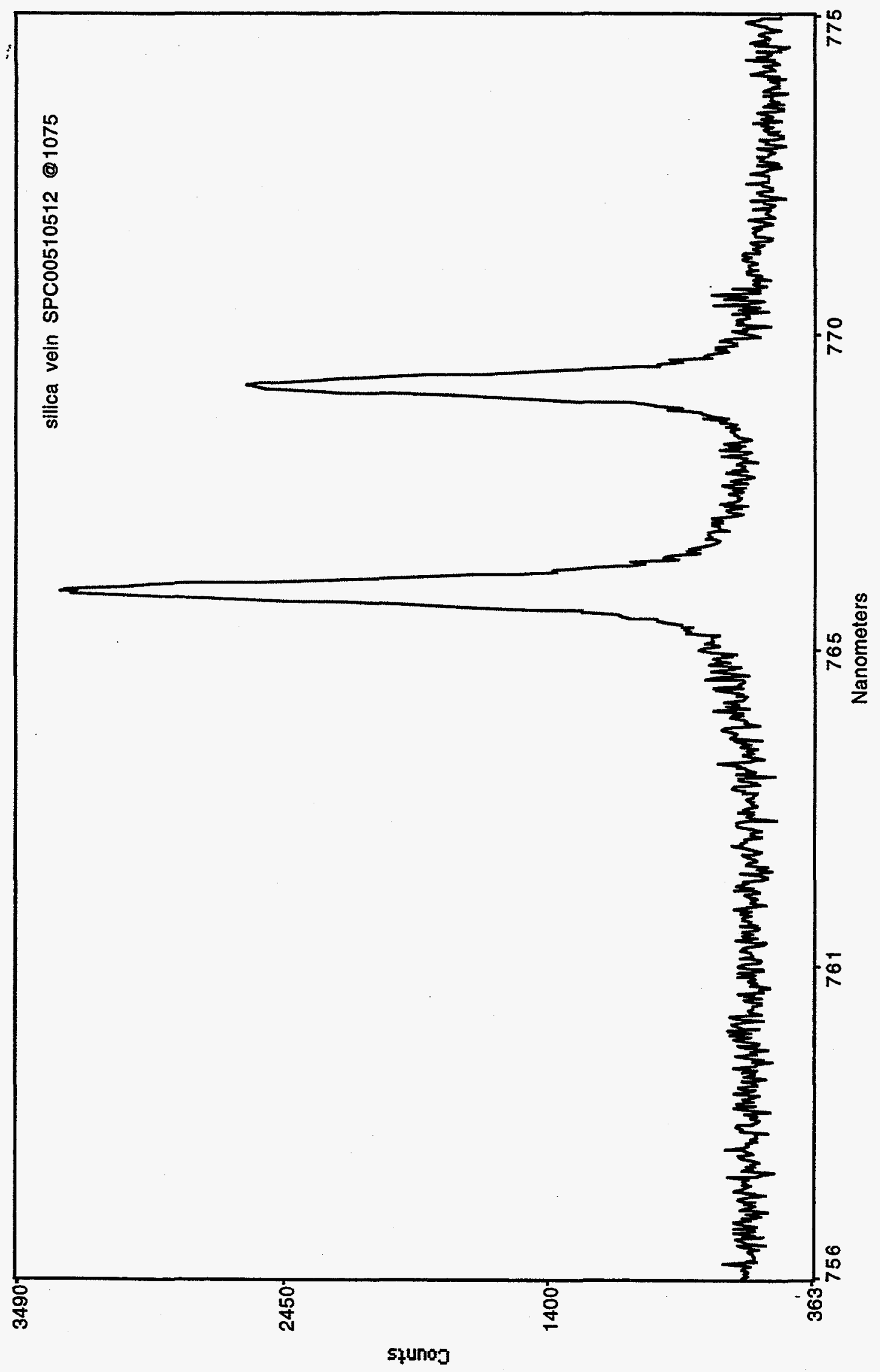




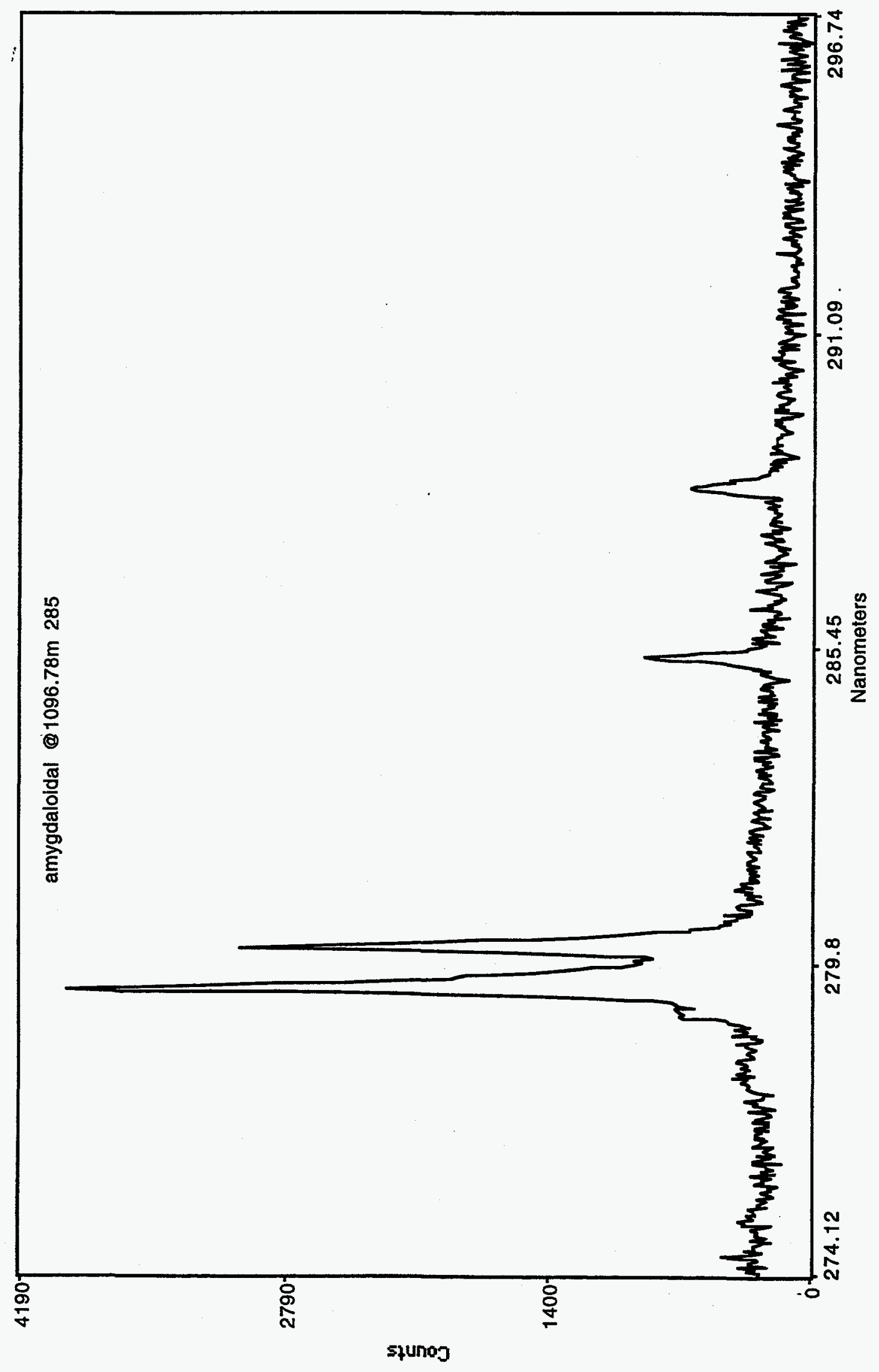




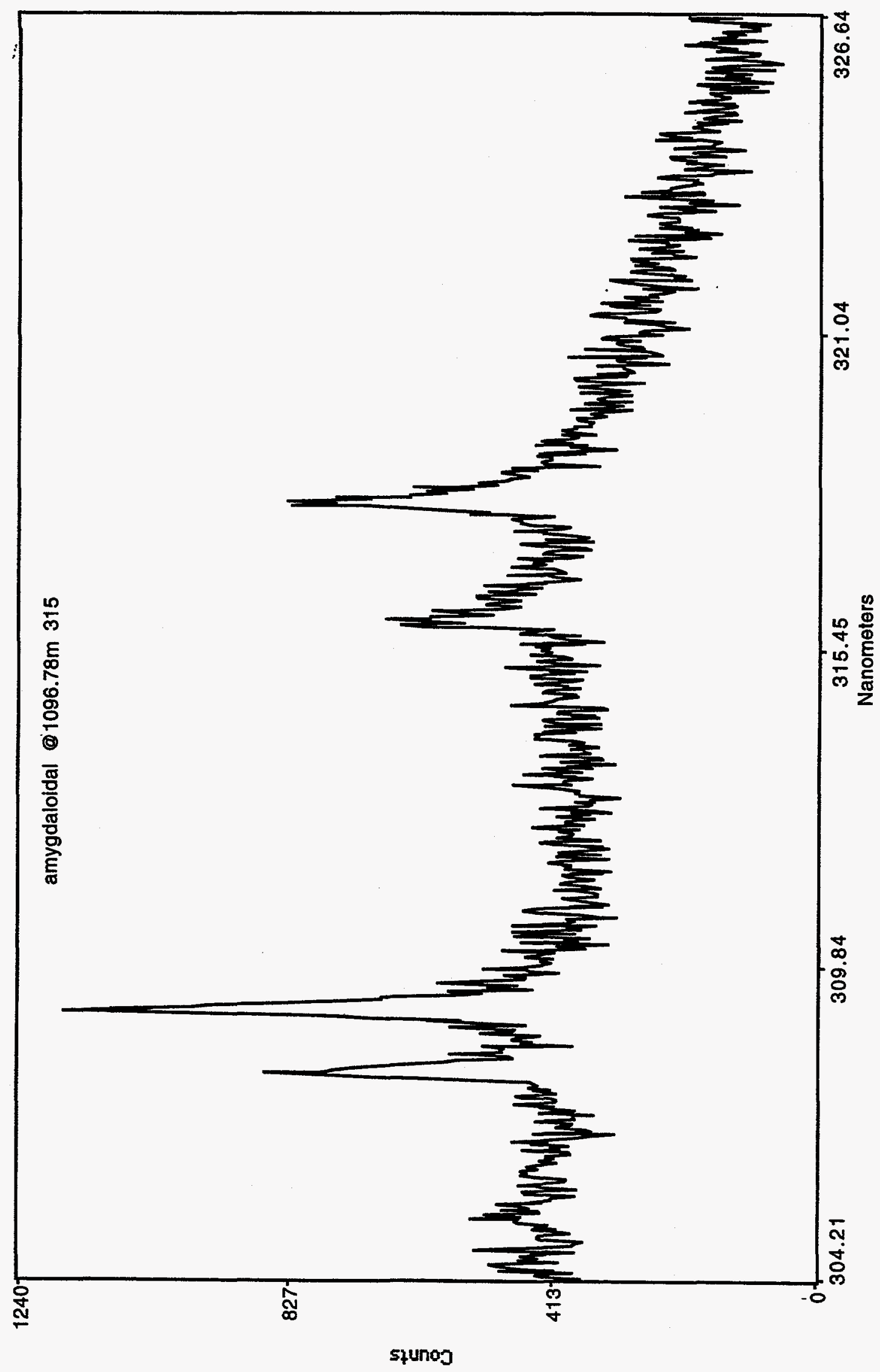




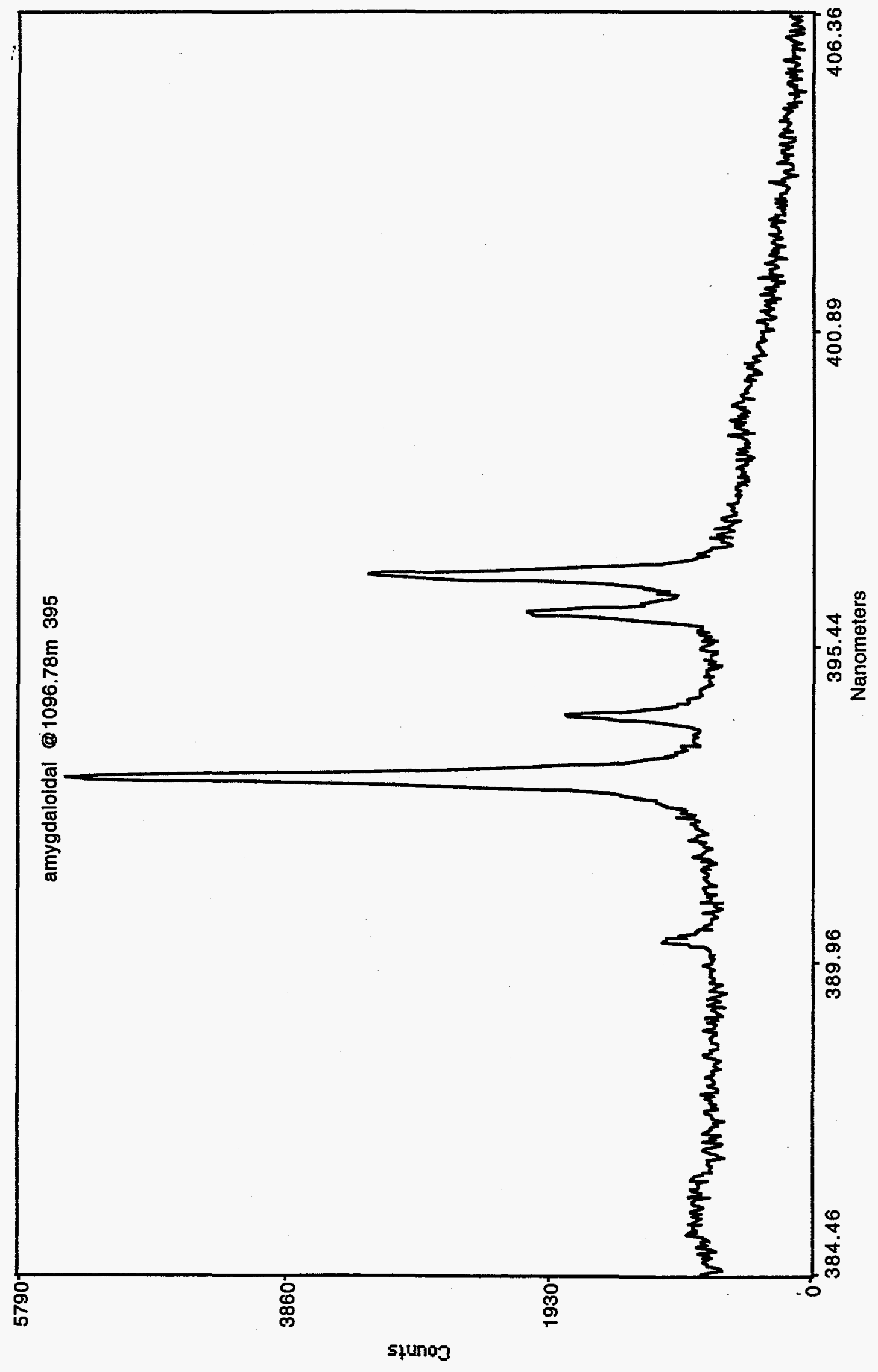


Counts

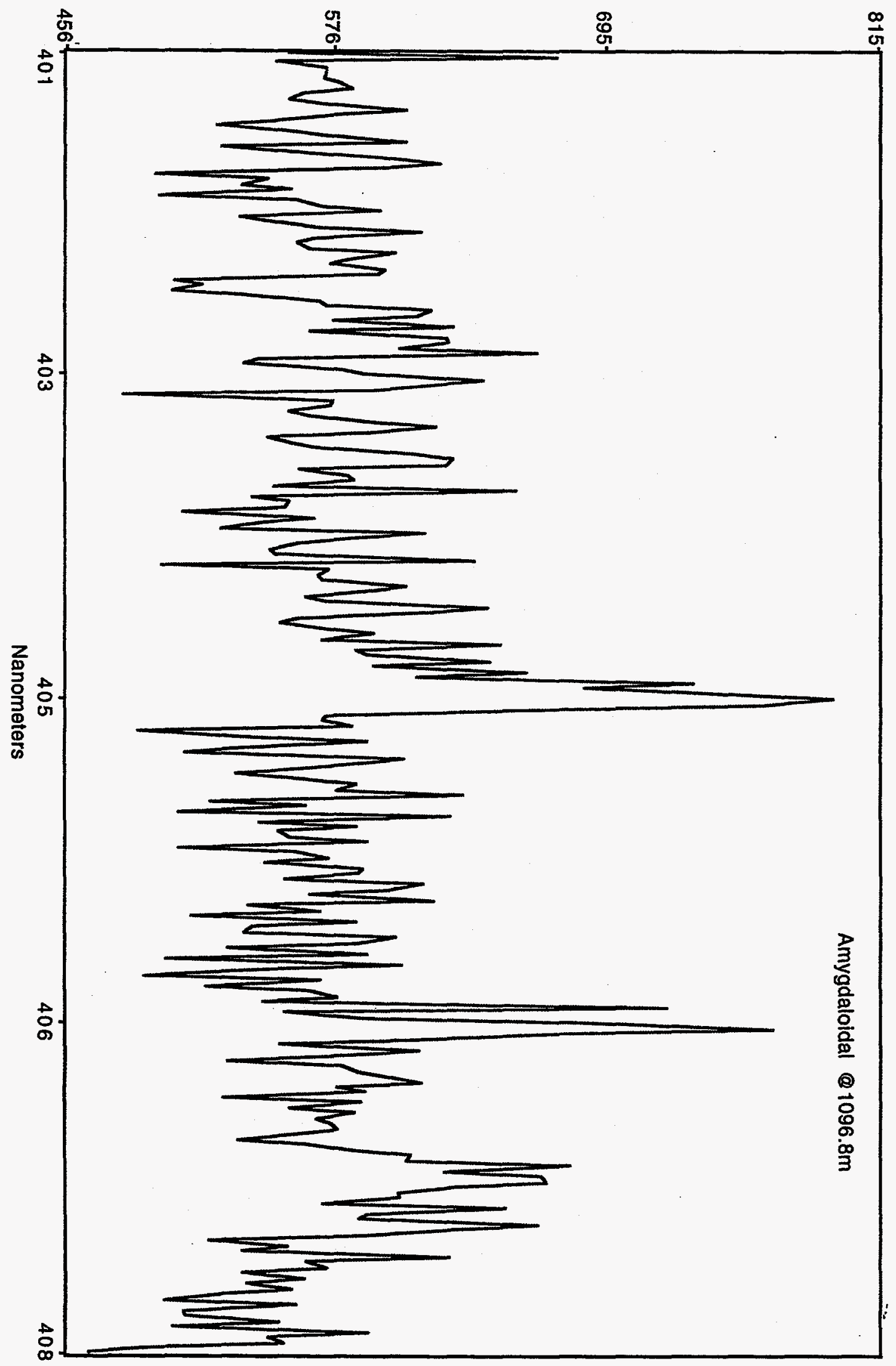




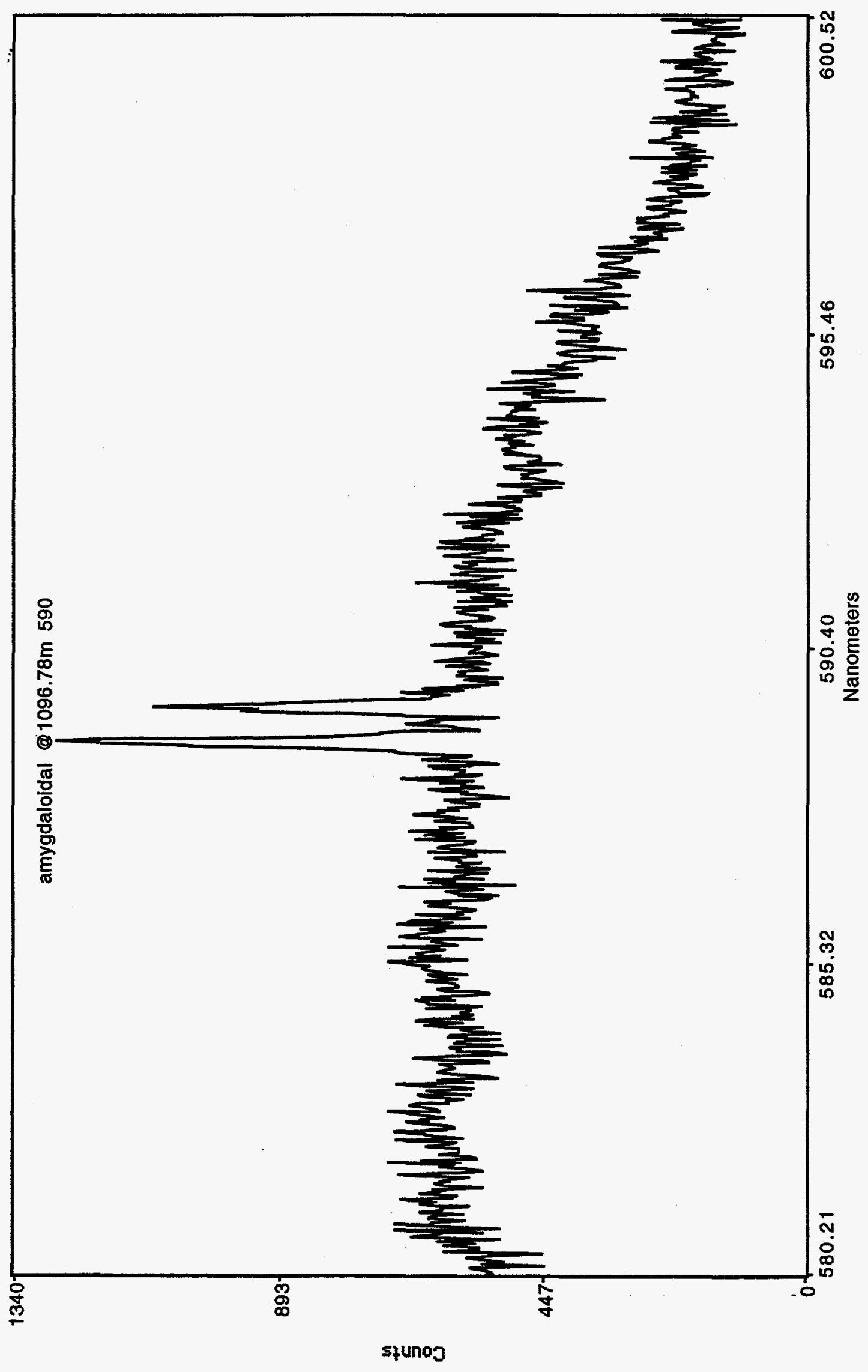




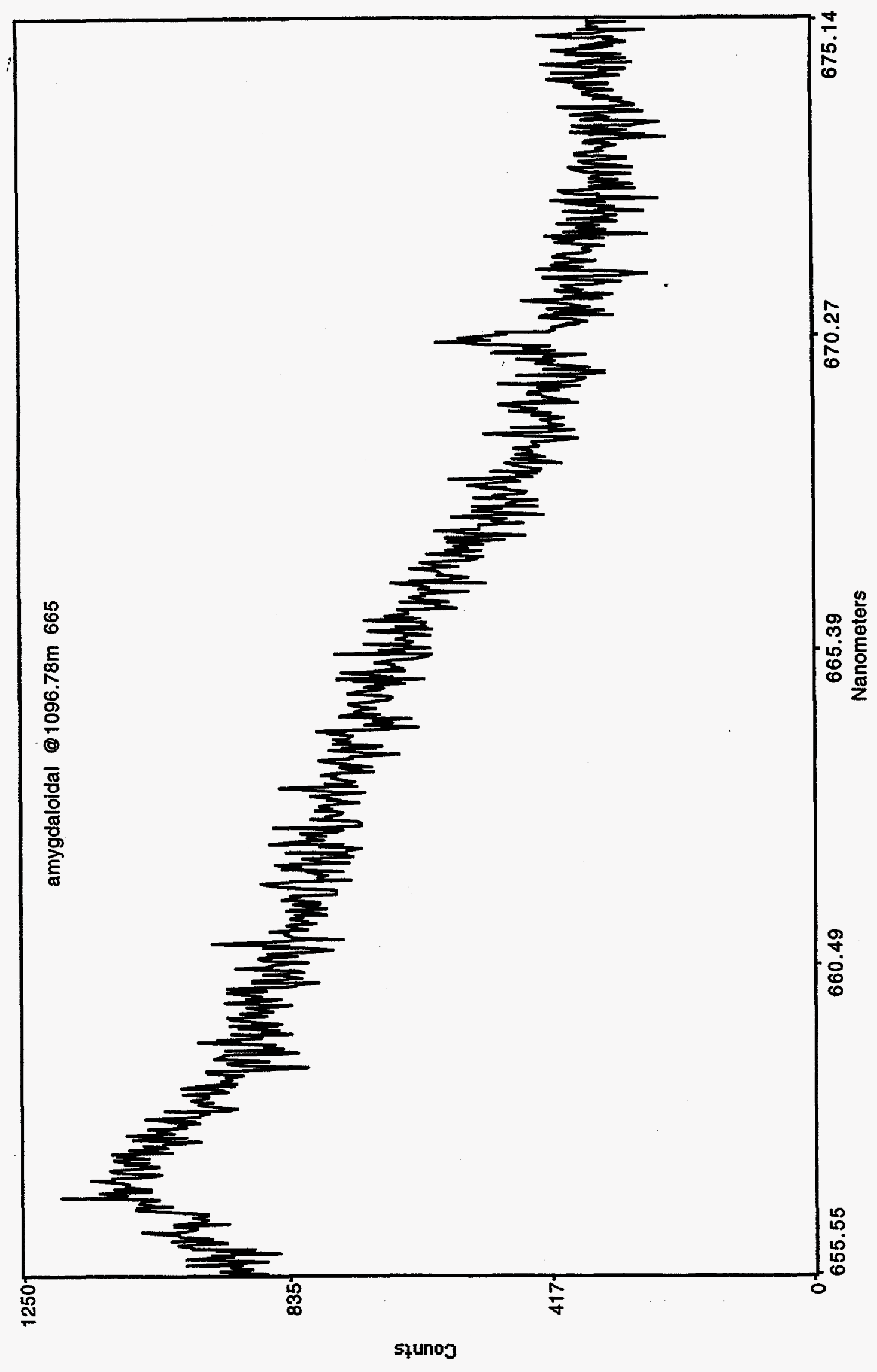




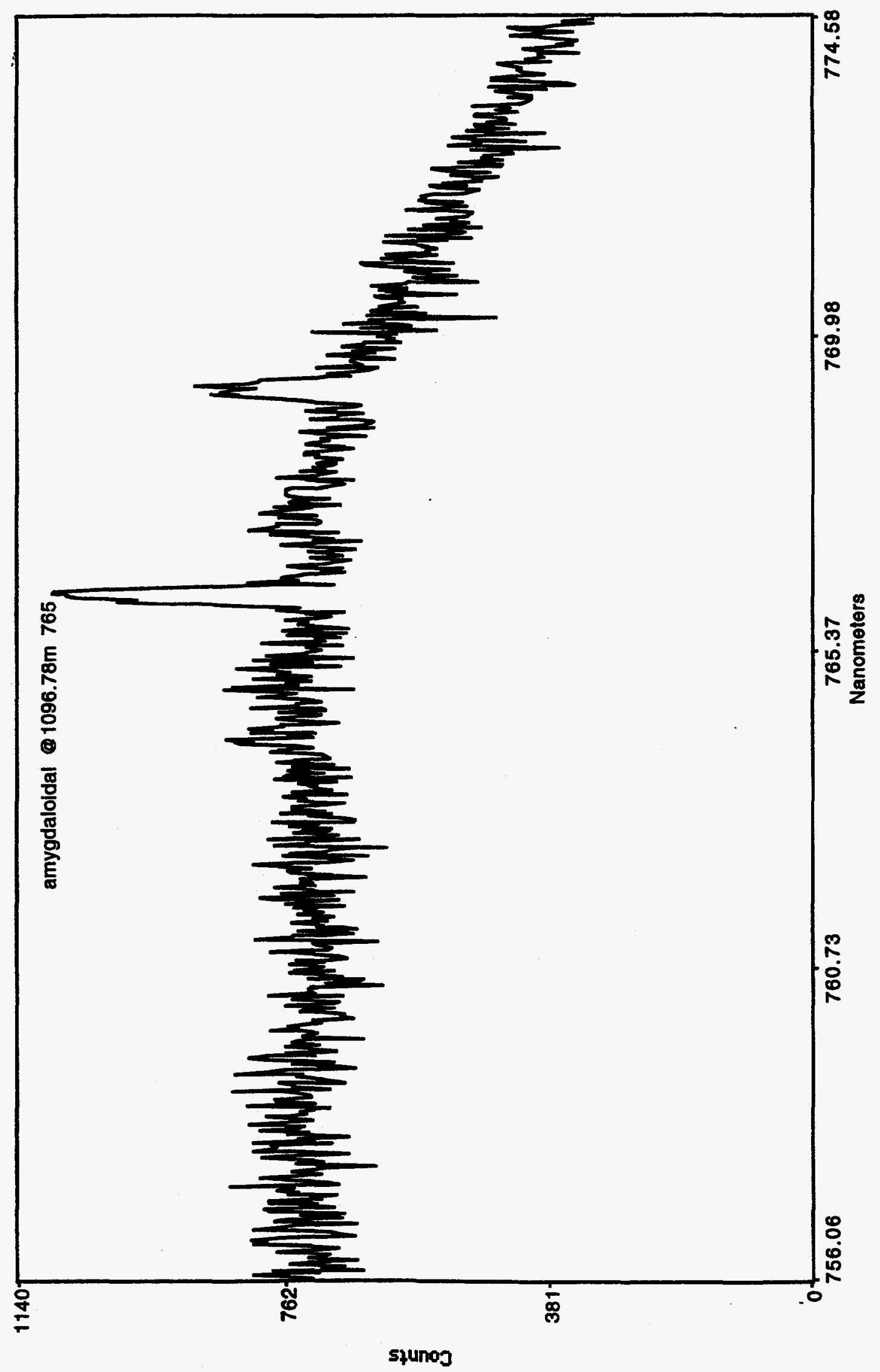

